Rafael Igrejas da Silva

\title{
Um Modelo Geral para Tomada de Decisão sob Incerteza e Flexibilidade em Parcerias Público-Privadas.
}

Tese de Doutorado

Tese apresentada ao Programa de Pós-Graduação em Administração de E mpresas da PUC-Rio como requisito parcial para obtenção do título de Doutor em Administração de Empresas.

Orientador: Prof. Luiz Eduardo Teixeira Brandão Co-orientador: Prof. Carlos de Lamare Bastian-Pinto 
Rafael Igrejas da Silva

\section{Um Modelo Geral para Tomada de Decisão sob Incerteza e Flexibilidade em Parcerias Público-Privadas.}

Tese apresentada ao Programa de Pós-Graduação em Administração de $\mathrm{E}$ mpresas da PUC-Rio como requisito parcial para obtenção do título de Doutor em Administração de Empresas. Aprovada pela Comissão Examinadora abaixo assinada.

Prof. Luiz Eduardo Teixeira Brandão Orientador

Departamento de Administração - PUC-Rio

Prof. Carlos de Lamare Bastian-Pinto Co-orientador IBMEC educacional

Prof. Javier Gutiérrez Castro

VLT Carioca S/A

Prof. Leonardo Lima Gomes

Departamento de Administração - PUC-Rio

Prof. Luiz de Magalhães Ozório IBMEC educacional

Prof. Marcus Vinicius Quintella Cury Fundação Getúlio Vargas - FGV

Profa. Mônica Herz vice-Decana de Pós-Graduação do Centro de Ciências Sociais - PUC-Rio 
Rio de Janeiro, 23 de dezembro de 2016.

Todos os direitos reservados. É proibida a reprodução total ou parcial do trabalho sem autorização da universidade, do autor e do orientador.

\section{Rafael Igrejas da Silva}

Graduado em Ciências Econômicas pela Universidade do Estado do Rio de Janeiro (2003), com mestrado em Administração pela PUC-Rio (2012). Experiência de 16 anos no mercado coorporativo; é professor do quadro complementar da PUC-Rio e tem atuado em projetos de pesquisa e consultorias a empresas, com foco em avaliação econômico-financeira de projetos em infraestrutura e energia.

Ficha Catalográfica

Silva, Rafael Igrejas da

Um modelo geral para tomada de de cisão sob incerteza e flexibilidade em parcerias público-privadas / Rafael Igrejas da Silva; orientador: Luiz Eduardo Teixeira Brandão; co-orientador: Carlos de Lamare Bastian-Pinto. $-2016$.

120 f.: il. color. ; $30 \mathrm{~cm}$

Tese (doutorado)-Pontifícia Universidade Católica do Rio de Janeiro, Departamento de Administração, 2016.

Inclui bibliografia

1. Administração - Teses. 2. Parcerias públicoprivadas. 3. Garantias. 4. Flexibilidades. 5. Opções collar. I. Brandão, Luiz Eduardo Teixeira. II. Bastian-Pinto, Carlos de Lamare. III. Pontifícia Universidade Católica do Rio de J aneiro. Departamento de A dministração. IV. Título. 
"Todo ato de erigir, construir é um ato de pedra a pedra. Onde uma pedra só pode ser colocada, quando a anterior já estiver ocupando o seu lugar.” 


\section{Agradecimentos}

À Deus acima de tudo, por me fazer perseverar, pela oportunidade de adquirir cada vez mais conhecimento e por fazer grandes amigos ao longo do caminho.

Ao meu pai e em especial aos meus avós pelo apoio incondicional.

À Juliana, pela compreensão, carinho e incentivo ao longo dos momentos mais difíceis do percurso.

À PUC-Rio e ao IAG PUC-Rio, pelo auxílio concedido, sem o qual este trabalho não poderia ter sido realizado.

Ao meu orientador, professor Luiz Eduardo Brandão, a quem sempre serei grato pela generosidade com que me acolheu no Núcleo de Pesquisa em Energia e Infraestrutura (NUPEI), pelos desafios compartilhados e pela atenção com que sempre trata seus alunos e orientandos.

Ao meu co-orientador, professor Carlos Bastian-Pinto, pela orientação motivadora, pela paciência, pelas enriquecedoras discussões sobre finanças, a inestimável ajuda e pelo frequente incentivo ao meu desenvolvimento no meio acadêmico.

Aos amigos Mauricio Portugal e Gabriela Engler, pelas discussões sobre o Setor de Infraestrutura e generosas contribuições sobre Parcerias Público-Privadas. 


\section{Resumo}

Silva, Rafael Igrejas da; Brandão, Luiz Eduardo Teixeira. Um modelo geral para tomada de decisão sob incerteza e flexibilidade em parcerias público-privadas. Rio de Janeiro, 2016. 120p. Tese de Doutorado Departamento de Administração, Pontifícia Universidade Católica do Rio de Janeiro.

As flexibilidades observadas em contratos de Parcerias Público-Privadas (PPPs) para projetos de infraestrutura rodoviária podem também ser compreendidas como opções contratuais. O modelo desenvolvido no presente estudo teve como principal foco o estabelecimento do nível ótimo de garantia governamental a ser ofertada à iniciativa privada em uma concessão de rodovia por PPP, utilizando a teoria de opções reais de forma integrada à métrica de performance Ômega, a qual obteve melhor resposta entre demais métricas VaR e CVaR propostas. Ainda de forma original, o modelo contemplou o apreçamento de garantias de receita mínima, como parte integrante do apreçamento de opções do tipo collar europeia (calls e puts) com caps, integrado ao apreçamento da opção americana de expansão (call) do projeto. O valor presente (VP) do projeto, considerando a opção de expandir a capacidade, foi calculado em R 2,73 bilhões, que comparado ao valor esperado de R \$ 2,65 bilhões sem flexibilidade, representa um aumento de R\$ 73 milhões ao valor do projeto no caso base. O valor presente do projeto com a flexibilidade de expansão (call americana) e com garantia de receita mínima (put europeia) com cap 10\% do Capex permite atingir o valor de 3,33 para a medida Ômega, que é muito superior ao valor anterior de 0,996 obtido somente com a modelagem de opções tipo collar.

\section{Palavras- Chave}

Parcerias público-privadas; garantias; flexibilidades; opções collar. 


\section{Abstract}

Silva, Rafael Igrejas da, Brandão, Luiz Eduardo Teixeira (Advisor). Modeling uncertainties and flexibilities in PPP projects. Rio de Janeiro, 2016. 120p. Doctoral Dissertation - Departamento de Administração, Pontifícia Universidade Católica do Rio de Janeiro.

The flexibilities observed in Public-Private Partnership (PPP) contracts for road infrastructure projects can also be taken as contractual options. The model developed in the present study had as main focus the establishments of the optimal level of government guarantee to be provided to private initiative in a PPP highway concession, using real option theory integrated with Omega measure, in which had a better response among other proposed VaR and CVaR metrics. Also in an original way, the model contribute to set a minimum revenue guarantees, as part of the european collar option (call and put), integrated to an expansion american call option. The project's present value (PV), considering an option for capacity expansion, was calculated at $\mathrm{R} \$ 2.73$ billion, which compared to the expected value of R 2.65 billion without flexibility, represents an increase of $\mathrm{R} \$$ 73 million to the value of the project in the base case scenario. The present value of the project with the flexibility of expansion (call) and with a minimum revenue guarantee with cap $10 \%$ of Capex, allows to reach the value of 3.33 for the Omega measure, which is much higher than the previous value of 0.996 , obtained only with the european collar option.

\section{Keywords}

Public-private partnerships; guarantees; flexibilities; collar options. 


\section{Sumário}

1 Introdução 12

2 Referencial Teórico e Revisão de Literatura 16

2.1. Referencial Teórico 16

2.1.1. Aspectos gerais sobre PPPs 16

2.1.2. Investimentos em Infraestrutura 18

2.1.3. Estruturação Financeira e Análise de Risco 26

2.1.4. Avaliação financeira de Projetos e PPPs 33

2.1.5. Medidas de risco e performance 36

2.1.6. Tomada de Decisão sob Incerteza 41

2.1.7. Processos Estocásticos $\quad 45$

2.1.8. Lema de Itô $\quad 47$

2.2. Revisão de Literatura 49

2.2.1. Análise de Viabilidade 49

2.2.2. Tomada de Decisão sob Incerteza 52

3 Metodologia Proposta $\quad 57$

3.1. Aspectos Conceituais do Modelo $\quad 57$

3.2. O Modelo Proposto $\quad 59$

3.2.1. Modelagem do Tráfego 61

3.2.2. Volatilidade 63

3.2.3. Prêmio de Risco 65

3.2.4. Fluxo de Caixa Estocástico e Opções Collar 69 
3.2.5. Análise de Riscos 77

3.2.6. Garantias Governamentais e Análise de Riscos 78

3.2.7. Combinação Risco e Retorno 81

3.3. Opção de Expansão 81

4 Aplicação do Modelo Proposto 88

4.1. Modelo Base 88

4.1.1. Taxa de desconto ajustada a risco 89

4.1.2. Resultados do Modelo Base 93

4.2. O Modelo com Flexibilidades 94

4.2.1. Análise do Modelo Estocástico 96

4.2.2. Níveis de Garantia pela Ótica do Governo 101

4.2.3. O Modelo com Opção de Expansão 104

5 Considerações Finais 109

6 Referências bibliográficas 111 


\section{Lista de figuras}

Figura 1 - Evolução no número de PPPs no Brasil por ano. 25

Figura 2 - Número de PPPs em execução e por setor 25

Figura 3 - Processo de determinação do valor de um projeto por PPP.

Figura 4 - Exemplificação VaR95\% 37

Figura 5 - Representação VaR versus CVaR. 38

Figura 6 - Processo básico de avaliação de projetos por opções reais

Figura 7 - Etapas da estrutura do modelo proposto 60

Figura 8 - Exemplo de compartilhamento com garantia de receita mínima.

Figura 9 - Exemplo simulação do efeito do collar sobre a demanda projetada

Figura 10 - Exemplo simulação do efeito do collar sobre os fluxos de caixa projetados.

Figura 11 - Visão parcial do m odelo com collar e opção de expandir

Figura 12 - Análise da demanda

Figura 13 - VPL do projeto sem opções

Figura 14 - VP com collar sem cap

Figura 15 - VPL com collar sem cap

Figura 16 - Distribuições de probabilidade do VPL com diferentes níveis de collar

Figura 17 - Distribuição de probabilidade acumulada para cada cenário de garantia com CAP

Figura 18 - Valor das opções para cada nível de cap de garantia. 


\section{Lista de tabelas}

Tabela 1 - Gastos mundiais infraestrutura - 2000 a 2010 (\% do PIB mundial)

Tabela 2 - Investimentos mundiais infraestrutura - 2005 a 2010 (US\$ bilhões)

Tabela 3 - Investimentos infraestrutura por setor 2007 a 2014 (R\$ bilhões)

Tabela 4 - Investimentos infraestrutura por setor em \% do PIB, média de $p$ eríodos decenais e $r$ edução proporcional entre $o$ primeiro e último período (em \%).

Tabela 5 - Erros em estimativa de c ustos de pr ojetos de transporte no mundo.

Tabela 6 - Níveis de compensação da demanda

Tabela 7 - Parâmetros do modelo $\quad 89$

Tabela 8 - Análise Preliminar Viabilidade do Projeto 93

Tabela 9 - Risco do projeto com garantia e sem cap (R\$ milhões) 99

Tabela 10 - Cenários para liberação de garantias 99

Tabela 11 - Análise de resultados do projeto 100

Tabela 12 - Condições simuladas para a garantia por nível de cap 103 


\section{Introdução}

Os investimentos em infraestrutura estão, historicamente, relacionados a decisões de políticas governamentais que envolvem significativos volumes de recursos financeiros e retornos de longo prazo. Investimentos privados em infraestruturas públicas e em parceria com governos são observados desde o século XVIII. No século XX, essa tendência de constituição de parcerias se ampliou, principalmente após as duas grandes guerras mundiais. Na década de 1980, ressurgiu o conceito de grandes projetos de infraestrutura com financiamento, desenvolvimento e operação pela iniciativa privada e que foram intitulados primeiramente como build-operate-transfer (WALKER;SMITH, 1995).

Outros projetos semelhantes foram desenvolvidos no Reino Unido, no início da década de 1980, e passaram a ser identificados inicialmente como Iniciativa Público-Privada (PFI na sigla em inglês). Posteriormente, tais projetos passaram a ser conhecidos como Parcerias Público-Privadas (PPPs) (LEVY, 1996).

Tendo em vista a possibilidade de contornar as limitações do investimento estatal por PPPs, vem se observando desde o final dos anos 1990 um crescimento no volume de projetos de parcerias entre estados e iniciativa privada por essa abordagem (TANG;SHEN;CHENG, 2010).

No Brasil, o processo de modernização e redução da presença do Estado na economia, observada a partir do final da década de 1970 em outros países, teve início com a publicação do Decreto 83.740/1979, que tinha como objetivo simplificar o funcionamento da administração pública federal. Em 1998, o Programa Nacional de Desestatização, tinha entre seus objetivos prover serviços públicos, por meio de concessões e permissões à iniciativa privada. Este processo estendeu-se até o final de 2004 e abrangeu a privatização de empresas de grande porte e historicamente estatais, principalmente dos setores de telecomunicações, siderurgia e energia (CARVALHO, 2001).Ainda em 2004, foi promulgada no 
Brasil a Lei $n^{\circ} 11.079$, que instituiu o atual modelo de concessões por PPPs como uma nova forma para transferência de responsabilidades entre o poder público e a iniciativa privada, buscando prover infraestrutura pública em equipamentos e serviços à sociedade, sendo o concessionário de maneira geral responsável pela construção, execução e manutenção de equipamentos públicos.

Ainda que existam projetos de investimento em infraestrutura de grande interesse público a serem licitados no Brasil, os mesmos não têm criado a atratividade esperada para a iniciativa privada, mesmo via PPPs. Ocorreram, por exemplo, inúmeras tentativas, no âmbito federal, para licitar o projeto do "Trem Bala” entre Rio de Janeiro e São Paulo e rodovias no Norte e Centro-Oeste. O que se observou foi a ausência de interessados nos certames e muitos questionamentos quanto à viabilidade dos projetos. Além disso, as PPPs no Brasil que são consideradas exitosas têm apresentado problemas recorrentes quanto à necessidade de reequilíbrios econômico-financeiros e gastos excessivos pelo governo, em função de estruturas contratuais deficientes (OLIVEIRA;MARCATO;SCAZUFCA, 2013).

Nestes projetos, frequentemente realizam-se análises de viabilidade baseadas estritamente no método do Fluxo de Caixa Descontado (FCD), o qual não leva em conta as flexibilidades destes projetos. Além disso, a ênfase atribuída ao apreçamento de flexibilidades e análise de riscos nessa classe de projetos é relativamente recente na literatura sobre o tema.

Apesar de muitas vezes as flexibilidades não serem adequadamente identificadas em transações comerciais entre o ente público e a iniciativa privada, a adequada modelagem das flexibilidades pode agregar valor aos contratos e, contribuir para mitigar gastos governamentais. A tomada de decisões ótimas, de forma a responder eficientemente às mudanças não previstas no momento da contratação e às incertezas inerentes ao mercado, exige o uso de métodos de análise de decisão e apreçamento adequados às flexibilidades embutidas nestes contratos.

Além disso, poucos estudos encontrados na literatura valoram flexibilidades, atentando para a aderência da metodologia à ótica do governo. Como resultado, os estudos acabam por apresentar inconsistências, que muitas vezes levam a avaliações equivocadas sobre o risco financeiro do governo. Nesse sentido, o aprimoramento do arcabouço metodológico de análise de viabilidade e 
análise de riscos para o governo pode contribuir para o processo de tomada de decisão e formulação de licitações em infraestrutura, a partir de abordagens que busquem minimizar gastos governamentais.

Este tipo de análise se faz necessária em função da lacuna metodológica observada quanto a determinação do nível ótimo de garantia a ser concedida pelo governo à iniciativa privada, em projetos de PPPs sob condições de incerteza, de forma que também integre análise de riscos para o governo.

A abordagem da pesquisa proposta considera as condições de contorno presentes em contratos de PPPs no Brasil, e parte do interesse em atender a uma lacuna observada na literatura quanto aos métodos de análise de viabilidade em PPPs. Diante da relevância das Parcerias Público-Privadas para projetos de rodovias no Brasil, cabe a seguinte questão de pesquisa: Quais contribuições metodológicas para a modelagem financeira de projetos por PPPs greenfield podem minimizar gastos para o governo e ainda promover a atração de investimentos privados, em meio a cenários de incertezas?

Assim, o presente estudo tem como objetivo principal desenvolver um arcabouço metodológico para a determinação do nível ótimo de garantias governamentais em projetos de PPPs de rodovias, que permita mitigar gastos do governo pelo apreçamento de flexibilidades, com a utilização de métricas de risco e performance, integradas em um mesmo modelo de análise de decisão sob condições de incertezas e riscos, ainda não observado na literatura.

No presente estudo, buscou-se ainda atender os seguintes objetivos intermediários:

- Analisar as propostas existentes na literatura para a modelagem financeira de projetos por Parcerias Público-Privadas e as lacunas existentes.

- Testar o modelo em uma concessão rodoviária greenfield no Brasil, a partir da metodologia de Opções Reais, introduzindo métricas de risco e performance para a tomada de decisão.

- Trazer contribuições para a formulação de modelos financeiros em licitações de PPPs pelo governo.

Este trabalho está organizado da seguinte forma. Após esta introdução, o capítulo 2 apresenta o referencial teórico e a revisão de literatura, descrevendo os 
principais conceitos e motivadores para discussão, bem como os principais modelos avaliados sobre viabilidade de projetos e garantias governamentais em Parcerias Público-Privadas, os quais contribuíram para o desenvolvimento do presente estudo. O capítulo 3 apresenta as principais ferramentas utilizadas e metodologias propostas para o desenvolvimento do modelo. O capítulo 4 apresenta a aplicação da metodologia por meio de um estudo de caso hipotético para avaliar projetos por PPPs em rodovias. O capítulo 5 apresenta as considerações finais e as sugestões para trabalhos futuros e no capítulo 6 descrevem-se as referências bibliográficas utilizadas. 


\section{Referencial Teórico e Revisão de Literatura}

\section{1. \\ Referencial Teórico}

\subsection{1.}

\section{Aspectos gerais sobre PPPs}

Para atender aos objetivos definidos, foi desenvolvido um referencial teórico e em seguida uma revisão de literatura sobre análise de viabilidade em projetos de infraestrutura, analisando os achados sobre as metodologias utilizadas, bem como sua aderência às modelagens necessárias para valorar projetos por PPPs. Para tanto, foram considerados artigos em journals de primeira linha, contratos e editais licitados, além da regulação específica.

As PPPs ganharam maior destaque no Reino Unido na década de 1980 e tinham como foco inicial a contratação e operação de serviços públicos pela iniciativa privada, como alternativa às restrições orçamentárias e de déficit público a época. Em 1992, o governo britânico lançou oficialmente programas a partir do conceito do Private Finance Initiative (PFI) e em 1994, este passou a ser utilizado em grande escala pelo setor público já com a denominação de PublicPrivate Partnerships ou Parcerias Público-Privadas (PPP). O modelo de PPPs naquele momento passou a envolver a estruturação, o financiamento, a construção e a operação de serviços e infraestruturas públicas em áreas urbanas (HMTREASURY, 1995).

Os arranjos contratuais para a estruturação de PPPs podem se diferenciar em combinações de responsabilidades, entre a iniciativa privada e o ente público para cada fase do projeto. É muito comum o ente público ficar responsável por riscos políticos e licenças administrativas, enquanto a iniciativa privada arca com riscos de construção, financiamento, operação e manutenção (SHEN;WU, 2005). Entre os arranjos mais comuns, o ente público pode em alguns casos ceder o controle à 
iniciativa privada para todas as etapas do projeto, compreendendo concepção, desenho, financiamento, construção, operação e manutenção, além da gestão sendo a propriedade mantida como do ente público, que em inglês é conhecido pelo modelo DBFOM (design, build, finance, operate and manage). Há a possibilidade da iniciativa privada desenhar, obter financiamento, construir e operar, sendo o equipamento como pertencente ao ente publico ao final do projeto (DBFO - design build, finance and operate). Pode-se observar a possibilidade da iniciativa privada construir e operar um equipamento de sua propriedade, ficando demais responsabilidades a cargo do governo, que ao final do projeto receberá a propriedade do equipamento público (BOO - build, own, operate); além de haver a possibilidade de somente haver a construção e operação pela iniciativa privada, as demais responsabilidades podem ser atribuídas ao governo, mas com posterior transferência de propriedade à iniciativa privada (BTO - build, transfer and operate). E ainda pode haver a possibilidade de construção e operação pela iniciativa privada, ficando a propriedade também para a iniciativa privada (BOOT - build, own, operate and transfer).

Ao permitir o financiamento privado de projetos de infraestrutura para o setor público, observou-se um grande crescimento de projetos por PPPs nas últimas décadas (TANG et al., 2010). No entanto, percebem-se algumas diferenças na conceituação deste modelo de estruturação de projetos. O Programa de Desenvolvimento das Nações Unidas (UNPD, 2005) definiu PPP como "um mecanismo de parceria entre governo, empresa e sociedade, para desenvolvimento e acesso a serviços básicos como tratamento de agua e esgoto, energia, educação e saúde”. O Conselho Nacional para Parcerias Público-Privadas (NCPPP, 1985) dos Estados Unidos da América definiu PPP como “o compartilhamento de riscos e recursos entre uma agência do setor público e um desenvolvedor privado, por meio de uma estrutura contratual cujo objetivo é prover serviços ou infraestrutura pública”. O Conselho Canadense de Parcerias Público-Privadas (CCPPP, 1993) conceitua PPPs como "uma iniciativa de investimento compartilhado entre os setores público e privado, para desenvolver projetos com o expertise de cada ente, de forma que melhor atenda as necessidades do setor público, através de uma alocação eficiente de recursos, riscos e ganhos”. De certa forma, as definições convergem ou se complementam tendo como origem os modelos de concessões e 
privatizações realizadas no passado por estes países, bem como a necessidade de melhoria no processo de contratação pelo Estado.

A estruturação de projetos por PPPs, desde o início representou a possibilidade de reorientar e redimensionar investimentos do setor público e de aproximar a iniciativa privada do setor público, a partir da cooperação para a provisão de infraestrutura e de serviços públicos. Ao equilibrarem provisão, financiamento e prestação de serviços públicos, as PPPs do tipo DBFOM (design, build, finance, operate and manage) podem passar a fazer parte das soluções governamentais para redução dos déficits de infraestrutura e restrições orçamentárias, encontrados na maioria dos países emergentes (AZEVEDO NETO, 2008).

Segundo o Banco Mundial (2013) entre as principais características dos modelos de PPPs do tipo DBFOM (design, build, finance, operate and manage), destacam-se:

- O setor público define os requisitos em termos de resultados e passa a regular a prestação.

- O setor privado desenvolve, constrói, obtém financiamento, opera e mantém a infraestrutura, que é de propriedade do setor público.

- O pagamento se inicia com a entrega do ativo e varia de acordo com a disponibilidade e desempenho dos serviços prestados.

- Os mecanismos de incentivo para cumprir prazos e orçamento devem ser definidos via contrato.

- Há maior previsibilidade de custos operacionais e de investimento ao longo da vida do projeto.

\subsection{2.}

\section{Investimentos em Infraestrutura}

Os países que foram precursores no desenvolvimento de PPPs passaram a buscar na iniciativa privada um meio de prover obras e serviços que eram, historicamente, prerrogativas governamentais, considerando a necessidade de redução de gastos públicos e por outro lado tendo que impulsionar investimentos em infraestrutura. 
Os gastos médios mundiais em infraestrutura, na década passada somaram 3,3\% do PIB em paridade de poder de compra (PPC), conforme a Tabela 1. Os investimentos concentraram-se em telecomunicações, água e esgoto e rodovias. No entanto, no mesmo período as demandas estimadas recomendavam investimentos em torno de 4,5\% do PIB mundial (FRISCHTAK, 2013).

Tabela 1 - Gastos mundiais infraestrutura - 2000 a 2010 (\% do PIB mundial)

\begin{tabular}{lc}
\hline \multicolumn{1}{c}{ Setor } & $\mathbf{\%}$ \\
\hline Rodovias & 0,38 \\
Aeroportos & 0,10 \\
Portos & 0,05 \\
Ferrovias & 0,09 \\
Telecomunicações & 1,14 \\
Geração & 0,27 \\
Transmissão e Distribuição & 0,22 \\
Agua e Esgoto & 1,01 \\
Total & 3,26 \\
\hline
\end{tabular}

Fonte: Frischtak (2013).

Quanto a participação de PPPs nos investimentos globais, estes eram de 5,24\% em 2005 e chegaram a 7,36\% em 2010 (Tabela 2), baseando-se nos dados disponibilizados pelo Banco Mundial (2013).

Tabela 2 - Investimentos mundiais infraestrutura - 2005 a 2010 (US\$ bilhões)

\begin{tabular}{lrc}
\hline & $\mathbf{2 0 0 5}$ & $\mathbf{2 0 1 0}$ \\
\hline PIB mundial em PPC & 56.800 & 76.300 \\
Investimentos em infraestrutura (aprox.) & 1.826 & 2.442 \\
Investimentos em PPP & 95,3 & 179,7 \\
Participação das PPPs (em \%) & 5,24 & 7,36 \\
\hline
\end{tabular}

Fontes: Frischtak (2013).

Os investimentos em infraestrutura no Brasil nas últimas décadas acabaram sendo significativamente impactados por crises no cenário internacional e por restrições orçamentárias dos governos estaduais e da própria União, mesmo com a diminuição da abrangência do Estado observada nos anos 1990.

Na realidade, já no final da década de 1970 houve a publicação do Decreto 83.740, de 18 de Julho de 1979, que instituiu o Programa Nacional de Desburocratização, que tinha como objetivo simplificar o funcionamento da 
administração pública federal. Entre os anos 1981 e 1989 foram privatizadas empresas que apresentavam elevado grau de endividamento junto ao setor público.

Em 1998, o Programa Nacional de Desestatização pautado pela falência do Estado, tinha entre seus objetivos a execução indireta de serviços públicos, por meio de concessões e permissões. Nessa fase, o Estado estava redefinindo seu papel e deixando de atuar em setores como indústria, infraestrutura e serviços, e direcionando suas atividades na regulação e fiscalização de serviços públicos essenciais. Essa fase estendeu-se até o final de 2004 e abrangeu a privatização de empresas de grande porte e historicamente estatais, principalmente dos setores de telecomunicações, siderurgia, energia e saneamento (FRISCHTAK, 2008).

Mesmo com essa redução da presença do Estado e aumento da participação privada em serviços anteriormente providos pelo governo, a taxa de investimento média no Brasil foi de 17,9\% entre 2003 e 2011, ultrapassada por China (42,4\%), Índia (31,6\%) e México (24,7\%), no mesmo período (CNI, 2013).

Ao considerar o investimento em infraestrutura com relação do PIB, o quadro é ainda mais grave. O Brasil em 2007 investia 2,36\% do PIB em infraestrutura, enquanto países emergentes apresentaram taxas de 6,2\% no caso do Chile, 5,8\% para a Colômbia e 5,6\% na Índia, segundo Frischtak (2013). A relação entre investimento e PIB no Brasil evoluiu pouco nos últimos anos, chegando em 2014 à taxa de 2,30\% e mantendo uma média de 2,20\% entre 2007 e 2014, segundo relatório da Confederação Nacional da Indústria (CNI, 2016). Ao observar horizontalmente a evolução dos investimentos em infraestrutura por setor no mesmo período, percebe-se um incremento no setor de transportes (em média 18\% no período), cujos volumes concentraram-se no modal rodoviário. Os ganhos do setor de transportes em relação ao PIB representam em média 0,9\%, dos quais 0,5\% correspondem ao modal rodoviário, como indicado na Tabela 3. 
Tabela 3 - Investimentos infraestrutura por setor 2007 a 2014 (R\$ bilhões)

\begin{tabular}{lcccccccc}
\hline \multicolumn{1}{c}{ Segmento } & $\mathbf{2 0 0 7}$ & $\mathbf{2 0 0 8}$ & $\mathbf{2 0 0 9}$ & $\mathbf{2 0 1 0}$ & $\mathbf{2 0 1 1}$ & $\mathbf{2 0 1 2}$ & $\mathbf{2 0 1 3}$ & $\mathbf{2 0 1 4}$ \\
\hline Energia Elétrica & 15,3 & 19,1 & 21,1 & 26,8 & 31,3 & 33,7 & 37,3 & 37,5 \\
Telecomunicações & 12,4 & 24,8 & 18,5 & 16,1 & 21,4 & 23,9 & 22,3 & 29,3 \\
Saneamento & 3,7 & 6,8 & 8,1 & 8,3 & 7,6 & 9,3 & 10,8 & 11 \\
Transportes & $\mathbf{1 7 , 2}$ & $\mathbf{2 3 , 2}$ & $\mathbf{3 0 , 1}$ & $\mathbf{3 7 , 1}$ & $\mathbf{3 6 , 4}$ & $\mathbf{4 0 , 4}$ & $\mathbf{5 1 , 2}$ & $\mathbf{5 2 , 3}$ \\
Rodoviário & 9,6 & 12,4 & 18,2 & 22,0 & 21,0 & 18,8 & 24,8 & 24,8 \\
Ferroviário & 3,1 & 5,1 & 3,6 & 5,6 & 6,2 & 6,2 & 7,6 & 8,9 \\
Mobilidade Urbana & 1,5 & 3,2 & 5,6 & 3,7 & 3,5 & 5,0 & 8,2 & 9,4 \\
Aeroportuário & 0,7 & 0,5 & 0,5 & 0,7 & 1,2 & 2,8 & 5,9 & 5,1 \\
Portuário & 1,9 & 1,3 & 1,1 & 4,0 & 3,8 & 7,1 & 4,1 & 3,3 \\
Hidroviário & 0,4 & 0,7 & 1,1 & 1,1 & 0,8 & 0,5 & 0,6 & 0,8 \\
Investimento Infra. Total & $\mathbf{4 8 , 6}$ & $\mathbf{7 3 , 9}$ & $\mathbf{7 7 , 8}$ & $\mathbf{8 8 , 3}$ & $\mathbf{9 6 , 7}$ & $\mathbf{1 0 7 , 3}$ & $\mathbf{1 2 1 , 6}$ & $\mathbf{1 3 0 , 1}$ \\
PIB Nominal & $\mathbf{2 . 7 1 8}$ & $\mathbf{3 . 1 0 8}$ & $\mathbf{3 . 3 2 8}$ & $\mathbf{3 . 8 8 7}$ & $\mathbf{4 . 3 7 5}$ & $\mathbf{4 . 8 0 5}$ & $\mathbf{5 . 3 1 6}$ & $\mathbf{5 . 6 8 7}$ \\
\hline Invest. /PIB (\%) & $\mathbf{1 , 7 9 \%}$ & $\mathbf{2 , 3 8 \%}$ & $\mathbf{2 , 3 4 \%}$ & $\mathbf{2 , 2 7 \%}$ & $\mathbf{2 , 2 1 \%}$ & $\mathbf{2 , 2 3 \%}$ & $\mathbf{2 , 2 9 \%}$ & $\mathbf{2 , 2 9 \%}$ \\
\hline
\end{tabular}

Fonte: CNI (2016).

Ao se observar investimentos realizados em relação ao PIB em décadas passadas, os investimentos no setor de transportes que representaram 2,0\% na década de 1970, se reduziram para 0,7\% em média no período entre 2001 e 2014. Ao considerar todo o período, o percentual médio foi de 1,2\%. Ao comparar o percentual de investimentos em relação ao PIB no período 1971-1980 (coluna A) e 2001-2014 (coluna B), houve uma queda expressiva também para todos os setores, conforme a Tabela 4 a seguir (CNI, 2016).

Tabela 4 - Investimentos infraestrutura por setor em \% do PIB, média de períodos decenais e redução proporcional entre o primeiro e último período (em \%).

\begin{tabular}{lccccc}
\hline \multicolumn{1}{c}{ Segmento } & $\mathbf{1 9 7 1 - 1 9 8 0}(\mathbf{A})$ & $\mathbf{1 9 8 1 - 1 9 8 9}$ & $\mathbf{1 9 9 0 - 2 0 0 0}$ & $\mathbf{2 0 0 1 - 2 0 1 4}(\mathbf{B})$ & (A-B)/A \\
\hline Total (\% do PIB) & $5,4 \%$ & $3,6 \%$ & $2,3 \%$ & $2,2 \%$ & $60,1 \%$ \\
Energia Elétrica & $2,1 \%$ & $1,5 \%$ & $0,8 \%$ & $0,6 \%$ & $70,0 \%$ \\
Telecomunicações & $0,8 \%$ & $0,4 \%$ & $0,7 \%$ & $0,6 \%$ & $21,3 \%$ \\
Agua e Sane amento & $0,5 \%$ & $0,2 \%$ & $0,2 \%$ & $0,2 \%$ & $58,7 \%$ \\
Transportes & $2,0 \%$ & $1,5 \%$ & $0,6 \%$ & $0,7 \%$ & $65,5 \%$ \\
\hline
\end{tabular}

Fonte: CNI (2016).

Os investimentos (públicos e privados) em infraestrutura de transportes (rodovias, ferrovias, portos e aeroportos) em 2015 chegaram a 0,6\% do PIB, enquanto países emergentes como Rússia, Índia, China, Coreia, Vietnã, Chile e Colômbia atingem em média 3,4\% do PIB (CNI, 2016). Estima-se que o Brasil precisaria investir ao menos 0,9\% do PIB para apenas compensar a depreciação de capital fixo per capita (PINHEIRO;MONTEIRO;GONDIM;CORONADO, 2015).

Entre 2014 e 2015, os investimentos no setor de infraestrutura de transportes sofreram redução de 37,6\%, de $\mathrm{R} \$ 15,7$ bilhões para $\mathrm{R}$ \$ 9,8 bilhões, tendo 
passado por uma redução de 52,6\% entre 2010 e 2015. No que se refere às rodovias, apenas as que apresentam tráfego intenso têm se tornado atraentes à iniciativa privada ou do contrário, tornam-se viáveis financeiramente por meio de repasse tarifário aos usuários finais (CNI, 2016).

Além do baixo nível de investimentos, destaca-se ainda a ineficiência dos investimentos em infraestrutura no Brasil, a exemplo dos projetos previstos pelo PAC e PAC 2 (CNI, 2014). Por outro lado, as ineficiências de investimentos em infraestrutura também têm histórico em outros países, como observado em Flyvbjerg (2009, apud PINHEIRO et al., 2015, p.53), que identificou que de um total de 258 projetos no segmento de transportes em 25 países, os custos dos projetos foram em média 33\% mais elevados do que o previsto (Tabela 5).

Tabela 5 - Erros em estimativa de custos de projetos de transporte no mundo.

\begin{tabular}{cccc}
\hline Tipo de proje to & Número de casos & $\begin{array}{c}\text { Custo adicional } \\
\text { médio (\%) }\end{array}$ & $\begin{array}{c}\text { Desvio padrão } \\
\text { (\%) }\end{array}$ \\
\hline Ferroviário & 58 & 44,7 & 38,4 \\
Pontes e Túneis & 33 & 33,8 & 62,4 \\
Rodovias & 167 & 20,4 & 29,9 \\
\hline Média & 86 & 33,0 & 43,6 \\
\hline
\end{tabular}

Fonte: Flyvbjerg (2009, apud PINHEIRO et al., 2015, p.53).

Em Savi, Albuquerque e Rebelatto (2010) já havia sido proposta a criação de uma nova política de cooperação entre o setor público e o privado, direcionada principalmente para a área de infraestrutura, que tradicionalmente necessita de altos investimentos e retorno de longo prazo.

Em meio a esse cenário, as PPPs poderiam representar um diferencial para a recuperação dos investimentos em infraestrutura desde sua criação, que formalmente aconteceu pela Lei Federal $n^{\circ}$ 11.079/2004, que definiu em seu parágrafo $2^{\circ}$ as parcerias público-privadas como um “contrato administrativo de concessão, na modalidade patrocinada ou administrativa”. Assim, os dois novos modelos de concessão passaram a se diferenciar das concessões comuns reguladas pela Lei Federal 8.987/1995. Na modalidade de PPPs patrocinadas, e pelo formato desenhado pelo arcabouço legal, os usuários do serviço público oferecido arcam 
com parte ou grande parte da remuneração do concessionário. Estas concessões de serviços ou equipamentos públicas são similares às concessões criadas pela Lei 8.987/1995, porém envolvendo, adicionalmente à tarifa cobrada dos usuários, uma contraprestação pecuniária do parceiro público.

Já na concessão administrativa, como previsto no art. $2^{\circ}$, inciso segundo da Lei 11.079/2004, a administração pública remunera diretamente o concessionário pelo investimento realizado, mesmo que envolva a execução de obras ou fornecimento de bens e instalações.

A Lei Federal 11.079/2004 institui, entre outras prerrogativas a serem observadas na contratação de PPPs:

a) valor do contrato superior a $\mathrm{R} \$ 20.000 .000,00$;

b) período de vigência contratual não inferior a 5 anos, nem superior a 35 anos, incluindo eventual prorrogação;

c) remuneração pelo parceiro público ao parceiro privado somente após a disponibilização do serviço;

d) remuneração variável pelo parceiro público ao parceiro privado vinculada ao seu desempenho;

e) compartilhamento de riscos entre o parceiro público e o parceiro privado;

f) a prestação, pelo parceiro privado, de garantias de execução suficientes e compatíveis com os ônus e riscos envolvidos;

g) eficiência no cumprimento das missões do Estado e no emprego dos recursos da sociedade;

h) respeito aos interesses e direitos dos destinatários dos serviços e dos entes privados incumbidos de sua execução;

i) indelegabilidade das funções de regulação, do exercício do poder de polícia e de outras atividades exclusivas do Estado;

j) responsabilidade fiscal na celebração e execução de parcerias;

k) transparência dos procedimentos e das decisões;

l) sustentabilidade financeira e vantagens socioeconômicas dos projetos de parceria.

Os contratos de PPPs diferenciam-se de forma muito positiva aos contratos de concessões tradicionais principalmente no que se refere ao compartilhamento de riscos entre as partes envolvidas e restrição orçamentária de gastos do governo. 
Neste modelo, as partes tomariam decisões ótimas, à medida que conseguissem ex-ante prever, controlar e mitigar possíveis riscos operacionais através das condições contratuais já estabelecidas.

O prazo de vigência dos contratos de PPPs deve ser compatível com a amortização dos investimentos, e, não sendo inferior a cinco anos ou superior a trinta e cinco anos. Outra diferença das PPPs com relação às concessões, diz respeito a obrigatoriedade da constituição de uma SPE (Sociedade de Propósito Especifico) antes da assinatura do contrato, para assegurar a gestão exclusiva do objeto da parceria. A justificativa para se exigir a criação da SPE se deve a necessidade de simplificação do controle sobre o cumprimento do contrato e a inconveniência em misturar recursos públicos e privados, destinados uns e outros a finalidades diversas (SOUZA, 2008).

No Brasil, até janeiro de 2016 foram realizados 86 projetos de PPPs, sendo 71 na modalidade administrativa e 15 na modalidade patrocinada (RADARPPP, 2016). Apesar deste crescimento, no entanto, entre 2010 e 2014 ao observar o total de projetos planejados, apenas $28 \%$ atingiram à fase de consulta pública, $21 \%$ se transformaram em editais publicados e $12,3 \%$ em contratos assinados (PINHEIRO et al., 2015).

Após um crescimento observado no número de PPPs entre 2012 e 2014, o que se viu de forma subsequente foi uma queda significativa deste tipo de iniciativa (Figura 1, a seguir), que em grande parte pode ser explicada pela forte retração dos investimentos privados e públicos (federais) em infraestrutura de transportes (rodovias, ferrovias, portos e aeroportos) no período. Laffont e Tirole (1993, apud PINHEIRO et al., 2015, p.18) sugere que o descompasso entre a alta incidência de estudos realizados, versus projetos licitados está relacionado: aos altos custos de transação para o poder público, decorrentes do processo licitatório; à assimetria de informações do gestor público quanto a eficiência das empresas e características do projeto; e ao desalinhamento de incentivos . 


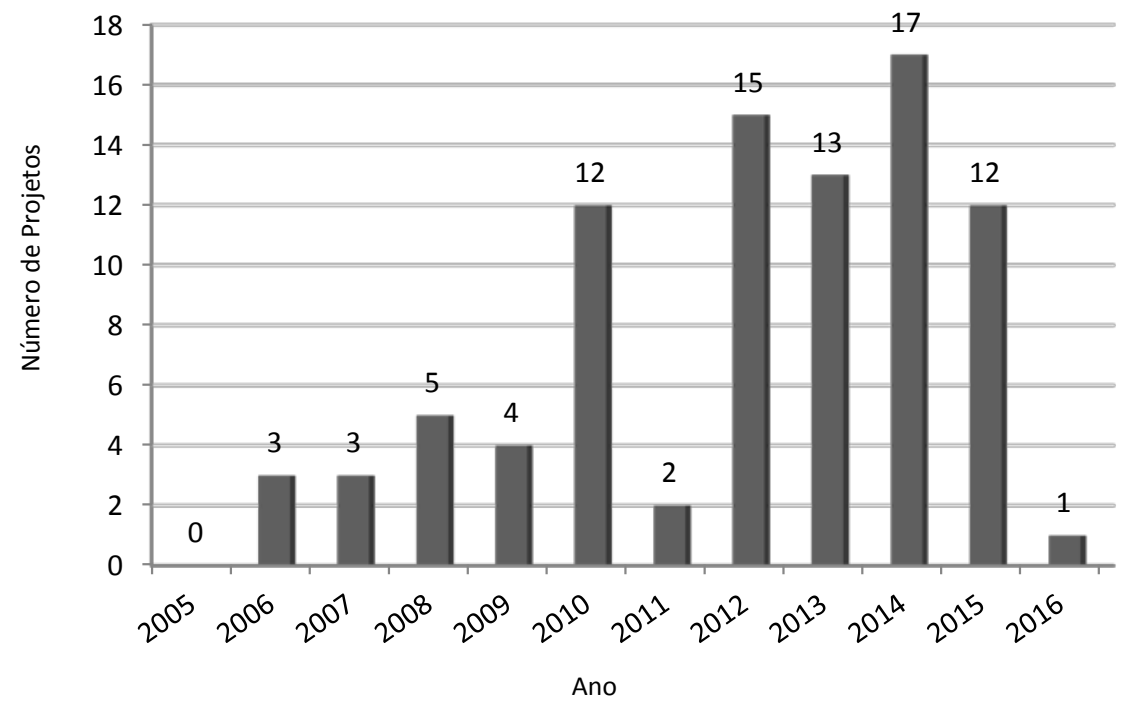

\section{Figura 1 - Evolução no número de PPPs no Brasil por ano.}

Fonte: Radar PPP (2016).

Em relação ao aspecto setorial, ao observar PPPs assinadas até 2016, podese perceber o foco dado a resíduos sólidos e saneamento, que corresponderam a $40 \%$ (Figura 2).

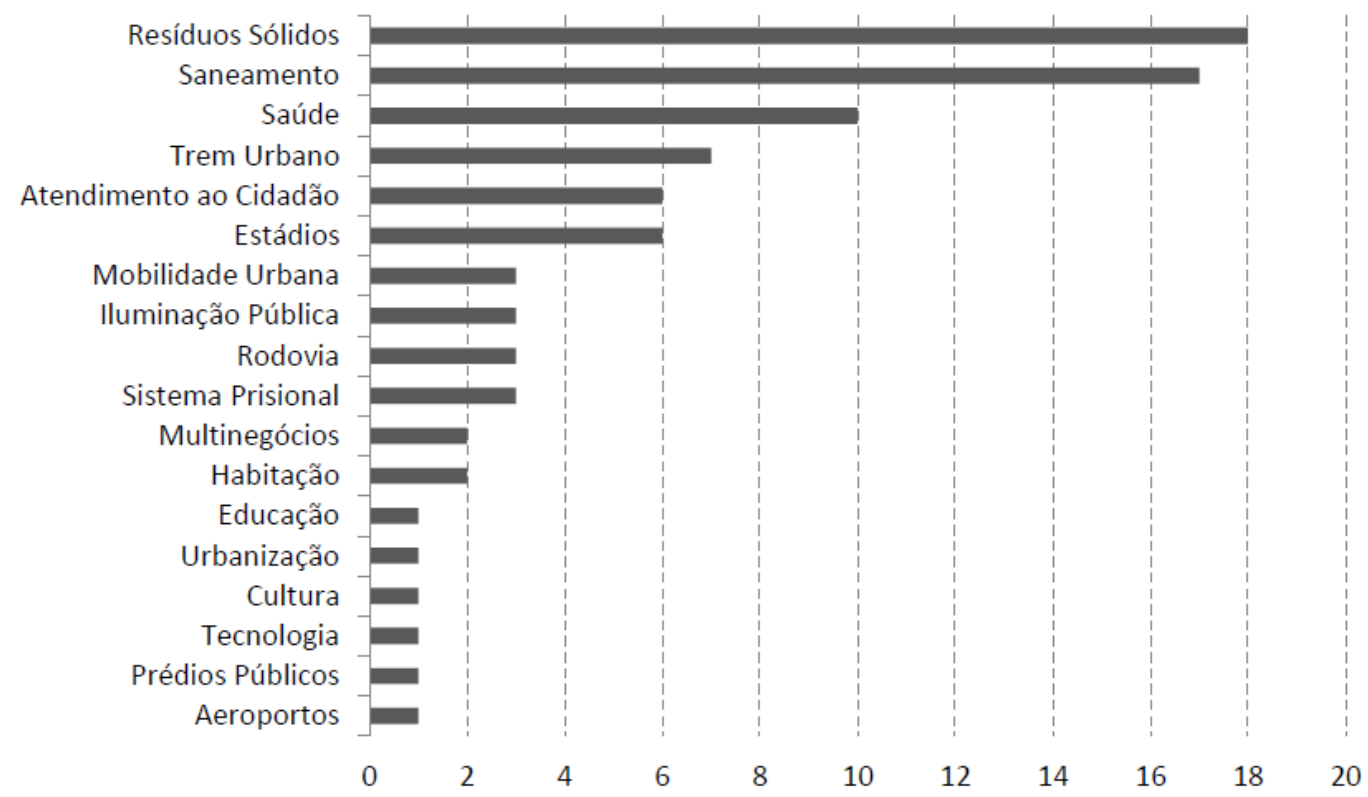

Figura 2 - Número de PPPs em execução e por setor

Fonte: Radar PPP (2016).

A urgência em promover PPPs no Brasil, demonstra-se relacionada a carência de infraestrutura básica que é sabida pelo governo, mas também claramente conhecida pela população. 


\subsection{3.}

\section{Estruturação Financeira e Análise de Risco}

O setor de infraestrutura é significativamente impactado por consideráveis riscos e por exigências de retornos dos acionistas, em função grandes investimentos iniciais de capital, da presença de capacidade ociosa e de demanda com baixa elasticidade de preço. Por outro lado, as margens operacionais são mais elevadas e duradouras, quando comparados a outros setores industriais. Este conjunto de características possibilita o aumento considerável da alavancagem financeira no equacionamento das fontes de recursos para a implantação de projetos nos setores de infraestrutura, invariavelmente por meio de estruturas financeiras do tipo project finance.

A utilização da estrutura do project finance começou a ser discutida no Brasil a partir da segunda metade da década de 1990, como uma das alternativas para viabilizar a alavancagem de projetos de Parcerias Público-Privadas. O início das reformas institucionais nos setores de infraestrutura gerou um natural questionamento quanto ao papel do Estado como principal investidor em projetos. Naquele momento, a estruturação dos projetos via project finance, baseada em contratos privados de longo prazo, não era tão necessária, uma vez que obter financiamento para obras de infraestrutura estatais não demandava garantias aos entes financeiros

públicos

(FILHO;ALONSO;CHAGAS;SZUSTER;SUSSEKIND, 2009).

Os projetos focaram principalmente nos setores de telecomunicações, energia elétrica, petróleo e gás e infraestrutura de transporte. No entanto, com o passar do tempo vem se percebendo a importância de contar com a participação da iniciativa privada, e cuja estruturação financeira pode se viabilizar via project finance.

Entre as definições de project finance, pode-se sintetizar como um mecanismo de estruturação de financiamento a uma unidade ou conjunto de unidades produtivas legalmente independentes dos investidores (patrocinadores), na qual os financiadores assumem que o fluxo de caixa a ser gerado e os ativos do projeto são as fontes primárias de pagamento e garantia do financiamento. O fato de o projeto ser legalmente independente significa que os investidores devem 
constituir uma sociedade independente (sociedade de propósito específico - SPE) para a implantação do projeto (FILHO et al., 2009).

Grandes empreendimentos têm recorrido à estruturação financeira por project finance para a obtenção de créditos de projetos, com em alguns países emergentes que adotaram leis locais e licenciamento ambiental para diminuir os impactos ambientais e sociais em áreas beneficiadas por grandes projetos, seja na área de petróleo e gás natural, energia, transportes ou infraestrutura em geral. As exigências ambientais são incluídas neste caso como especificações técnicas do project finance.

Como já observado em Rodrigues Jr. (1997), o project finance em muitos países já faz parte da estrutura básica de PPPs, contribuindo para sua viabilidade metodológica e econômica. Dentro desta perspectiva, diversas modalidades de PPPs desenvolvidas como build, transfer and operate - BTO, ou build, own, operate and transfer - BOOT, ou Build, Own and Operate - BOO e, até mesmo, os contratos de gestão e arrendamento, têm sido considerados como operações do tipo project finance.

Com relação ao período de implantação do projeto é comum observar que os financiadores podem recorrer - integralmente (full-recourse) ou não recorrer (norecourse) - aos ativos dos investidores para assegurar o pagamento do crédito. Em outras palavras, ainda que desejável, não há a obrigatoriedade de que os projetos sejam completamente autossuficientes desde seu início, fazendo com que os credores prescindam da solidariedade dos patrocinadores. Dessa forma, o project finance difere do financiamento corporativo, pois este é amparado por ativos e pelo fluxo de caixa dos investidores.

No project finance também são utilizados contratos formais de garantia com certos dispositivos que restringem as atividades da empresa-projeto, denominados covenants. Estes mecanismos aliados às auditorias e instrumentos de acompanhamento são essenciais para a gestão do projeto. Por outro lado, uma condição básica para a estruturação de um projeto a partir do project finance é a identificação de todos os riscos inerentes a sua implantação, de forma a mitigalos, alocando-os às partes envolvidas na estruturação do projeto. Entre as partes, destacam-se: a SPE; os patrocinadores (investidores que aportam capital na SPE); os financiadores/ debenturistas; as seguradoras; os agentes administradores de contas (trustees); construtores; o poder concedente; os compradores dos produtos 
produzidos; os fornecedores de insumos; e os operadores do projeto na sua fase operacional.

Importante ressaltar que as diferenças conceituais entre riscos e incertezas em projetos já são conhecidas há bastante tempo. Como fora abordado por Knight (2005), tanto riscos quanto incertezas se referem à imprevisibilidade a respeito dos resultados futuros. As incertezas estão associadas às variáveis não conhecidas ou ausência de evidências suficientes, cujos impactos reais não são facilmente mensuráveis e que envolvem certa complexidade quanto ao seu tratamento. $\mathrm{O}$ conceito de risco, em linhas gerais, está relacionado ao conhecimento sobre as variáveis em questão e às probabilidades dos resultados futuros ocorrerem do ponto de vista matemático ou em função de experiências passadas. Por estas razões, ao longo deste estudo serão considerados tratamentos diferenciados para a modelagem de incertezas e a avaliação de riscos em projetos por PPPs.

A análises de risco é determinante na estruturação do project finance para projetos de infraestrutura, sobretudo considerando as modalidades das PPPs. Segundo Tinsley (2000) e Grimsey e Lewis (2002), os riscos podem ser classificados nas fases de desenvolvimento, implantação e operação e agregados em nove categorias principais:

a) Risco de suprimento:

O risco de suprimento se refere ao acesso a insumos para o projeto e deve ser mitigado ou compartilhado contratualmente com seus fornecedores, de forma a garantir quantidades mínima e/ou preço máximo de fornecimento. Esses contratos podem imputar ao fornecedor a responsabilidade pela produção de insumos com terceiros, caso ele não possa honrá-lo. Os riscos de suprimento também podem ser mitigados por mecanismos de gatilho. Já o patrocinador pode contratar seguros contra a falta de insumos ou, proteger-se contra oscilações no preço do insumo com mecanismos de hedge, tais como contratos futuros, contratos a termo, ou opções.

\section{b) Risco de mercado:}

Risco de possíveis disparidades entre as previsões que serviram de base para avaliar a viabilidade econômica, em relação ao dimensionamento da operação e a demanda real de bens e serviços a que ela se destina a satisfazer. 


\section{c) Risco operacional:}

Envolve aspectos tecnológicos, gerenciais e de custo, que são inerentes à fase operacional. Avanços tecnológicos podem impactar significativamente o desenvolvimento, a implantação ou expansão de projetos tecnologicamente intensivos. Entretanto, nenhum projeto está imune a falha humana, material, ou outros que venham a prejudicar os lucros. Nesse sentido, a celebração de contratos de longo prazo de operação e manutenção pode ser com os próprios patrocinadores, embutindo seguros operacionais. Esses contratos são essenciais para a estruturação dos projetos, pois o fluxo de caixa dos mesmos é a principal garantia do financiamento durante a fase operacional e, precisam ser "blindados" dos possíveis impactos negativos da alocação de tais riscos.

O risco operacional apresenta ainda um componente gerencial relacionado à ineficiência administrativa. A SPE pode ser também protegida por regras rígidas e claras de governança corporativa, reduzindo possíveis conflitos entre os patrocinadores. A inclusão de covenants ou obrigações podem ser incluídas no contrato de financiamento, aliada a necessidade de atingir determinados índices financeiros, necessidade de anuência dos credores para a celebração de contratos e restrições na administração.

\section{d) Risco de implantação:}

Está associado principalmente a não conclusão da planta e aos custos irrecuperáveis (sunk costs) provenientes da sua não completude. Pode ser considerada a fase de maior risco para o project finance, podendo inclusive desencadear outros riscos que podem impedir, postergar ou prejudicar a fase operacional do projeto. Os possíveis arranjos de garantias para mitigar o risco de não conclusão envolvem compromissos de entrega em um prazo estabelecido, havendo margens predefinidas para atrasos, baseadas em indicadores de eficiência operacional e, em alguns casos, de cumprimento do orçamento da construção.

Os credores comumente exigem que os patrocinadores se comprometam a aportar recursos próprios antecipadamente à liberação do financiamento e que celebrem contrato de suporte para garantir o aporte para eventuais aumentos no orçamento. Do mesmo modo, aos acionistas cabe não apenas aportar os recursos próprios, mas garantir, empenhar ações e principalmente os recebíveis dos projetos, que podem garantir a cobertura do serviço da dívida, por intermédio da 
cessão e da reserva de meio de pagamento. À medida que os índices que compõem os testes vão sendo atingidos, os suportes de garantia fornecidos pelos patrocinadores tendem a ser regressivamente exigidos pelos credores, cada vez em menor grau, até que cessem as exigências. Caso o projeto não tenha êxito nos testes de conclusão, podem ser acionadas as cláusulas de vencimento antecipado da dívida.

\section{e) Risco de construção:}

São os riscos associados a erros na concepção do projeto que podem levar a um descumprimento dos prazos originais, a má performance do empreendimento, ao aparecimento de custos extras, ou até a sua inviabilização. Para que sejam mitigados, devem ser divididos de maneira adequada entre as partes responsáveis pela construção.

Os patrocinadores procuram transferir, ao máximo, o risco de conclusão para os construtores e fornecedores de equipamentos por meio da celebração de contratos turn-key lump sum do tipo empower procurement and construction (EPC), no qual o construtor é obrigado a entregar, por preço pré-determinado, o projeto operando sob determinadas especificações, tendo a responsabilidade de construção sobre todo o projeto.

Este tipo de projeto, por outro lado, é oneroso em função do risco dos construtores e fornecedores, cabendo a contratação de seguros diversos, de forma a reduzir os riscos por eles assumidos. Entre os seguros geralmente destacam-se os de engenharia; responsabilidade civil; transportes; e lucros cessantes - nas modalidades advance loss of profit (ALOP) e delay in start-up (DSU).

\section{f) Risco ambiental:}

Pode ter origem no aumento de custos com compensações ambientais, com a paralisação das obras ou operação do projeto, por questões ambientais, manifestações de grupos ambientalistas etc. Problemas socioambientais podem ainda deteriorar as relações entre as partes envolvidas, entre os patrocinadores e autoridades governamentais. 


\section{g) Riscos de custos financeiros:}

Ocorrem após a estruturação das fontes de recursos do projeto, que podem ser por meio do project finance ou não. No caso do project finance, o valor do financiamento baseia-se na capacidade de pagamento do fluxo de caixa do projeto sobre o fluxo de pagamentos de principal e juros da dívida (índice de cobertura do serviço da dívida). A capacidade de pagamento do financiamento pode ser comprometida em casos extremos de descasamento acentuado entre os indicadores de correção dos ativos e passivos do projeto. No caso de financiamentos em moeda estrangeira, a variação cambial pode implicar em movimentos súbitos do fluxo de pagamento da dívida em relação ao fluxo operacional, comprometendo, portanto, a capacidade de pagamento do projeto.

Os riscos que envolvem a estruturação do financiamento podem ser mitigados de diferentes formas. Para dívidas em moedas externas, pode-se exigir à SPE a contratação de instrumentos de hedge cambial versus índice de inflação de indexação das receitas (IPCA, IGP-M, etc).

O financiamento deverá contar ainda com uma folga mínima do índice de cobertura do serviço da dívida (normalmente igual a 1,3) e reserva dos meios de pagamento, composta de: (i) conta centralizadora de receitas; e (ii) conta reserva não inferior ao fluxo de pagamento de três meses do serviço da dívida e custos operacionais (não movimentáveis pela SPE), além da conta movimento (BNDES, 2016).

\section{h) Risco dos participantes:}

Diz respeito à capacidade creditícia e a relação entre as partes envolvidas (patrocinadores, investidores de capital próprio, credores, detentores de títulos de dívida emitidos pelo projeto, governo, fornecedores, construtores, operadores, compradores da produção, consultores financeiros, legais, ambientais, engenheiros independentes etc.).

Este risco pode ser mitigado por intermédio de instrumentos que evitem recusa ou transferência de responsabilidade entre as partes, dando atenção ao compliance de contratos e input de garantias cruzadas entre os agentes envolvidos em determinado contrato. 


\section{i) Risco legal:}

São riscos decorrentes dos efeitos prejudiciais advindos das relações contratuais entre elas e terceiros (microeconômicos) ou relativamente aos sistemas jurídicos do país e/ou de domicílio dos principais agentes envolvidos (macroeconômicos). Pelo sistema jurídico brasileiro o interesse público pode sobrepor-se ao privado (contratos administrativos), e seus instrumentos legais são menos efetivos e mais frágeis, exigindo maior cautela por parte dos investidores do que no ambiente da common law (CHAGAS, 2006).

\section{j) Risco País:}

É expresso como decorrente do risco de crédito ao qual estão submetidos os investidores estrangeiros quando investem no país. Segundo o BACEN (2010) os indicadores diários mais utilizados são o Emerging Markets Bond Index Plus (EMBI+Br), e o Credit Default Swap (CDS) do Brasil.

O EMBI+ é medido pelo Banco J.P. Morgan Chase e é medido como um índice ponderado composto por instrumentos de dívida externa, negociados e em dólar por governos de países emergentes. É calculado pelo movimento de preços dos títulos que o compõem e é dado pela média ponderada dos retornos diários pagos por esses títulos. Já o CDS pode ser usado como medida de risco país, na medida em que representa uma medida de risco de crédito da entidade de referência e é cotado em pontos-base. Este se constitui a partir de um contrato bilateral que permite ao investidor comprar proteção para crédito específico contra evento de crédito do emissor de determinado ativo.

Outro aspecto levantado por Borges (2005), é que no Brasil, o agente fiduciário não tem a propriedade dos bens sobre os quais deve agir, sendo, no máximo, fiel depositário de alguns bens ou direitos, ou, em outros casos, administrador ou gestor de recursos de terceiros. Com isso, os contratos nos quais ativos são transferidos para a propriedade de um terceiro designado para agir de determinada forma ou para atingir certo fim, não são aceitos no Brasil por atentar contra princípios de sucessão e de insolvência. 


\subsection{4.}

\section{Avaliação financeira de Projetos e PPPs}

A adequada mensuração de riscos e análise dos mesmos em projetos de infraestrutura por PPPs é indispensável para avaliação dessa classe de projetos. No entanto, os métodos tradicionais de avaliação financeira empregados na modelagem de projetos de infraestrutura buscam basicamente mensurar riscoretorno sistemático, ou em outras palavras, que não pode ser reduzido via diversificação e impacta todo o mercado.

Invariavelmente, a metodologia de avaliação mais utilizada é a do Fluxo de Caixa Descontado (FCD), que parte do princípio de que a estimativa de uma taxa média de retorno de um empreendimento permite o cálculo do Valor Presente Líquido (VPL) e da Taxa Interna de Retorno (TIR), assim como o tempo médio de retorno daquele projeto (payback) (BRIGHAM;HOUSTON, 2012).

Pela metodologia do FCD, em termos gerais o valor de um projeto será o resultado do somatório das projeções de fluxo de caixa futuros trazido a valor presente a um custo de capital compatível com o risco do projeto. Para projetos de infraestrutura por PPPs, Zhang (2005) propõe pela metodologia com base no fluxo de caixa descontado, tendo como foco otimizar a estrutura de capital do projeto, de forma a maximizar a taxa interna de retorno do equity (capital próprio) em $k$ anos, definida como $I R R E_{k}$ e que consequentemente trará o máximo valor presente líquido do projeto, definido pela variável $N P V^{K}$.

$\mathrm{O}$ autor define o equity do projeto no longo prazo como sendo $E P R$ e a parcela do equity sujeita a riscos de mercado dada pela variável $R E P R_{k}$. Além disso, as variáveis de input contemplam o custo básico de construção definido como $C_{B}$, a taxa de custos escalonáveis $e_{k}$, o tempo duração da construção $D_{C}$, a demanda de mercado $Q_{j}$, o preço $P_{j}$, o custo de operação e manutenção $O M_{j}$, a taxa de inflação $r_{I}$, a taxa básica de juros da dívida $r_{B}$, a capacidade de autofinanciamento SFA, o nível mínimo de equity requerido $R_{\min }$, a margem de lucro da construção $M L_{C}$, o percentual mínimo de equity requerido em relação aos riscos do projeto $R E P R_{\min }$, o nível mínimo de cobertura do serviço da dívida $D S C R_{\min }$, a alíquota de impostos $r_{\operatorname{tax}}$ e a taxa de juros da dívida $r_{D}$, como função da taxa básica de juros $r_{B}$ e o nível do equity $R$, que é dado por $R: r_{D}=f\left(r_{B}, R\right)$. 
A partir da definição das variáveis de input e supondo $k=1$ e $R_{k}=R_{\min }$, o percentual do equity anual definido por $E^{K}$ é calculado, ao considerar o percentual de dívida definida como $D^{K}$, bem como $R E P R k, D S C R k, N P V^{K}$ e IRREk. Na etapa seguinte, supondo $k=k+1$ e $R_{k}=R_{k}+1 \%$ e se $R_{k}=1$, dar-se início a análise sobre a combinação ótima das variáveis $R_{k}, R E P R k, D S C R_{k}$, na qual $R E P R k \geq R E P R_{\text {min }}$ e $D S C R_{k} \geq D S C R_{\text {min }}$. Em seguida, segue-se a análise do $N P V^{K}$ do projeto e definição da viabilidade financeira do projeto, ao nível de equity estimado. As etapas da otimização da estrutura de capital e análise de viabilidade do valor do projeto podem ser observadas pela Figura 3 a seguir:

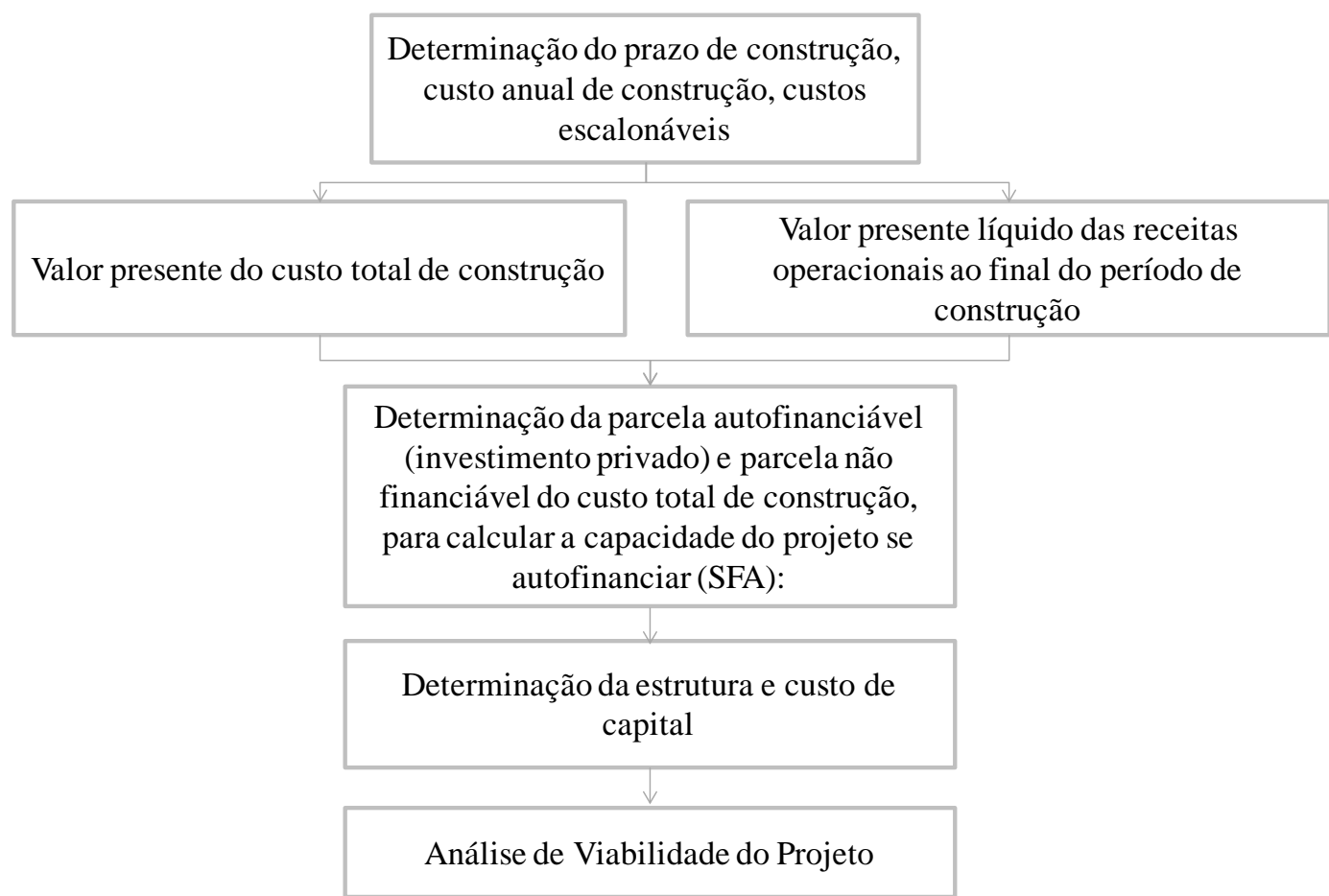

Figura 3 - Processo de determinação do valor de um projeto por PPP.

Fonte: Zhang (2005).

De maneira geral, os métodos de cálculo da taxa de desconto podem envolver o Capital Asset Pricing Model (CAPM) proposto por Sharpe (1964) e o Arbitrage Pricing Theory (APT) proposto por Ross (1976). A metodologia do FCD aplicada a projetos de infraestrutura prevê ainda que os fluxos de caixa possam ser calculados pelo Fluxo de Caixa da Empresa (FCE) e pelo Fluxo de Caixa do Acionista (FCA), a depender das partes interessadas no projeto (GRIMSEY;LEWIS, 2002). 
A primeira abordagem, conhecida como Fluxo de Caixa Livre da Empresa (FCLE) considera a empresa como um todo, incluindo a participação acionária e a participação dos demais detentores de direitos da empresa, como os credores. A partir dos fluxos de caixa esperados provenientes das operações da empresa, são deduzidos todos os custos e despesas operacionais, a depreciação, as necessidades de reinvestimentos e os impostos, mas não os fluxos de capital de terceiros e serviço da dívida. Em seguida, estes valores são descontados a valor presente por uma taxa de retorno, que é estruturada a partir do custo médio ponderado de capital (WACC). A segunda abordagem, denominada Fluxo de Caixa Livre do Acionista (FCLA), considera apenas a participação acionária do negócio. Neste caso, os fluxos de caixa após as deduções de todas as despesas operacionais, incluindo despesas financeiras, o principal da dívida e impostos, são descontados ao custo do capital do acionista pelo modelo CAPM (SHARPE, 1964), ou seja, a taxa de retorno exigida pelos investidores para os fluxos de caixa residuais, considerando o capital empregado no projeto. Como esse fluxo residual já contemplou todos os pagamentos devidos a terceiros, o seu valor será revertido em sua totalidade para o acionista ou investidor. Em cada uma destas abordagens são obtidos fluxos de caixa distintos que são descontados utilizando taxas de retorno diferentes, mas que se realizados corretamente, ambos os métodos fornecem resultados convergentes (RADARPPP, 2014).

No cálculo da taxa de retorno, que também pode ser entendida como a taxa de desconto ajustada a risco ou taxa mínima de atratividade, para fins de desconto dos fluxos de caixa futuros, já estão embutidos todos os riscos (sistemáticos) relativos ao projeto em avaliação, a partir do modelo CAPM. O calculo da taxa de desconto ajustada a risco ( $\mu$ ) pela ótica do custo de capital consiste basicamente em estimar uma taxa livre de risco (r) e um prêmio pelo risco de mercado ( $\beta$ ), para se chegar a $\mu=r+\beta$. A taxa de retorno pode ser considerada como o somatório do ganho de capital ( $\alpha$ ), com a taxa de dividendos $\delta$, resultando em $\mu=\alpha+\delta$.

No entanto, sabe-se que a taxa de retorno calculada a partir do modelo CAPM, que é amplamente utilizada em avaliação de projetos, não incorpora incertezas e riscos não sistemáticos, tais como decorrentes de variações de demanda, preços, custos, atrasos e restrições técnicas. Sendo assim, cabe a 
introdução de abordagens que complementem a teoria tradicional de avaliação de riscos em projetos pela metodologia do Fluxo de Caixa Descontado, para avaliações mais robustas de projetos de infraestrutura.

\subsection{5.}

\section{Medidas de risco e performance}

O risco pode ser observado como uma variável aleatória, cuja distribuição de probabilidade indicará maior ou menor exposição. A análise de risco pode ser conduzida de forma isolada sob a ótica de um ativo ou para uma carteira de vários ativos, como já proposto por Markowitz (1952) para ativos financeiros, ao utilizar a Média-Variância dos retornos de uma carteira de ativos como medida de risco. De acordo com o autor, os investidores determinam carteiras ótimas, a partir de uma fronteira eficiente, na qual minimizam-se os riscos (variâncias) das carteiras para cada nível de retorno (médias). Esta teoria parte do princípio de que os retornos dos ativos da carteira seguem uma distribuição normal, o que acaba sendo uma limitação do método, uma vez que preços e custos de mercado apresentam comportamentos aleatórios diversos.

Posteriormente surgiu a metodologia do $\mathrm{VaR}$ (value-at-risk), que é uma métrica desenvolvida inicialmente para ativos financeiros para avaliar exposição a riscos. Esta metodologia representa uma estimativa da perda máxima esperada, dado um determinado nível de significância e em um horizonte de tempo sob condições normais de mercado (SHARPE, 1970). Sua simplicidade em resumir a avaliação do risco utilizando um único número, a tornou amplamente utilizada pelo mercado. A técnica resulta do esforço de determinar em um único número a exposição total ao risco em cada periodo.

Formalmente, o VaR descreve o quartil da distribuição projetada de ganhos e perdas previstas num horizonte de tempo. Se “c” é o nível de confiança, o VaR corresponderia a “1-c” (JORION, 2000). Considerando que a função de probabilidade condicional se torna conhecida, a definição estatística para o VaR é dada por:

$$
\operatorname{Pr}[\Delta P(N)<\operatorname{VaR}]=F[\Delta P(-\operatorname{VaR})]=\int_{-\infty}^{V a R^{*}} f(\Delta P(x)) d x=1-c
$$


onde $\operatorname{Pr}[\Delta P()$.$] é a função de distribuição acumulada dos retornos \Delta P, f(\Delta P(x))$ da função de densidade de probabilidade de $\Delta P, c$ de nível de significância e $\Delta P(N)=\Delta P_{t}(N)$ a mudança relativa no valor do portfólio ao longo do horizonte de tempo $N . \quad \Delta P_{t}(N)=P(t+N)-P_{t} \cdot P(t+N)$ é o logaritmo natural do valor do portfólio no tempo $t+N$ e $P(t)$ é o logaritmo natural do valor do portfólio no tempo t. Por métodos de simulação, pode-se gerar $N$ possíveis valores de portfólios para uma data futura $t+N$. Dessa forma, o VaR tem como ser obtido a partir da distribuição de valores simulados. Na Figura 4, que ilustra a distribuição de probabilidades do resultado líquido (VPL) de um projeto de investimento, pode-se perceber que o $\mathrm{VaR}_{95 \%}$ dessa distribuição seria de \$ 2,33 milhões, ou seja, resultados abaixo desse valor são esperados em apenas 5\% dos casos.

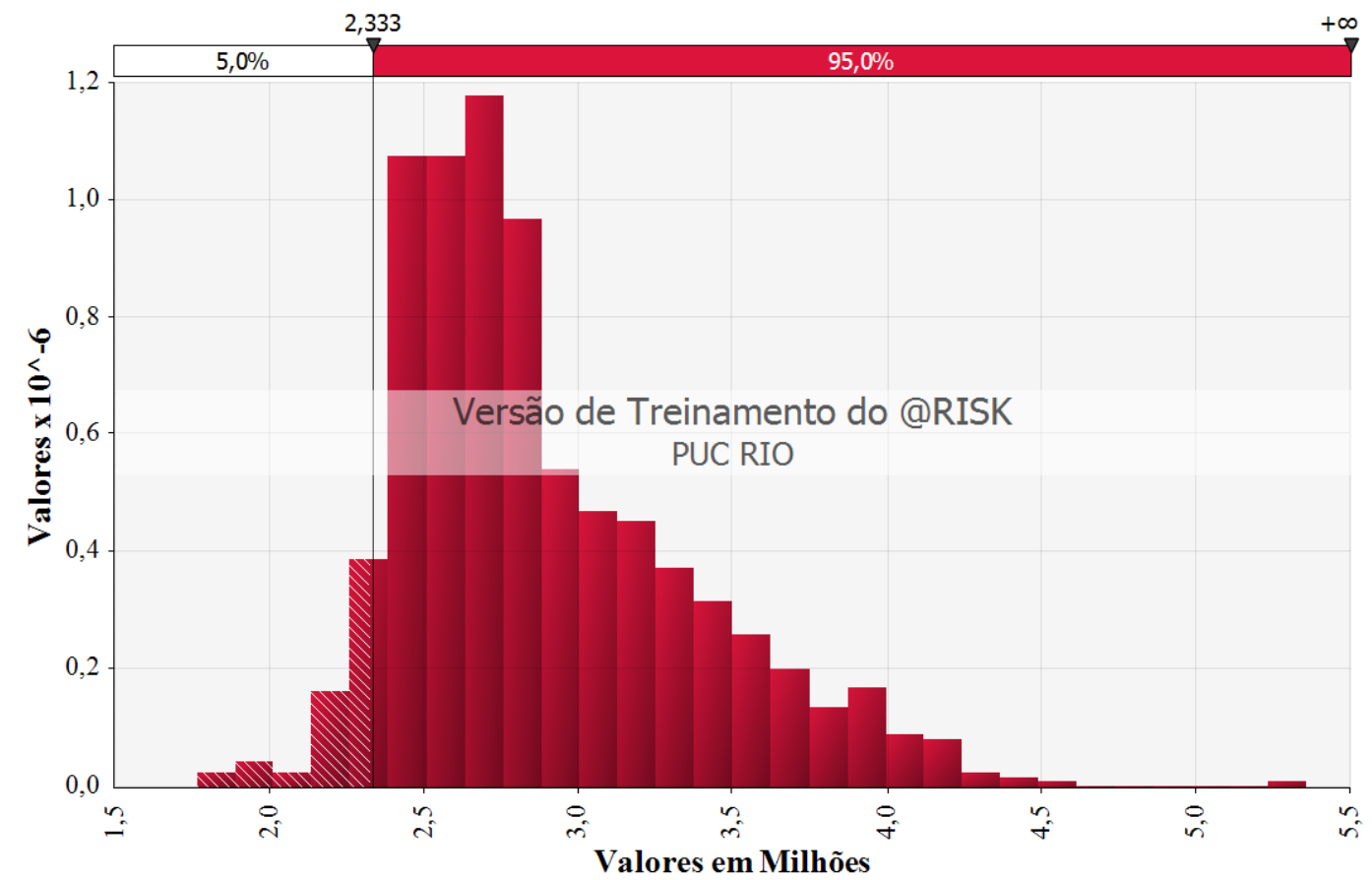

Figura 4 - Exemplificação VaR95\%

Marzano (2004) ressalta a relevância dessa métrica para análise de projetos, já que a mesma pode balizar suas operações através do máximo valor em risco admitido por uma empresa ou projeto, forçando o seu VaR a ser inferior (ou igual) aquele valor determinado.

Por outro lado, o VaR é uma métrica de risco que indica apenas a probabilidade de perda acima de um limite, (ROCKAFELLAR ;URYASEV, 2000). O VaR tem sido utilizado como medida complementar de avaliação de 
viabilidade de projetos de infraestrutura do tipo BOT em poucos estudos observados na literatura, apesar do seu caráter intuitivo (HMTREASURY, 1995; LEVY, 1996; RANASINGHE, 1999; YE;TIONG, 2000). Alguns estudos utilizaram VaR especificamente como foco para avaliar PPPs (KE;LIU;WANG, 2008; WALKER;SMITH, 1995; ZHANG, 2005).

Com a evolução dos processos de simulação e melhor compreensão dos eventos relacionados à distribuição dos retornos, surgiu o CVaR (Conditional Value at Risk), que analisa em sua estrutura, resultados sobre eventos que ocorrem nas caudas das distribuições de probabilidades (TORRES, 2006). Aguiar (2008) apresenta uma breve comparação entre VaR e CVaR para duas distribuições, uma com menor profundidade de cauda (A) e outra com possibilidade de eventos catastróficos e consequente maior profundidade de cauda (B). De acordo com a Figura 5 é possível que ambas distribuições tenham o mesmo VaR para um determinado nível de significância. Porém o autor ressalta que em cenários de perda, a distribuição B oferece maior risco, mesmo tendo um valor esperado médio maior do que a distribuição A. Logo, um modelo que visa maximização do valor esperado com uma restrição de risco limitado ao VaR apontaria como decisão ótima a opção B.

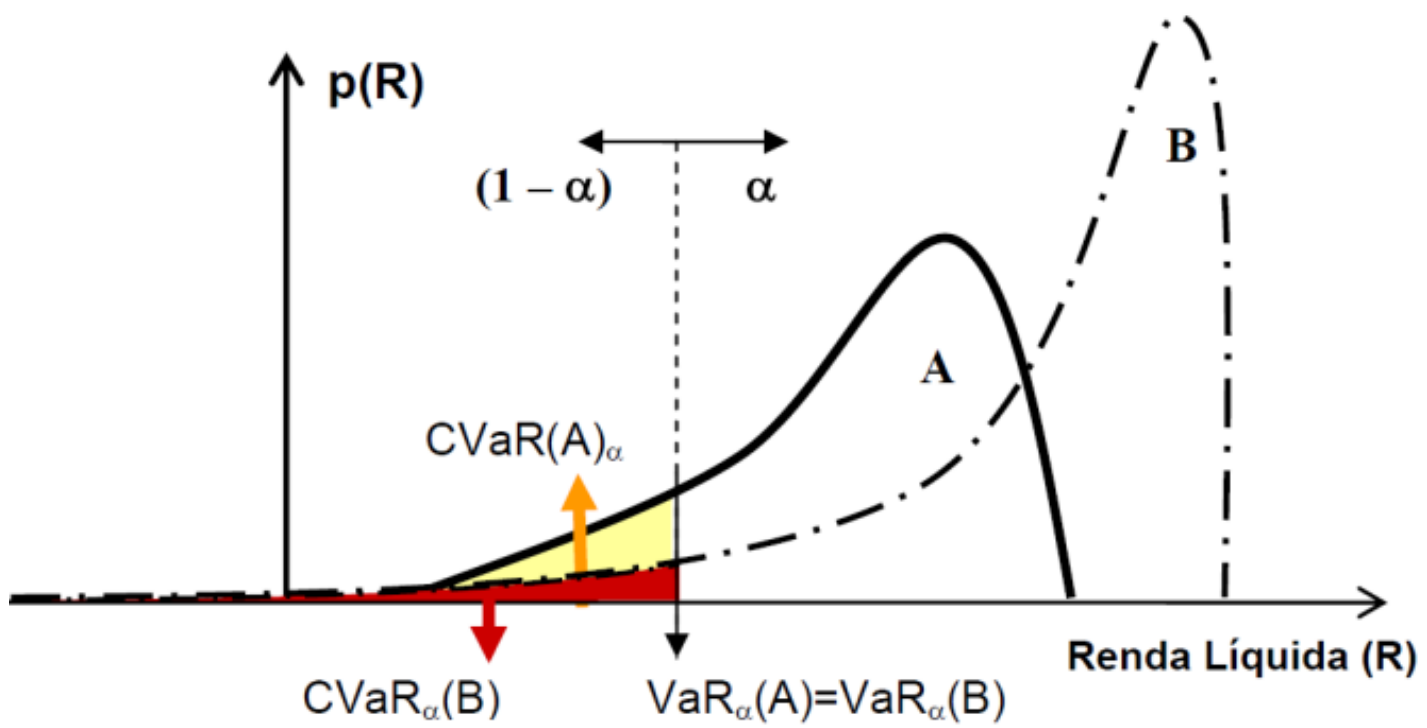

Figura 5 - Representação VaR versus CVaR.

A definição clássica para o Conditional Value-at-Risk $(\mathrm{CVaR} \alpha)$ de uma variável R com função de probabilidade acumulada $F R(r)=P(R \leq r)$ é: 


$$
\operatorname{CVaR}_{\alpha}(R)=E[R \mid \Psi]=\int_{\Psi} R d F_{R \mid \Psi}
$$

onde $\Psi=\left\{R: R \mid \leq \operatorname{VaR}_{\alpha}(R)\right\}$ é o conjunto de valores inferiores ao $\mathrm{VaR} \alpha$ (R) que a variável pode assumir e $R \mid \Psi$ é uma função de probabilidade condicionada ao evento. O CVaR teve historicamente mais aplicações para análise de ativos financeiros, juntamente com outras métricas de risco que se baseiam nos dois primeiros momentos da distribuição de probabilidade dos retornos, os seja, média e variância (SCHUHMACHER;ELING, 2012).

Além disso, tem se observado poucas aplicações do VaR e CVaR na literatura voltada para avaliações financeiras de projetos, que poderiam contribuir para tomada de decisão e análise de risco sobre ativos reais.

A aplicação destes índices assim como do $\mathrm{VaR}$ e CVaR, encontra certas limitações que dificultam sua ampla disseminação para análise de investimentos em ativos reais. Entre estas limitações, considera-se de pouca aceitação empírica que média e variância possam descrever completamente a distribuição de retornos de investimentos em ativos reais.

Por outro lado, recentemente Keating e Shadwick (2002) desenvolveram a medida ômega ( $\Omega$ ), que possui como uma de suas características a capacidade de capturar todos os momentos da distribuição de retornos de um ativo (assimetria, curtose, cauda da distribuição, valores extremos, etc). A medida ômega ( $\Omega$ ) exige a definição de um retorno limite $(L)$, que é necessário para dividir a distribuição de probabilidades dos retornos entre uma área que pode ser definida como de ganhos e por uma área definida como de perdas.

Após ser definido o retorno limite $(L)$, deve-se identificar as condições para determinar o valor esperado condicional de ganhos e o valor esperado condicional de perdas. O valor esperado condicional dos retornos que excedem $L$ é definido como o ganho esperado e pode ser expresso por $E(r-L \mid r \geq L)$. Já a perda esperada será dada pelo valor esperado condicional dos retornos que sejam menores do que $L$ e expressa como $E(L-r \mid r<L)$.

Assim, com os valores obtidos para cada ponto da distribuição, podem-se comparar os ganhos e as perdas potenciais, ponderados por suas próprias probabilidades de retornos $\left(r_{i}\right)$ para encontrar o valor da medida ômega $(\Omega)$ : 


$$
\Omega(L)=\frac{\sum E\left(r_{i}-L \mid r_{i=1}^{m} \geq L\right) \cdot \operatorname{Prob}\left(r_{i}\right)}{\sum E\left(L-\left.r_{i}\right|_{i=1} ^{m}<L\right) \cdot \operatorname{Prob}\left(r_{i}\right)}
$$

Na forma contínua, a medida ômega ( $\Omega$ ) também pode ser representada como:

$$
\Omega(\Lambda)=\frac{\int_{L}^{b}[1-F(x)] \cdot d x}{\int_{a}^{L} F(x) \cdot d x}
$$

onde, $\mathrm{F}(\mathrm{x})$ = Função de Distribuição Cumulativa (FDC) dos ganhos “x”; e L = nível mínimo requerido de ganho; a = retorno mínimo; e b = retorno máximo.

Alguns estudos focaram em comparar o desempenho da medida ômega com outras medidas de risco para otimização de portfólio, mas direcionados para ativos financeiros e estratégias de investimentos (DICHTL;DROBETZ;WAMBACH, 2014; DU;LI, 2008; KANE;BARTHOLOMEW-BIGGS;CROSS;DEWAR, 2009; KAPSOS;CHRISTOFIDES;RUSTEM, 2014; NGUYEN, 2014; SCHUHMACHER;ELING， 2012; XU;YEUNG;CHAN;CHAN;WANG;KE, 2010).

Por outra abordagem, Simões e Gomes (2011) utilizaram a medida ômega $(\Omega)$ como método para tomada de decisão para o valor de sazonalização de contratos de energia no Brasil, considerando restrições de valor em risco (VaR). Os autores escolheram a sazonalização e maximização de medida ômega, dado um nível de $\mathrm{VaR}_{95 \%}$, como critérios para chegar ao resultado otimizado do modelo.

Entre os estudos levantados, é importante ressaltar que poucos estudos endereçam o uso de aplicações das métricas de risco e performance, em meio a análise de viabilidade de projetos sob ativos reais. A análise de tomada de decisão de investimentos considerando tais métricas pode contribuir para modelos mais robustos de avaliação, inclusive para integração com metodologias direcionadas exclusivamente a modelagem de incertezas e flexibilidades. 


\subsection{6.}

\section{Tomada de Decisão sob Incerteza}

As flexibilidades contratuais em concessões públicas por Parceria PúblicoPrivadas possuem significativo valor quando adequadamente apreçadas e vêm despertando grande interesse do meio acadêmico. Em meio a este processo, identificam-se estudos que buscam cobrir a lacuna metodológica quanto à tomada de decisão sob incerteza, sobretudo concentrando-se no desenvolvimento de modelos baseados na Teoria de Opções Reais (TOR).

A partir de trabalhos pioneiros para a avaliação de opções financeira (BLACK;SCHOLES, 1973), surgiram estudos que passaram a incorporar métodos semelhantes ao processo de tomada de decisão de investimentos sob condições de incerteza. Esta teoria visa agregar o valor da flexibilidade gerencial à metodologia de valoração tradicional do FCD. Uma particularidade importante das opções é o fato delas proporcionarem ao seu titular um direito (mas não uma obrigação) de serem exercidas no futuro. Existe um custo associado à obtenção desse direito, o qual é comumente definido como prêmio.

Uma opção real é o direito, e não a obrigação, de agir (i.e. abandonar, expandir, adiar, etc.) a um custo predeterminado, chamado de preço de exercício, durante um período de tempo determinado pela duração da opção, chamado de período de exercício ou vida da opção. Para que um projeto apresente valor de opção, no entanto, três condições são necessárias (DIXIT;PINDYCK, 1994): o investimento é total ou pelo menos parcialmente irreversível; existe flexibilidade de decisão suficiente para que gerência opere o projeto de forma diferenciada (adiando, suspendendo, ampliando, abandonando, etc.) dependendo do estado da natureza que venha a ocorrer no futuro e; há incerteza sobre o nível dos fluxos de caixa futuros que este projeto poderá gerar.

As opções do tipo americanas podem ser exercidas antes de seu vencimento. Já as opções europeias, de forma geral são exercidas no seu vencimento. A possibilidade de antecipação do exercício e a possibilidade de pagamento de dividendos, ou retiradas de fluxo de caixa livre, fazem com que a fórmula de Black e Scholes (1973) não se aplique com amplitude para projetos corporativos. Entre outras contribuições, Merton (1976) estendeu a citada fórmula para incluir os dividendos no seu calculo. 
Os principais tipos de opções reais e suas modelagens são resumidos a seguir (TRIGEORGIS, 1993):

a. A opção de diferir o investimento: opção de compra americana;

b. A opção de interromper a implementação: opção de venda americana;

c. Opção de interromper (e recomeçar) um projeto: opção de venda americana;

d. Opção de expansão: opção de compra americana;

e. Opção de contrair: opção de venda americana;

f. Opção de abandono por valor de recuperação: opção de venda americana;

g. Outros modelos mais complexos, como por exemplo: opção de conversão; opções arco-íris, ou opções com múltiplas fontes de incerteza; opções compostas e ou sequenciais.

A abordagem apresentada por Copeland e Antikarov (2002) para cálculo de opções, parte de um portfólio de hedge composto de uma ação de um ativo subjacente, replicante do projeto em questão, e uma posição vendida de uma certa quantidade de ações da opção que está sendo apreçada. Esse coeficiente de hedge é determinado de jeito que o portfólio esteja livre de risco: dessa forma uma eventual perda com o ativo replicante será compensada pelo ganho da posição vendida da opção de compra. No entanto, para poder fazer uso deste principio é necessário considerar a atuação em mercados completos nos quais sempre existirá uma carteira de ações que possa simular o projeto avaliado. Quando não é possível montar um portfólio de ativos que mapeie as mudanças estocásticas do projeto, ou quando a correlação entre o projeto e o portfólio de mercado é menos do que perfeita, diz-se que o mercado é incompleto.

Copeland e Antikarov (2002) propõem que se adote inicialmente o Valor Presente (VP) do projeto sem nenhuma opção, com a taxa de desconto calculada de acordo com a metodologia do CAPM, ou seja, uma avaliação pelo método do Fluxo de Caixa Descontado (FCD) tradicional, com o seu valor de mercado. Isso permite a utilização do próprio projeto como o ativo básico do projeto com opções. A esta premissa dá-se o nome de Market Asset Disclaimer (MAD) ou Negação do Ativo Negociado. A utilização do próprio projeto como seu ativo básico e parte do seu portfólio replicante, torna o mercado completo para este projeto, e garante, então, uma perfeita correlação entre o projeto e este portfólio replicante. 
Já a modelagem discreta através de árvores binomiais, contribui para contornar as principais lacunas da formula de Black e Scholes (1973), pois sendo uma modelagem discreta, possibilita a análise de opções americanas, checando-se em cada nó o exercício ou não da opção modelada (COPELAND;ANTIKAROV, 2002).

Cox, Ross e Rubinstein (1979) foram os primeiros a propor um modelo binomial para valoração de opções, que permitiu que fosse desenvolvida uma aproximação discreta e computacionalmente eficiente para a modelagem estocástica de um ativo básico para o problema da valoração de projetos, ao replicar uma opção a partir de um portfólio equivalente (ou replicante), de ativos negociados, considerando um mercado chamado completo.

Para modelar opções por árvore binomial, considera-se em qualquer nó $i$ desta binomial, em que $i$ não seja o período final e sendo: $q$ a probabilidade de ocorrer o movimento ascendente no período seguinte a $i$, e (1-q) a de ocorrer o movimento descendente. Na binomial, $k$ é a taxa de desconto do projeto, e $\sigma$ sua volatilidade):

Valor presente no nó: $V_{i}=\left(q \times V_{u}+(1-q) \times V_{d}\right) \times e^{-k}$

Movimentos ascendente e descendente: $u=e^{\sigma}$, e: $d=e^{-\sigma}=1 / u$

Assim, as probabilidades objetivas são: $q=\frac{e^{k}-d}{u-d} \quad$, e $1-q=\frac{u-e^{k}}{u-d}$

Como as variáveis de entrada do modelo contém o seu custo de capital $k$ e a sua volatilidade $\sigma$, pode-se concluir que as probabilidades objetivas $q$ e (1-q) são decorrentes dos valores daquelas variáveis e não variáveis independentes em si.

Para o cálculo de opções reais, partindo do pressuposto de um portfólio de hedge, pode-se assumir que o resultado estará livre de risco, uma vez que o valor presente do projeto seja um estimador de seu valor de mercado, considerando o mercado como completo e a solução do problema através de probabilidades neutras ao risco. Sendo: $r$, a taxa livre de risco, Cox, Ross e Rubinstein (1979) definem as seguintes variáveis, $p$ e (1-p) como: 


$$
p=\frac{e^{r}-d}{u-d}, \quad \text { e }(1-p)=\frac{u-e^{r}}{u-d}
$$

e chamadas de probabilidades neutras ao risco e comprovam que, não havendo oportunidades de ganhos livres de risco, o valor da opção de compra C, será:

$$
C=\left(p \times C_{u}+(1-p) \times C_{d}\right) \times e^{-r}
$$

onde: $C_{u}$, e $C_{d}$, são os valores dessa opção nos movimentos ascendentes e descendentes. Dessa forma, Cox, Ross e Rubinstein (1979) mostram que a avaliação do valor da opção pela árvore binomial torna o resultado do valor da opção independente das probabilidades objetivas: q e (1-q). Este tratamento matemático também usado por outros autores (KENMA, 1993; TRIGEORGIS, 1993), considera que as opções reais podem ser modeladas na árvore binomial, a partir do passo final desta, calculando-se o payoff de traz para frente, descontando-se a taxa livre de risco, período á período, até o valor inicial, para obter o Valor Presente Líquido (VPL) Expandido do Projeto, o qual Trigeorgis (1993) define como o VPL dos fluxos de caixa esperados somado ao valor oriundo da flexibilidade gerencial.

A avaliação de projetos usando a Teoria de Opções Reais (TOR) pode ser resumida em algumas etapas básicas, como demonstrado na Figura 6. O método parte da avaliação tradicional usando o Fluxo de Caixa Descontado, do qual se obtém o valor esperado do projeto. Neste ponto da análise, tem-se apenas um cenário determinístico refletindo o que, na avaliação dos gerentes, acontecerá no empreendimento. No entanto, o fluxo de caixa do projeto está sujeito a inúmeras incertezas, entre as quais algumas se destacam como capazes de influenciar mais significativamente a geração de caixa e, portanto, o valor do projeto. A segunda etapa da metodologia envolve modelar matematicamente o comportamento das incertezas presentes no projeto e o processo estocástico que tais variáveis seguem. Através de procedimentos numéricos, deve-se ainda obter a taxa de desconto neutra a risco do projeto, que se diferencia do ativo objeto por ser a taxa de desconto que irá fazer com que o valor presente no modelo estocástico tenha convergência para o valor determinístico. A partir daí, procuram-se identificar as flexibilidades de decisão (opções), disponíveis para os gestores do projeto. E a medida que o tempo passa, revelam-se novos cenários para o projeto, tendo os 
gestores a flexibilidade de decidir entre caminhos alternativos à luz de maiores e melhores informações. Ao final do processo, pode-se aferir o impacto das flexibilidades gerenciais como o valor expandido sobre o valor esperado do empreendimento (supondo projetos que tenham flexibilidade), o que em outras palavras significa poder mensurar o valor do possível exercício de flexibilidades ao longo da vida do projeto. Entre as alternativas comumente utilizadas para cálculo de opções, destaca-se o cálculo por árvore binomial, como já mencionado.

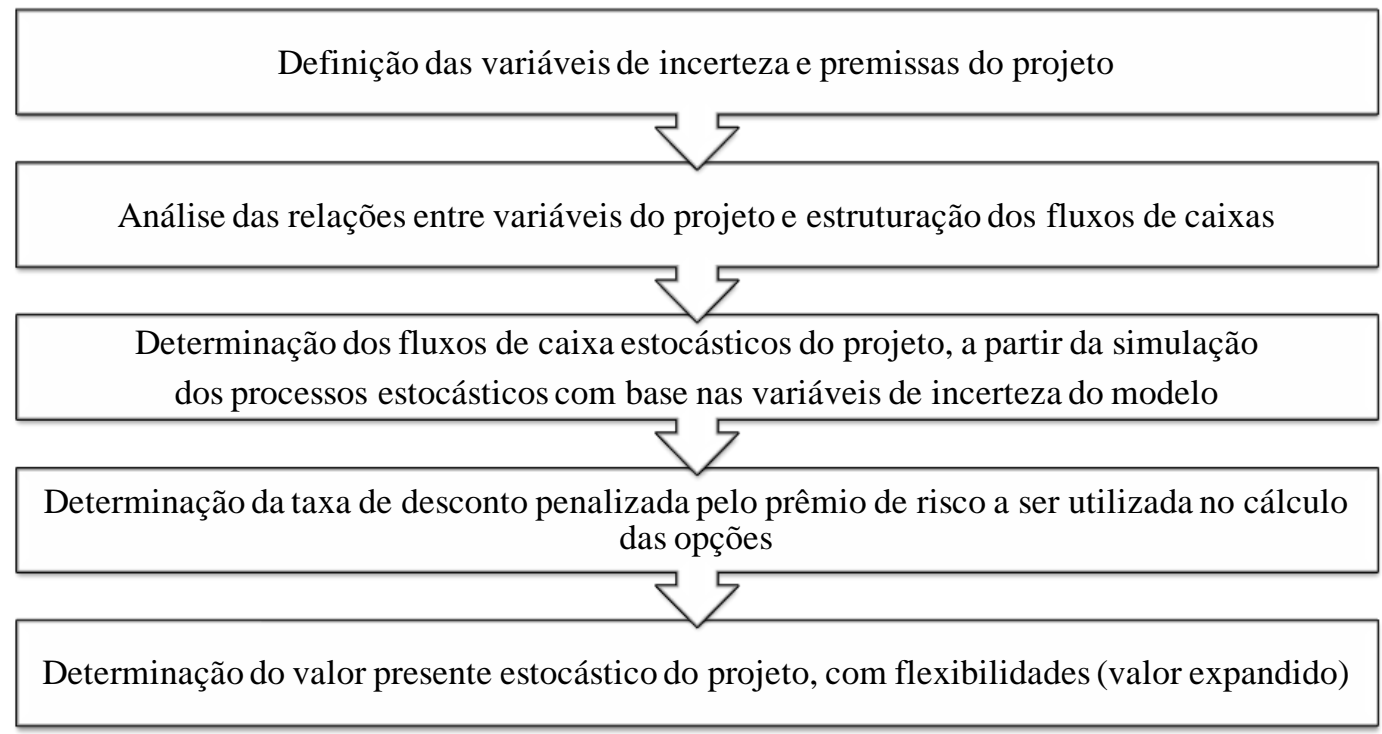

\section{Figura 6 - Processo básico de avaliação de projetos por opções reais}

Fonte: Elaboração própria com base em Brandão e Dyer (2005).

\subsection{7.}

\section{Processos Estocásticos}

As incertezas estão presentes na grande maioria dos projetos e são as principais fontes de riscos e oportunidades. Entre as etapas de cálculo de opções reais, a modelagem de incertezas é fundamental para avaliação das mesmas. As variáveis incertas podem ser de diversas origens e tipos, tais como: quantidade de veículos que trafegam por uma rodovia, demanda futura por um serviço, investimentos, prazo de execução de uma obra, etc.

As variáveis de incerteza seguem processos aleatórios, ou seja, as variáveis desenvolvem-se no tempo de forma aleatória ou parcialmente aleatória e, portanto 
imprevisível. Em outras palavras, o processo estocástico representa a evolução da variável $x$, durante o tempo $T$ e respeitando propriedades estatísticas.

Os processos estocásticos podem ser classificados, de maneira geral como: 1) processos estacionários, em que as propriedades estatísticas dadas por média e variância da variável observada são constantes no tempo; e 2) processos não estacionários: o valor esperado da variável aleatória pode crescer sem limite e sua variância $\sigma^{2}, T$ anos à frente, aumenta com $T$ (FAN, 2000).

Além disso, os processos estocásticos podem ocorrer em tempo discreto ou contínuo. Em tempo discreto, o valor da variável somente pode mudar em determinados intervalos. Já em tempo contínuo, a variável pode sofrer variações de forma contínua no tempo.

A escolha do processo estocástico poderá depender tanto de considerações estatísticas quanto teóricas, como por exemplo, a intuição com relação aos mecanismos de equilíbrio do ativo modelado (DIXIT;PINDYCK, 1994).

O Processo de Markov é um tipo de processo estocástico onde apenas o valor presente de uma variável é relevante para prever o futuro. O random walk é um Processo de Markov bastante conhecido e em tempo discreto, que pode ser definido pela equação $x_{t}=x_{t-1}+\varsigma_{t}$, no qual $\operatorname{prob}\left(\varsigma_{t}=1\right)=\operatorname{prob}\left(\varsigma_{t}=-1\right)=\frac{1}{2}$. Nesta equação $x_{t}$ é a variável aleatória e $x_{0}$ é uma variável conhecida no instante $t$ $=0 . \operatorname{Em} t=1,2,3, \ldots=>x_{t}$ assume saltos de tamanho 1 para cima ou para baixo, sempre com probabilidade $1 / 2$ e $\varsigma_{t}$ é a variável aleatória com distribuição de probabilidade.

O processo de Wiener, ou movimento browniano, é descrito como um caso particular de processo de Markov em tempo contínuo. Tratar-se de um processo de Markov, com distribuição de probabilidades dos valores futuros dependentes somente do valor atual. É um processo com variações normalmente distribuídas e de incrementos independentes, com variância aumentando linearmente com o tempo. Sendo $z(t)$ um processo de Wiener, a relação entre $d z$ e $d t$ é dada por $d z=\varepsilon_{t} \cdot \sqrt{d t}$, no qual $\varepsilon_{t}$ possui uma distribuição normal de média igual a zero e variância igual à um: $\varepsilon_{t} \sim N(0,1)$. A variável aleatória $\varepsilon_{t}$ não tem correlação, e, portanto $E\left(\varepsilon_{t}, \varepsilon_{c}\right)=0$, para $t \neq c$. Um processo de Wiener muito usado é o movimento geométrico browniano, será também utilizado para o presente estudo e 
é descrito como $d x=\alpha x d t+\sigma x d z$, onde: $d z$ é um incremento de Wiener e é igual a: $\varepsilon d t^{1 / 2}$ (sendo $\varepsilon$ a distribuição normal padrão); $\alpha$ o desvio (drift), e $\sigma$ a volatilidade de $v$.

$\mathrm{Na}$ literatura voltada para a modelagem de incertezas por processos estocásticos, observam-se processos estocásticos aritméticos e geométricos, além de estacionários e não estacionários. O Movimento Geométrico Browniano (MGB) é um processo não estacionário, frequentemente escolhido para a modelagem de incertezas associadas a projetos de infraestrutura. Há ainda processos estacionários que são amplamente utilizados na modelagem de preços e commodities em geral, partindo de modelos como Pindyck (1999), modelo 1 de Schwartz (1997), Dias/Marlim (1999), Brennan e Schwartz (1985); Metcalf e Hasset (1995); Geman (2005).

Para o presente estudo, buscou-se aderência à estudos de modelagem de incertezas em PPPs, que adotam em sua maioria o uso do MGB em seus modelos (ALONSO-CONDE;BROWN;ROJO-SUAREZ， 2007; CHEAH;LIU， 2006; GARVIN;CHEAH, 2004; RUS;NOMBELA, 2003). A adoção do MGB pode ainda descrever de forma mais adequada o comportamento de tráfego em rodovias, considerando que o comportamento da demanda no longo prazo tende a apresentar forte correlação com o crescimento do PIB, cuja distribuição de probabilidade tende a uma log-normal.

\subsection{8.}

\section{Lema de Itô}

Para resolver de equações com variáveis estocásticas, comumente utiliza-se o Lema de Itô, considerando que $d x$ é um processo estocástico sob a forma:

$$
d x=a(x, t) d t+b(x, t) d z
$$

onde dz é um processo de Wiener e F como função de $x$ e $t, F(x, t)$, por expansão de Taylor, obtêm-se:

$$
\begin{aligned}
& d F=\frac{\partial F}{\partial x} d x+\frac{\partial F}{\partial t} d t+\frac{1}{2 !} \frac{\partial^{2} F}{\partial x^{2}}(d x)^{2}+\frac{1}{2 !} \frac{\partial^{2} F}{\partial t^{2}}(d t)^{2}+\frac{1}{2 !} \frac{\partial^{2} F}{\partial x \partial t} d x d t \\
& +\frac{1}{3 !} \frac{\partial^{3} F}{\partial x^{3}} d x^{3}+\frac{1}{3 !} \frac{\partial^{3} F}{\partial t^{3}} d t^{3}+\ldots
\end{aligned}
$$


Substituindo a equação (1) na (2), e desconsiderando os termos superiores a segunda ordem, chega-se a:

$$
\begin{aligned}
& d F=\frac{\partial F}{\partial x} a(x, t) d t+b(x, t) d z+\frac{\partial F}{\partial t} d t+\frac{1}{2 !} \frac{\partial^{2} F}{\partial x^{2}}(d x)^{2} \\
& +\frac{1}{2 !} \frac{\partial^{2} F}{\partial t^{2}}(d t)^{2}+\frac{1}{2 !} \frac{\partial^{2} F}{\partial x \partial t} d x d t
\end{aligned}
$$

Considerando:

$$
(d x)^{2}=a^{2}(x, t)(d t)^{2}+2 a(x, t) b(x, t) d t d z+b^{2}(x, t)(d z)^{2}
$$

Assumindo que:

$$
d z=\varepsilon \sqrt{d t} \rightarrow(d z)^{2}=(\varepsilon \sqrt{d t})^{2} \therefore E\left[(d z)^{2}\right]=E\left[\varepsilon^{2} d t\right]=d t . E\left[\varepsilon^{2}\right]
$$

e que $E\left[\varepsilon^{2}\right]=1$, temos que $(d z)^{2}=d t$

$$
d t d z=d t \varepsilon \sqrt{d t}=\varepsilon d t^{3 / 2}
$$

$(d x)^{2}=a^{2}(x, t)(d t)^{2}+2 a(x, t) b(x, t) \varepsilon d t^{3 / 2}+b^{2}(x, t) d t$

Considerando que, para um tempo $d t$ tendendo a zero, todos os termos $d t$ elevados a fator de potência maior que um tenderão a zero antes de $d t$, assim:

$$
\begin{aligned}
& (d x)^{2}=b^{2}(x, t) d t \\
& d x d t=a(x, t)(d t)^{2}+b(x, t) d z d t=a(x, t)(d t)^{2}+b(x, t) \varepsilon d t^{3 / 2}=0
\end{aligned}
$$

Dessa forma, a equação (3) pode ser resumida a:

$$
d F=\frac{\partial F}{\partial x}(a(x, t) d t+b(x, t) d z)+\frac{\partial F}{\partial t} d t+\frac{1}{2 !} \frac{\partial^{2} F}{\partial x^{2}} b^{2}(x, t) d t
$$

A mesma, sendo reescrita irá resultar em:

$$
d F=\left[\frac{\partial F}{\partial t} d t+\frac{\partial F}{\partial x} a(x, t) d t+\frac{1}{2} \frac{\partial^{2} F}{\partial x^{2}} b^{2}(x, t)\right] d t+\frac{\partial F}{\partial x} b(x, t) d z
$$




\section{2.}

\section{Revisão de Literatura}

\subsection{1.}

\section{Análise de Viabilidade}

Os projetos por PPPs tem atraído atenção de pesquisadores desde que esse modelo de estruturação de projetos passou a ser utilizado em infraestrutura urbana (BASTIAN-PINTO;BRANDAO;GOMES, 2011; CHANG, 2013; GRIMSEY;LEWIS, 2002; XIONG;ZHANG, 2014). Muitos destes estudos identificaram gaps metodológicos dos modelos implementados e priorizaram contribuir com o aprimoramento contratual destes mecanismos, a partir da sua ampla disseminação, que se deu a partir do final da década de 1980.

A partir da avaliação documental em estudos já realizados sobre PPPs em outros países, foi possível identificar um conjunto de vantagens apresentadas por Parcerias Público-Privadas, quando comparadas a outros modelos de estruturação de projetos:

- Fortalecimento das próprias relações de parceria entre os setores público e privado (ZHANG;KUMARASWAMY, 2001; ZHANG;KUMARASWAMY;ZHENG;PALANEESWARAN, 2002);

- Melhoria no contingenciamento e gestão de risco em projetos (FERNANDEZ;CARRARO, 2006; GRIMSEY;LEWIS, 2002; SHEN;WU, 2005);

- Maior transparência de políticas governamentais e controle orçamentário estatal (ESTACHE;GONZÁLEZ;TRUJILLO, 2002;

ESTACHE;GUASCH;TRUJILLO-CASTELLANO, 2003; FERNANDEZ;CARRARO, 2006);

- Observação dos fatores críticos para o sucesso dos projetos (DALTON;ALLAN;BEAUMONT;GEORGAKAKI;HACKING;HOOP ER;KERR;O’HAGAN;REILLY;RICCI;SHENG;STALLARD, 2015);

- Aprimoramento dos modelos de contratação (SHEN;LI;LI, 2002; SHEN;WU, 2005; ZITRON, 2006);

- Desenvolvimento de modelos de avaliação financeira utilizando riscos e incertezas (BRANDÃO, 2002; BRANDÃO;CURY, 2006; 
BRANDÃO;SARAIVA, 2008;

CARBONARA;COSTANTINO;PELLEGRINO, 2014;

HUANG;CHOU, 2006; MOREIRA, 2010).

Entre os estudos avaliados, observaram-se de forma mais direcionada os que se destinam a avaliação financeira de projetos do tipo DBFOM (design, build, finance, operate and manage) por Parcerias Público-Privadas (PPPs).

Em grande parte, estes estudos se limitaram a análise do valor esperado dos projetos, pela aplicação da metodologia do Fluxo de Caixa Descontado (FCD) com análise de cenários, para estimar o valor e o prazo contratual (ARAKI;YOSHIZU, 2007; NG;XIE;CHEUNG;JEFFERIES, 2007; SHEN et al., 2002; SHEN;WU, 2005; YE;TIONG, 2003). Alguns autores buscaram o mesmo enfoque, mas passaram a abordar o uso de simulação de Monte Carlo, como técnica para incorporar incertezas aos modelos tradicionais baseados no fluxo de $\begin{array}{lll}\text { caixa } \quad \text { descontado 2008; } & \text { (DU;LI, }\end{array}$ FANTOZZI;BARTOCCI;D'ALESSANDRO;ARAMPATZIS;MANOS, 2014; KE et al., 2008; NG et al., 2007; RANASINGHE, 1999; SHEN;WU, 2005; SPACKMAN, 2002; XU;SUN;SKIBNIEWSKI;CHAN;YEUNG;CHENG, 2012; YE;TIONG, 2000).

A preocupação com o compartilhamento de riscos em projetos de PPPs também tem se mostrado relevante (BING;AKINTOYE;EDWARDS;HARDCASTLE， 2005; GRIMSEY;LEWIS, 2002; MOREIRA, 2010; SHEN;PLATTEN;DENG, 2006), ainda que predominem aplicações do Fluxo de Caixa Descontado, com pequenas variações baseadas no conceito do Value for Money (COULSON, 2008; GRILO, 2008; GRIMSEY;LEWIS, 2005; NISAR, 2007), que em outras palavras representa a melhoria do serviço público de forma proporcional ao dispêndio financeiro, em comparação a como o setor público gastaria para entregar um projeto similar.

Nestes estudos, o Value for Money (VFM) é caracterizado como uma técnica para comparar os resultados de projetos realizados pela iniciativa privada por meio de PPPs. Os resultados são simulados para avaliar como seriam observados caso os projetos fossem desenvolvidos pelo governo. O Value for Money pode ser visto como: uma análise custo-benefício das possíveis alternativas em a realização de um serviço pela iniciativa privada ou pelo setor público; o cálculo do custo de referência (benchmark) para a prestação do serviço 
especificado no âmbito dos contratos públicos tradicionais, comparado com o custo da prestação do serviço especificado ao abrigo de um contrato PPP; e por processo de licitação após se estabelecer uma PPP, para determinar as melhores propostas de preço e técnica de forma comparativa a alternativa pública (GRIMSEY;LEWIS, 2005).

Os estudos direcionados a avaliação viabilidade de projetos $D B F O M$, no qual o concessionário é responsável por desenvolver a estrutura de financiamento, construção, operação, manutenção e gerenciamento, até a transferência dos ativos ao governo em um prazo especificado, vem ganhando notoriedade em função do elevado risco de tais projetos. Alguns autores reiteram a necessidade de utilização de metodologias que permitam identificar, analisar, elencar e alocar diferentes tipos de risco para que projetos de infraestrutura possam ser considerados válidos para serem executados. Ng, et al (1999) apresentaram um modelo de tomada de decisão multi-objetivo utilizando lógica fuzzy e tendo como principais objetivos, maximizar a taxa de retorno e minimizar tanto o custo tarifário quanto o prazo de concessão. Zayed e Chang (2002) propuseram um índice para interpretar as variáveis potenciais de geração de riscos como medidas quantitativas de valor, utilizando o método AHP (Analytical Hierarchy Process). Os autores mapearam os riscos de diferentes projetos, segmentando-os nas fases de desenvolvimento, construção e operação. Zhang e Zou (2007) propuseram uma estrutura hierárquica de mapeamento de riscos para projetos de construção e com base na avaliação de especialistas, as ponderações dos coeficientes de risco são integradas ao modelo pelo método AHP e por lógica fuzzy os fatores de risco são incluídos à matriz de avaliação fuzzy, para posterior geração do vetor das condições de risco do projeto. Salman, Skibniewski e Basha (2007) identificaram uma combinação de 21 fatores que impactam o processo de decisão em projetos de infraestrutura e classificaram os mesmos (jurídico, ambiental, financeiro, comercial e técnico) para determinar suas interrelações. O método de ponderação também partiu da aplicação do AHP, para determinar os fatores que influenciam a viabilidade de projetos BOT. Xu et al. (2010) desenvolveram um modelo sintético por métodos fuzzy, para avaliação do nível de risco associado a projetos de PPPs na China. Após levantamento por survey dos principais riscos em projetos já concretizados, os dados foram tratados por análise fatorial até estabelecer uma pontuação média que foi utilizada para 
classificação dos riscos. Com os critérios de classificação estabelecidos, os autores incorporam métodos fuzzy para avaliação do projeto.

Nestes estudos, entretanto, não se observam metodologias que permitam de forma robusta modelar incertezas, apreçar flexibilidades contratuais, mensurar riscos e nem tão pouco de forma integrada, para que se possa avaliar projetos de concessões e PPPs. Cabe destacar que o mapeamento e compartilhamento de riscos entre o governo e o concessionário, mencionados nestes estudos, não significam mensuração dos mesmos e nem a incorporação a uma análise de viabilidade de projetos. As exceções a esta colocação, são quanto aos modelos de avaliação financeira utilizando modelagem de incertezas e mensuração de riscos, que são detalhados na subseção 2.2.2 a seguir, e que demonstram ser mais robustos para a avaliação de concessões e PPPs.

\subsection{2.}

\section{Tomada de Decisão sob Incerteza}

Alguns estudos sobre Parcerias Público-Privadas já no final da década de 1990 propuseram a introdução de métodos para modelar variáveis de incerteza em PPPs. Walker e Smith (1995) desenvolveram um modelo de análise de viabilidade, partindo do fluxo de caixa descontado e utilizando mecanismos de receita mínima garantida. Os autores foram precursores em avaliar projetos de infraestrutura, para determinar a atratividade de investimentos privados em projetos do tipo DBFOM (design, build, finance, operate and manage).

O estudo de Rose (1998) utilizou simulação de Monte Carlo para modelar incertezas e apreçar múltiplas flexibilidades (calls e puts) embutidas em um contrato entre o governo e o concessionário de um projeto de infraestrutura na Austrália. Além do cálculo de opções, o autor analisa a interação entre as opções Apesar do caráter inovador ao introduzir o apreçamento de flexibilidades, o autor conduz o trabalho sem tanto rigor quanto a definição de parâmetros para avaliação básica do projeto sem opções, tais como projeção de demanda, cálculo da taxa de desconto, dispêndios de capital e prazo de execução das obras. As principais variáveis de incerteza são tratadas por simulação de Monte Carlo.

Charoenpornpattana, Minato e Nakahama (2002) abordaram o problema da avaliação de mecanismos de apoio governamental com garantia de receita mínima 
(MRG) e pedágio sombra como opções compostas independentes em concessões governamentais. Rus e Nombela (2003) avaliaram flexibilidades na concessão de garantias por opções reais e utilizaram a teoria dos leilões para avaliar estratégias em contratos de PPPs, considerando incertezas de demanda. Bowe e Lee (2004) avaliaram opções de expansão, adiamento, redução e abandono em um projeto de construção de um trem de alta velocidade em Taiwan, além de considerar a opção da concessionária em desenvolver projetos imobiliários ao longo da faixa de domínio da concessão. Garvin e Cheah (2004) avaliaram a relevância da taxa de retorno para viabilidade de um projeto e realizaram um estudo de caso, utilizando opção de adiamento de investimentos com base na incerteza de tráfego. Cheah e Liu (2006) propuseram um modelo por opções reais, utilizando simulação de Monte Carlo para apreçar a garantia de receita mínima (MRG), como mecanismo de incentivo flexível para o projeto de uma ponte pedagiada na Malásia. Huang e Chou (2006) também utilizaram uma abordagem por opções reais para avaliar a garantia de receita mínima (MRG), mas neste caso com foco na opção de abandonar em um projeto de trem de alta velocidade em Taiwan. Chiara, Garvin e Vecer (2007) sugerem um modelo de avaliação para concessões do tipo BOT utilizando garantia de receita mínima (MRG), com apreçamento por opções do tipo bermudas e australianas. Brandão e Saraiva (2008) apreçaram o valor de garantias de tráfego mínimo (MTG) em uma estrada pedagiada no Brasil, como um mecanismo para limitar a exposição do governo enquanto mantém benefícios para o investidor privado. Os autores propõem o uso de garantias governamentais com limites de gastos (caps), como uma solução para atrair investimentos privados para projetos governamentais de alto risco.

O estudo de Moreira (2010) reiterou as vantagens da implementação de garantias mínimas concedidas pelo governo em projetos de infraestrutura, tendo em vista o impacto do deslocamento da distribuição de probabilidade do valor presente do projeto, reduzindo o risco do mesmo. De forma mais ampla, Brandão, Bastian-Pinto, Gomes e Labes (2012) avaliaram o impacto dos incentivos governamentais por garantias de tráfego mínimo com níveis de cobertura, oferecidas inclusive no edital e contrato de concessão da Linha 4 do Metrô de São Paulo. Os autores analisaram tais níveis de cobertura de garantia como mecanismos para minimizar o impacto do exercício dessas garantias para o governo sem, no entanto, definir quais seriam os níveis ótimos de garantia. Rocha 
Armada, Pereira e Rodrigues (2012) propuseram um modelo no qual é proposto o uso de subsídios de investimentos, subsídios de receitas, garantias de demanda mínima e um opção de extensão de prazo contratual, os quais em conjunto poderiam ser otimizados para induzir investimento privado. Cabral e Silva $\mathrm{Jr}$ (2013) realizaram uma avaliação de PPPs de estádios de futebol por opções reais, com a perspectiva de que o governo deveria ofertar garantias de receita mínima ao concessionário para mitigar o risco de demanda do empreendimento.

Todos estes estudos supracitados utilizam garantias de receita mínima como uma flexibilidade contratual relevante em termos de mecanismo de incentivo para concessões e PPPs, mesmo com algumas variações. Este aspecto demonstra a importância e certa padronização de tal mecanismo de incentivo em estudos acadêmicos. Cabe, entretanto, observar que os autores identificados nestes estudos definiram, em sua maioria, como "certa" a possibilidade do governo ofertar garantias de receita mínima à demanda não realizada, sem considerar a probabilidade de recorrência ao uso destes recursos pelo concessionário e possível inviabilidade desse mecanismo no longo prazo em contratos de PPPs

Além disso, cabe avaliar que entre os estudos relacionados, o foco se deu ao apreçamento das opções, mas não foi modelado o nível ótimo de garantias a serem ofertadas pelo governo e nem mesmo o potencial gasto (e risco) governamental, a ser incorrido no caso de efetiva necessidade de execução das garantias pelo concessionário.

Não obstante os estudos mencionados, outras abordagens por opções reais também contribuíram para avaliar projetos e observar possíveis lacunas para avaliação de concessões e PPPs. Neste aspecto, de forma diferenciada AlonsoConde, Brown e Rojo-Suarez (2007) utilizaram a teoria de Opções Reais como instrumento para avaliar garantias contratuais em uma concessão na Austrália. Os autores avaliam a opção do concessionário em adiar o pagamento ao governo, no caso dos retornos dos acionistas não superassem em 10\% o previsto. Além disso, analisaram de forma isolada a opção do governo em cancelar antecipadamente o período de concessão com base em indicadores de performance. Castro (2008) propôs um modelo por opções reais, que enfatiza o uso de medidas de risco e performance, com destaque para a medida Ômega, para auxiliar na tomada de decisão sob um portfólio de projetos, observando potenciais riscos e ganhos. O autor aplicou a medida Ômega como instrumento para tomada de decisão ao 
observar valor em risco versus potenciais ganhos, comparando-a aos índices tradicionalmente utilizados para medir risco em ativos e portfólio de ativos financeiros, tais como Índice de Sharpe (1966), Índice de Sortino (Fall 1994), Índice de Jensen (1968) e Indice de Treynor (1965). Ainda que abordagem de Castro (2008) se diferencie dos demais estudos analisados, sua contribuição quanto ao uso de métricas de risco e performance é relevante para compor um arcabouço metodológico mais sólido, quando flexibilidades contratuais são modeladas em avaliação de projetos.

De forma não menos importante, alguns estudos sobre tomada de decisão sob incerteza em concessões e PPPs, analisaram outros aspectos relativos a essa classe de projetos. Kruger (2012) analisa a opção de expansão de uma rodovia na Suécia e avalia as flexibilidades criadas, interpretando-as à luz da teoria dos contratos incompletos. Este estudo conclui que os custos de congestionamento geram impactos sociais indesejáveis e que não são contornados por contratos de Parcerias Público-Privadas. Martins, Marques e Cruz (2014) propuseram um modelo para tomada de decisão tanto nas fases de estruturação e investimento, quanto na fase operacional dos projetos, utilizando a metodologia de Opções Reais. Os autores apreçaram as opções europeias de investimento e espera, em função de incertezas de custos através de simulação de Monte Carlo. De forma simplificada, Rakić e Rađenović (2014) compararam o valor das opções de abandono americana e opções de abandono europeia pela ótica da iniciativa privada, quando em projetos de PPPs, mas sem propor alternativas para mitigar o abandono ou de outra forma, manter a atratividade dos investimentos pela iniciativa privada. Por outro lado, Xiong e Zhang (2014) propuseram o uso de opções reais como mecanismo de aprimoramento das renegociações contratuais em PPPs, na medida em que a captura do valor das flexibilidades contratuais pode auxiliar como base de informações para o aumento das recompensas em jogos estratégicos de barganha. Man et al. (2014) desenvolveram um modelo com foco em garantia de retorno mínimo sobre o investimento (ROI) para estimular a presença de empresas privadas e mitigar a recorrência de renegociações contratuais em PPPs.

Por fim, Blank, Samanez, Baydia e Dias (2016) voltam a reiterar a importância de garantias de receita mínima em concessões e propõem um modelo por opções reais, com o objetivo de avaliar o valor do abandono para a iniciativa 
privada em uma concessão, com a presença de níveis de garantias de receita mínima e máxima contratual (collar), sendo estes níveis propostos da mesma forma endereçada por Brandão et al. (2012).

Ao avaliar de forma crítica os achados da literatura sobre tomada de decisão sob condições de incerteza, percebem-se lacunas do ponto de vista metodológico. Apesar da metodologia de opções reais ter se mostrado a mais robusta e majoritariamente utilizada para avaliar flexibilidades em concessões e PPPs, sobretudo no que tange a adoção de garantias de receita mínima, os estudos observados não endereçam o nível ótimo de garantias a ser concedido pelo governo e nem ao menos os critérios e ou métodos a serem utilizados para a tomada de decisão.

Além da relevância em apreçar o valor da garantia de receita mínima como flexibilidade contratual em regime de opções collar e detalhar a viabilidade de projetos por PPPs, o modelo desenvolvido no presente estudo busca analisar a integração da metodologia de opções reais às métricas de avaliação de risco e performance, de maneira ainda não observada na literatura, para então propor o nível ótimo de garantia a ser concedido pelo governo à iniciativa privada. De forma indireta, o modelo se propõe também a aprimorar os contornos contratuais em projetos de PPPs pela ótica governamental, uma vez que o arcabouço proposto permite ainda a mensuração do valor em risco para o governo, mesmo que este estipule um limite de gastos (cap).

Dessa forma, o presente estudo explora uma abordagem ampliada a partir da teoria de Opções Reais e com uso de métricas de risco e performance em contratos de Parcerias Público-Privadas.

Em setores nos quais se busca uma forte presença de empresas privadas e intensivas em capital, em que o custo do excesso de capacidade ou o custo de oportunidade da capacidade subutilizada tem sido fatores determinantes para impulsionar o crescimento, torna-se fundamental estimular condições contratuais flexíveis que permitam o aumento da eficiência. 


\section{3}

\section{Metodologia Proposta}

\section{1.}

\section{Aspectos Conceituais do Modelo}

O modelo desenvolvido no presente estudo busca, a partir dos estudos existentes na literatura, propor como principal contribuição o estabelecimento do nível ótimo de garantia governamental a ser ofertada à iniciativa privada em uma concessão de rodovia por PPP, utilizando a teoria de opções reais de forma integrada com métricas de risco e performance. Para tanto, são apreçadas múltiplas flexibilidades contratuais, ao considerar a adoção do regime de garantia de receita mínima distribuída em níveis de cobertura e opções do tipo collar europeia (calls e puts), integrada ao apreçamento da opção americana de expansão do projeto, tendo como principal incerteza a demanda de tráfego da rodovia. Após a modelagem das opções, são então avaliadas as métricas de risco e performance.

As opções do tipo collar europeia são avaliadas como sendo uma em poder do governo e outra em poder do concessionário, e tratadas como mecanismos de incentivo e mitigação de riscos por Brandão e Saraiva (2008). O uso de garantias como opções do tipo collar tem se mostrado quase padrão em estudos de modelos financeiros para concessões e PPPs, como mencionado na subseção 2.2.2 e inclusive está presente no contrato de concessão do metrô de São Paulo, conforme demonstrado por Brandão et al. (2012).

As opções do tipo collar apresentadas no presente estudo são apreçadas considerando níveis de garantia, que determinam um escalonamento da cobertura das mesmas. Além disso, a garantia cobre possíveis descumprimentos de demanda, mas respeitando um limite total máximo (cap da garantia) ao longo do tempo. Pressupõe-se neste estudo que o governo e o concessionário são avessos a risco, sendo o primeiro em relação a excesso de gastos de recursos e o segundo em relação aos seus investimentos e retorno exigido. 
O problema foi desenhado ao considerar que a partir dos resultados da estruturação da garantia governamental, busca-se atender ao objetivo de minimizar custos esperados pelo governo e ao mesmo tempo atrair investimentos da iniciativa privada, a um nível de risco que pode ser considerado aceitável pelo concessionário.

A dinâmica de discussão do modelo a partir da análise de viabilidade compreende inicialmente a análise de resultados sobre o valor presente do projeto, para que logo em seguida sejam analisados aspectos ligados à avaliação pelo governo. Após a análise de resultados e impactos da aplicação das opções collar sobre um projeto hipotético foi então introduzida a flexibilidade de expansão da infraestrutura pelo concessionário.

O foco do estudo se dá pela ótica de análise pelo governo. Além do apreçamento das flexibilidades que podem mitigar gastos governamentais, o modelo avalia a viabilidade de se integrar o uso das medidas VaR, CVaR e Ômega ao modelo por opções reais. A integração destes instrumentos para tomada de decisão faz-se necessário para definição de níveis máximos de garantias a serem concedidos.

Tendo como objetivo validar a metodologia proposta, o modelo com opções collar foi desenvolvido por simulação de Monte Carlo utilizando o software @Risk. A partir da necessidade de avaliar a introdução da flexibilidade de expansão da infraestrutura de forma concomitante ao uso de garantias, seguiu-se à utilização do software $D P L$, para a modelagem do valor presente expandido do projeto.

Cabe ainda destacar que são adotados preços e custos em rodovias no Brasil como proxy, uma vez que as negociações de contratos ocorrem no Brasil. O desenvolvimento das condições de contorno, restrições e parâmetros contratuais tem como base, dados públicos e parâmetros típicos de projetos já licitados nos últimos anos no Brasil.

As projeções utilizadas na análise de viabilidade consideram horizontes temporais de vinte anos para contratos de PPPs. Ainda é importante salientar que o desenvolvimento das condições de contorno, restrições e parâmetros de mercado para o estudo desenvolvido têm como ênfase, contribuir para a modelagem em contratos pela ótica governamental na estruturação de projetos. 
Tendo em vista que o modelo proposto, ao utilizar opções collar também pode representar limitações a ganhos marginais no longo prazo, integra-se a opção americana de expansão, constituindo-se em uma contribuição ao arcabouço metodológico de avaliação de projetos. Não obstante, neste modelo avalia-se ainda a adoção de métricas de risco e performance de forma integrada ao modelo com opções collar europeia e put americana, contribuindo também de forma diferenciada e original como arcabouço metodológico para avaliação projetos por concessões e PPPs.

\section{2.}

\section{O Modelo Proposto}

O modelo proposto neste estudo diferencia-se dos demais observados para modelagem de projetos, por focar na determinação do nível ótimo de gastos governamentais em PPPs. Para atendimento a este objetivo, o modelo integra a modelagem de incertezas pela metodologia de Opções Reais, com métricas de risco de forma estruturada, mensurando o nível de exposição a riscos do governo.

O modelo apresenta-se estruturado em etapas, conforme detalhado na Figura 7 a seguir, tendo em vista o objetivo de minimizar custo com garantias e riscos pelo governo, além de observar condições que permitam gerar atratividade aos investimentos privados para projetos via PPPs.

Na Etapa 1, busca-se estruturar a análise de viabilidade pela metodologia do Fluxo de Caixa Descontado (FCD), partindo da definição das premissas básicas do modelo. Na Etapa 2, é realizada a modelagem da variável de incerteza, definindo o prêmio de risco, taxa livre de risco, volatilidade e por conseguinte chegando ao fluxo de caixa neutro a risco. Nesta etapa também é introduzida a modelagem da garantia com cap, além da análise da opção collar. Na Etapa 3, a partir do modelo com collar busca-se avaliar o risco do projeto para o concessionário, utilizando as medidas VaR, CVaR e Ômega. Na Etapa 4, a análise volta-se para análise do impacto da garantia, em que aplica-se a medida Ômega para determinar as condições de minimizarão o custo da garantia pelo governo e possível proposta de garantia ao concessionário.

Na Etapa 5, rediscute-se a a existência de opções collar, uma vez que esse é entendido como um limitador a expansão da capacidade do projeto, dado que os 
fluxos de caixa marginais deixariam de ser capturados exclusivamente pelo investidor privado. Entende-se que para atender as projeções de crescimento da demanda, o concessionário precisará realizar investimentos na expansão do projeto e esta flexibilidade é então apreçada a partir do período 10 do contrato, podendo o concessionário expandir o projeto a qualquer momento ao longo do prazo restante da concessão. Por último, a Etapa 6 endereça a análise do impacto de risco para o concessionário, considerando a integração da call americana de expansão ao modelo de demanda mínima garantida pela put europeia.

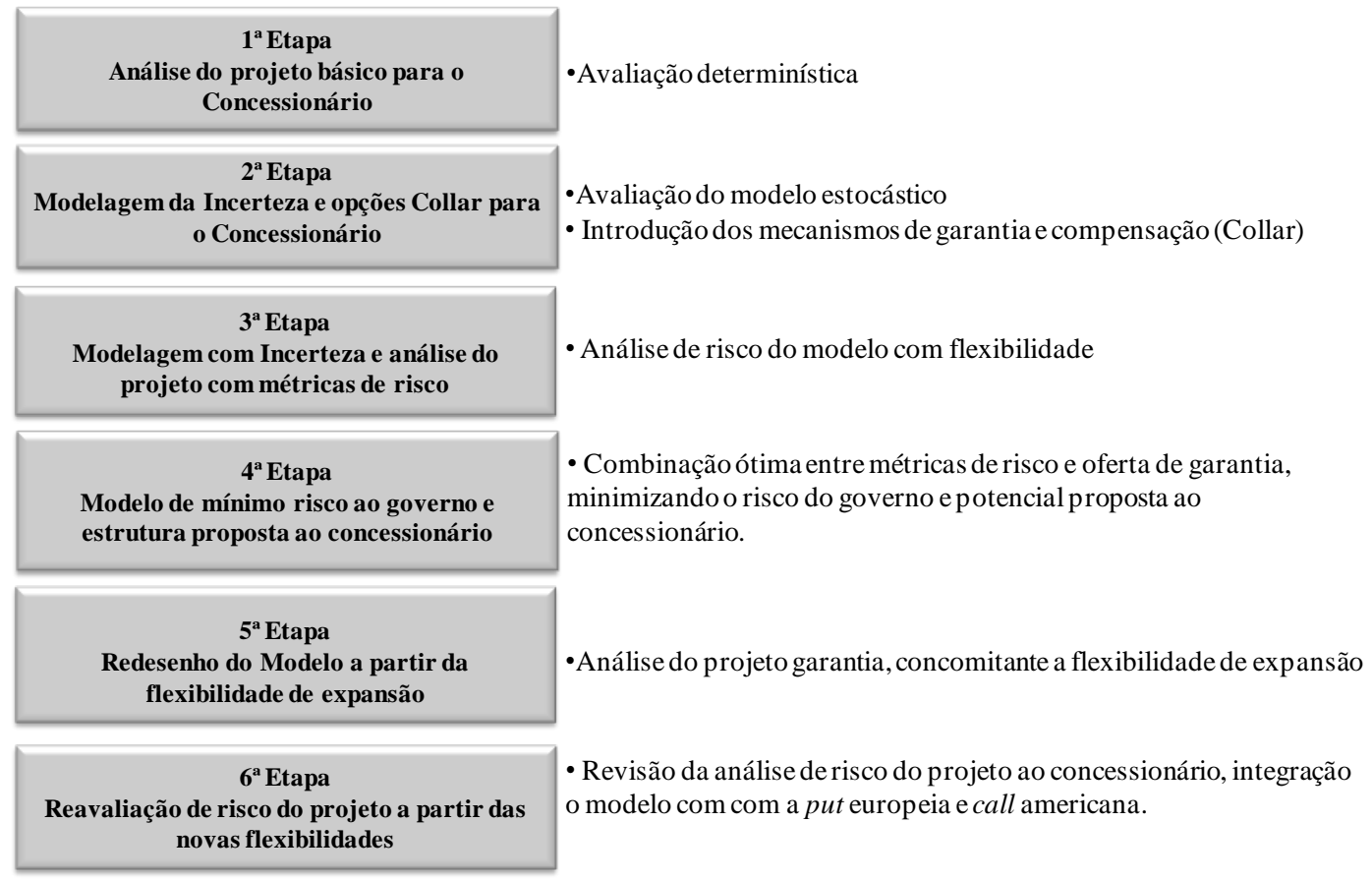

Figura 7 - Etapas da estrutura do modelo proposto

O modelo a ser desenvolvido está estruturado dentro deste marco, e como previamente estabelecido, será conduzido para a análise de viabilidade de projetos de rodovias por PPPs patrocinadas e abordando nesse caso a incerteza em relação à demanda. Por simplificação, o modelo não compreendeu o uso de indicadores de performance atrelados a remuneração do concessionário e nem ao menos penalidades, que poderiam alterar a remuneração prevista pelo concessionário privado no longo prazo.

Pela metodologia do Fluxo de Caixa Descontado (FCD), como previsto na etapa 1, projetam-se as receitas no ano $t$ do concessionário, pela equação a seguir: 


$$
R_{t}=p \cdot S_{t}
$$

na qual:

$R_{t}=$ Receita no ano $t$.

$S_{t}=$ Tráfego de viagens equivalentes no ano $t$.

$p=$ tarifa de tráfego médio previsto.

O valor do projeto no cenário base é calculado pela projeção dos fluxos de caixa, descontados pelo custo de capital.

$$
V_{2016}=\sum_{t=2016}^{2036} \frac{F C_{t}}{(1+\mu)^{t-2016}}
$$

(8)

$$
V P L_{2016}=V_{2016}-I_{2016}
$$

onde:

$V_{2016}=$ valor presente do projeto no ano de 2016.

$V P L_{2016}=$ valor presente líquido do projeto no ano de 2016.

$F(t)=$ fluxo de caixa do projeto no ano $t$.

$\mu=$ custo de capital.

I = valor presente dos investimentos em 2016.

Após obter o valor presente e o valor presente líquido do projeto determinístico, parte-se para a etapa 2, na qual busca-se desenvolver o modelo estocástico, inicialmente sem flexibilidades e logo em seguida adicionando as opções collar. Para tanto, cabe modelar a demanda como incerta, estimando a volatilidade do projeto e obtendo o prêmio de risco que permitirá chegar ao modelo neutro a risco.

\subsection{1.}

\section{Modelagem do Tráfego}

O tráfego é modelado, assumindo-se uma distribuição lognormal, como frequentemente observado em outros estudos de viabilidade em concessões. Considerando o tráfego no instante t, chamado $S_{t}$, segue um processo de Markov, 
no qual $S_{t}=S_{t-1} e^{\alpha_{t}} \quad$ e, considerando que $V=f(x)$ e $x=\ln (S), \quad V=f(\ln S)$. Considerando, que as receitas seguem um MGB sob a forma $d S=\alpha S d t+\sigma_{S} S d z$, é necessário calcular $d \ln (S)$. Para tanto, toma-se a variável $x=\ln S$, assim como um MGB sob a forma $d x=\alpha x d t+\sigma_{S} x d z$. Aplicando Itô, chega-se a:

$$
\begin{aligned}
d X=d \ln S & =\left[\frac{\partial X}{\partial t} d t+\frac{\partial X}{\partial S} \alpha_{S} S d t+\frac{1}{2} \frac{\partial^{2} S}{\partial S^{2}} \sigma_{S}^{2} S^{2}\right] d t+\frac{\partial X}{\partial S} \sigma_{S} S d z \\
\frac{\partial X}{\partial t} & =0 \\
\frac{\partial X}{\partial S} & =\frac{1}{S} \\
\frac{\partial^{2} X}{\partial S^{2}} & =-\frac{1}{S^{2}}
\end{aligned}
$$

Aplicando as derivadas parciais calculadas acima, a saber, na equação (9):

$$
d X=\left[0+\frac{1}{S} \alpha_{S} S d t+\frac{1}{2}\left(-\frac{1}{S^{2}}\right) \sigma_{S}^{2} S^{2}\right] d t+\frac{1}{S} \sigma_{S} S d z ; \text { simplificando, chega-se }
$$

a:

$$
d X=\left(\alpha_{S}-\frac{1}{2} \sigma_{S}^{2}\right) d t+\sigma_{S} d z
$$

Assim, são obtidos dois resultados: $\alpha_{x}=\alpha_{s}-\frac{1}{2} \sigma_{s}$ e $\sigma_{x}=\sigma_{s}$. Dessa forma, se $d S$ segue um MGB sob a forma $d S=\alpha S d t+\sigma_{S} S d z$, O $d \ln S$ seguirá um MGB sob a forma $d S=\left(\alpha-\frac{1}{2} \sigma_{S}\right) d t+\sigma_{S} d z$ e, como $d z$ segue um processo de Wiener padrão, chega-se a $d z=\varepsilon \sqrt{\Delta t}$, resultando em:

$$
d S=\left(\alpha-\frac{1}{2} \sigma_{S}\right) d t+\sigma_{S} \varepsilon \sqrt{\Delta t}
$$

Discretizando a equação (6), temos:

$$
\Delta S=\left(\alpha-\frac{1}{2} \sigma_{S}\right)+\sigma_{S} \varepsilon \sqrt{\Delta t}
$$


E finalmente chega-se a equação (12), que define o valor do tráfego estocástico $S$ no ano $t$, a ser designado como $S_{t}$.

$$
S_{t}=S_{t-1} \cdot \exp (\underbrace{\left(\alpha_{t}-\frac{1}{2} \sigma_{s}\right) \cdot \Delta t}_{\text {Determinístico }}+\underbrace{\sigma_{s} \cdot \varepsilon \cdot \sqrt{\Delta t}}_{\text {Estocástico }})
$$

Sendo $\alpha_{t}=\ln \frac{\bar{S}_{t}}{\bar{S}_{t-1}}$, onde $\bar{S}_{t}$ é o tráfego esperado para o ano $t$. Assim o crescimento do tráfego possui um componente determinístico (drift) acrescido a um componente estocástico.

\subsection{2.}

\section{Volatilidade}

Para o cálculo da volatilidade dos fluxos de caixa de um projeto, no qual não existe um ativo de mercado que replique o comportamento estocástico do projeto, característica essa observada em mercados incompletos, não se deve utilizar a volatilidade passada para estimar a volatilidade futura da variável estocástica do projeto.

No modelo proposto, o calculo da volatilidade foi realizado por simulação através do método BDH proposto por Brandão, Dyer, Hahn (2012), no qual a volatilidade do valor do projeto não depende de suas variáveis de entrada e pode ser obtido a partir de:

$$
z=\ln \left(\frac{V_{1}}{\bar{V}_{0}}\right)=\ln \left(\frac{F_{1}+P V_{1}\left(E_{1}\left(F_{2}\right), \ldots, E_{1}\left(F_{n}\right) \mid F_{1}\right.}{\bar{V}_{0}}\right)
$$

onde, $F_{1}$ é o valor estocástico do fluxo de caixa no período $1 . \bar{V}_{0}$ é o valor presente determinístico dos fluxos de caixa do projeto no tempo zero. $V_{1}$ é valor o presente do projeto no período subsequente ao período inicial, dado que todos os fluxos $F_{2}$ a $F_{n}$ são determinísticos. $P V_{1}\left(F_{2}, \ldots, F_{n}\right)$ é entendido como o valor presente dos fluxos de caixa no período subsequente ao período inicial. Busca-se, 
portanto, que após simular um número significativo de iterações, pode-se assumir que a volatilidade do valor do projeto seja a volatilidade da variável z.

O projeto com uma incerteza $S(t)$, como sendo a demanda e, por conseguinte impactando a receita de venda, apresenta somente custos variáveis $C(t)=c S(t)$, onde $c$ é uma constante e $c<1$. As receitas desse projeto seguem um Movimento Geométrico Browniano (MGB) dado por:

$$
d S=\alpha S d t+\sigma_{S} d z
$$

onde $\alpha$ é a taxa de crescimento das receitas, $\sigma_{S}$ é a volatilidade das receitas, e $d z=\varepsilon \sqrt{d t}$ é um processo de difusão de Wiener. Sendo $F(t)$ o fluxo de caixa do projeto no qual $c S$ é o custo variável. Logo $F(t)=S(t)-c S(t)=(1-c) S(t)$ e define-se $\gamma=1-c$, assim:

$$
F(t)=\gamma S(t)
$$

Pelo lema de Ito, chega-se ao processo de $F(t)$, que é um MGB com os mesmos parâmetros de $S(t)$, onde $d F=\alpha F d t+\sigma_{S} d z$ e onde $F=\gamma S$. Em seguida, os autores definem que o modelo estocástico para o valor do projeto pode ser definido pela taxa de desconto do projeto igual a $\mu$ e, para $t=\tau$. Assim,

$$
V_{\tau}=\int_{t=\tau}^{\infty} E[F(t)] * e^{-\mu(t-\tau)} d t
$$

sendo $E\left[F(\tau 0]=F_{0} e^{\alpha \tau}\right.$, então a relação entre $V(\tau)$ e $F(\tau)$ é dada por: $V(\tau)=\frac{F(\tau)}{\mu-\alpha}, \mu>\alpha$. A equação do valor estocástico do valor do projeto pode ser observada como $d V=\alpha V d t+\sigma_{s} V d z$. Assim, os autores demonstram que a volatilidade do valor do projeto é a mesma do fluxo de caixa que, por sua vez, é idêntica à das receitas, sendo independente do valor de $\lambda$.

Ao aplicar o lema de Ito à equação (14), deve-se obter $d F=\alpha \lambda S d t+\sigma_{S} \lambda S d z$. Chega-se a $d F=\alpha F(t) d t+\sigma_{S}(F(t) d z$.

$$
V=F+\int_{t=1}^{\infty} E[F(t)] e^{-\mu(t-1)} d t=F_{0}(t)+\int_{t=1}^{\infty} F e^{-\mu(t-1)} d t
$$

ou, $V=\frac{F(t)\left(\mu-\alpha+e^{\alpha}\right)}{\mu-\alpha}$.

Aplicando o lema de Itô: 


$$
\begin{gathered}
d V=\frac{\mu-\alpha+e^{\alpha}}{\mu-\alpha}(F) \alpha d t+\frac{\mu-\alpha+e^{\alpha}}{\mu-\alpha}(F) \sigma_{S} d z \\
d V=\alpha(V) d t+\sigma_{S}(V) d z
\end{gathered}
$$

Sendo $X=\ln V$ como o processo de retorno do valor do projeto, a equação que representa a dinâmica do retorno do projeto será:

$$
d X=\left[\alpha V-\frac{1}{2} \sigma^{2}(V)^{2}\right] d t+\sigma_{S}(V) d z
$$

Ao se obter a equação (17), cabe observar sua relevância para o apreçamento de flexibilidades em projetos de infraestrutura. $\mathrm{O}$ resultado demonstra que havendo custos fixos, a volatilidade do valor do projeto será igual à das receitas, multiplicada pelo termo $\Gamma$. Caso o projeto conte apenas com custos variáveis, pode-se afirmar que a volatilidade do projeto $\sigma_{P}$ será igual à das receitas $\sigma_{R}$; porém, na presença de custos fixos, a volatilidade do projeto será dada pela equação (18), abaixo.

$$
\sigma_{P}=\sigma_{R}=\Gamma \cdot \sigma_{R}
$$

\subsection{3.}

\section{Prêmio de Risco}

O custo de capital para o acionista em análise de projetos é tradicionalmente obtido por meio do modelo do CAPM (SHARPE, 1964). No entanto, as flexibilidades em projetos alteram o nível de risco dos mesmos e, portanto, o próprio custo de capital. Como esse custo de capital não é conhecido, uma das maneiras de apreçar opções pode se dar por portfólio neutro a risco (BLACK;SCHOLES, 1973)

No entanto, para ativos que não possuem correlação direta com incertezas de mercado, pode ser utilizado para o cálculo do prêmio de risco de um projeto um método proposto por Brandão e Saraiva (2008). Os autores partem do pressuposto de que o projeto apresenta apenas uma fonte de incerteza e com a receita seguindo um MGB, do tipo:

$$
d R=\alpha S d t+\sigma_{S} S d z
$$


Onde $\alpha$ é taxa de crescimento da receita, $\sigma_{S}$ é a volatilidade das receitas, e $z(t)$ segue um processo padrão de Wiener. Como o MGB pode ser representado como a evolução estocástica dos retornos, como na equação (20):

$$
d \ln S=\left(\alpha_{S}-\frac{1}{2} \sigma_{S}^{2}\right) d t+\sigma_{S} d z
$$

E discretizando-a, os autores chegam à equação:

$$
S_{t}=S_{t-1} e^{\left(\alpha_{t}-\frac{1}{2} \sigma_{S}\right) \Delta t+\sigma_{S} \cdot \varepsilon \sqrt{\Delta t}}
$$

Assumindo que a função de valoração do projeto $V=f(S)$ é uma função da receita, sendo regida pelo mesmo processo de Wiener $d z$, onde

$$
d V=\alpha V d t+\sigma_{V} V d z
$$

Aplicando o lema de Ito a equação (22), ou autores chegam a:

$$
d V=\left[\frac{\partial V}{\partial S} \alpha S+\frac{\partial V}{\partial t}+\frac{1}{2} \frac{\partial^{2} V}{\partial S^{2}} \sigma_{S}^{2} S^{2}\right] d t+\frac{\partial V}{\partial S} \sigma_{S} S d z
$$

Do CAPM temos: $\mu=r+\beta_{P}\left(E\left[S_{m}\right]-r\right)$

onde $\mu$ é a taxa de desconto ajustada ao risco do projeto e $\beta_{P}$ seu respectivo beta.

O prêmio de risco do projeto é dado por

$$
\mu-r=\beta_{P}\left(E\left[S_{m}\right]-r\right)
$$

O prêmio de risco do projeto também pode ser expresso por $\lambda$, obtendo-se a seguinte equação:

$$
\mu-r=\lambda
$$

Substituindo a equação (23) na equação (26), chega-se a:

$$
\begin{aligned}
& d V=\left[\frac{\partial V}{\partial S} \alpha R+\frac{\partial V}{\partial t}+\frac{1}{2} \frac{\partial^{2} V}{\partial S^{2}} \sigma_{S}^{2} S^{2}\right] \frac{1}{V}-r=\lambda\left[\frac{\partial V}{\partial S} \sigma_{S} S\right] \frac{1}{V} \mathrm{e} \\
& \frac{\partial V}{\partial S} S\left(\alpha-\lambda \sigma_{S}\right)+\frac{\partial S}{\partial t}+\frac{1}{2} \frac{\partial^{2} V}{\partial S^{2}} \sigma_{S}^{2} S^{2}-r V=0
\end{aligned}
$$


A equação (27) é a equação diferencial em que o valor do projeto depende da incerteza de receita.

De forma análoga à da equação (25), o prêmio de risco das receitas é dado por: $\alpha-r=\beta_{S}\left(E\left[S_{m}\right]-r\right)$

O prêmio de mercado $\lambda_{s}$ pode ser definido como:

$$
\lambda_{s}=\frac{\alpha-r}{\sigma_{s}}
$$

E o $\beta_{s}$ pode ser definido como $\beta_{s}=\frac{\sigma_{m, S}}{\sigma_{s}^{2}}$

Substituindo as equações (28) e (29) na equação (30), e multiplicando ambos os lados por $\frac{\sigma_{S}}{\sigma_{S}}$ e rearranjando, obtemos:

$$
\lambda_{S} \sigma_{S}=\left(\frac{\sigma_{m, S}}{\sigma_{m} \sigma_{S}}\right) \cdot\left(\frac{E\left[S_{m}\right]-r}{\sigma_{m}}\right) \sigma_{S}
$$

Onde $\rho_{S}=\frac{\sigma_{m, S}}{\sigma_{m} \sigma_{S}}$ representa a correlação entre as mudanças de receitas e o retorno do mercado.

Assim, a equação resultante torna-se: $\lambda_{S}=\rho_{S}\left[\frac{E\left[S_{m}\right]-r}{\sigma_{m}}\right]$

De forma similar, o prêmio de mercado do projeto $\lambda_{P}$ será: $\lambda_{P}=\rho_{P}\left[\frac{E\left[S_{m}\right]-r}{\sigma_{m}}\right]$

onde $\rho_{P}$ representa a correlação entre o retorno do projeto e o mercado.

Assumindo a receita como única fonte de incerteza do projeto, a correlação $\rho_{S}$ entre as mudanças de receitas e o retorno de mercado será idêntica a $\rho_{P}$ entre o retorno do projeto e do mercado.

Decorre daí que a equação (32) torna-se igual à equação (33), e $\lambda_{P}=\lambda_{S}=\lambda$

Das equações (29) e (30), pode-se obter:

$$
\lambda \sigma_{S}=\beta_{S}\left(E\left[S_{m}\right]-r\right)
$$

e, de forma similar: 


$$
\lambda \sigma_{P}=\beta_{P}\left(E\left[S_{m}\right]-r\right)
$$

O problema da equação (34) está relacionado ao valor de $\beta_{s}$ é desconhecido, fazendo com que ambos os lados da equação (35) sejam multiplicados por $\frac{\sigma_{S}}{\sigma_{P}}$, resultando em:

$$
\lambda \sigma_{P} \cdot \frac{\sigma_{S}}{\sigma_{P}}=\beta_{P}\left(E\left[S_{m}\right]-r\right) \cdot \frac{\sigma_{S}}{\sigma_{P}} \Rightarrow \lambda \sigma_{S}=\beta_{P}\left(E\left[S_{m}\right]-r\right) \cdot \frac{\sigma_{S}}{\sigma_{P}}
$$

E o processo neutro a risco das receitas será:

$$
d S=\left(\alpha-\lambda \sigma_{S}\right) S d t+\sigma_{S} S d z
$$

Brandão e Saraiva (2008) entendem que o fluxo de caixa determinístico deve ser descontado pela taxa de desconto ajustada ao risco do projeto $\mu$. O fluxo de caixa neutro a risco deve ser descontado pela taxa de desconto livre de risco, devendo ser ambos iguais, o que resulta na equação (38):

$$
\sum_{t=2016}^{2036} \frac{f(S)}{(1+\mu)^{t-2016}}=\sum_{t=2016}^{2036} \frac{f\left(S_{R N}\right)}{\left(1+r_{f}\right)^{t-2016}}
$$

onde:

$f(S)$ é o fluxo de caixa do projeto em função da receita.

$d S=\alpha_{t} S d t+\sigma_{S} S d z$ representa o processo estocástico da receita.

$d S_{R N}=\left(\alpha_{t}-\delta\right) S d t+\sigma_{S} S d z$ representa o processo estocástico neutra a risco, sendo $\lambda$ é o prêmio de risco e:

$\alpha_{t}$ é o crescimento da receita ano a ano.

$\mu$ é a taxa de desconto do projeto.

$r_{f}$ é a taxa de desconto livre de risco.

Já que todas as variáveis são conhecidas, com exceção de $\lambda$, chega-se um sistema de uma equação e uma variável com uma única solução, que pode ser resolvida por métodos numéricos. 


\subsection{4.}

\section{Fluxo de Caixa Estocástico e Opções Collar}

Ainda como parte integrante da etapa 2 do desenvolvimento do modelo, apresentado na Figura 8, nesta subseção a partir do modelo estocástico, introduzindo as opções collar, limitadas pelo cap da garantia.

A determinação do valor a ser ofertado como garantia governamental passa por uma análise sobre a principal incerteza do modelo e pela própria projeção de fluxos de caixa futuros do projeto. Neste contexto, a incerteza sobre a demanda foi considerada a principal variável estocástica que impacta o fluxo de caixa do projeto. O fluxo de caixa será definido como:

$$
F C_{t, w}=\bar{p} \cdot S_{t, w}-\bar{C}
$$

Para cada realização do processo estocástico $w \varepsilon[1, m]$ em cada instante de tempo $t \varepsilon[0, T]$ é definido o fluxo de caixa do projeto, que é estocástico, em função da quantidade demandada $(S)$, que segue um processo estocástico do tipo Movimento Geométrico Browniano (MGB). Esse processo é representado como $\Delta q=\alpha S \Delta t+\sigma S \Delta z$, no qual $\alpha$ é a taxa de crescimento, $\sigma$ a volatilidade e $\Delta z$ o processo de Wiener. Neste caso, o preço $(p)$ e o custo operacional (c) são considerados determinísticos e constantes ao longo do tempo.

Os parâmetros do modelo são obtidos a partir de uma série temporal de valores de $S_{t}$ de tráfego de uma rodovia já licitada no Brasil para servir como exemplo, calculando-se a série $\ln \left[S_{t} / S_{t-1}\right]$. O parâmetro de volatilidade $\sigma$ da série $S_{t}$ é o desvio padrão desta nova série calculada. Sendo que a volatilidade a ser utilizada para o modelo proposto é calculada pelo método BDH, já mencionado. Já o parâmetro de crescimento $\alpha$ (drift) da série $\mathrm{S}_{t}$ é obtido adicionando-se a metade da variância obtida $\left(\sigma^{2} / 2\right)$ à média da nova série calculada:

$$
\begin{aligned}
& \sigma=D P\left[\ln \left(S_{t} / S_{t-1}\right)\right] \\
& \alpha=\bar{q}\left[\ln \left(S_{t} / S_{t-1}\right)\right]+\frac{\sigma^{2}}{2}
\end{aligned}
$$

O apreçamento do valor da garantia de receita mínima adiciona valor à receita realizada do projeto, que é expressa como $R_{t, w}=\bar{p} \cdot S_{t, w}$. Considerando que 
o fluxo de caixa sofre um processo aleatório decorrente da variável aleatória $S_{t, w}$, multiplicada pela constante $(p)$, pode-se assim afirmar que a receita realizada é descrita como $\left.R_{t, w}=R_{t-\Delta t} \cdot e^{\left[\left(\alpha-\frac{\sigma^{2}}{2}\right) \cdot \Delta t+\sigma \Delta z\right.}\right], \Delta z=\varepsilon \sqrt{\Delta t}$ e $\varepsilon_{t} \sim N(0,1)$.

Dessa forma, considerando o sorteio da variável aleatória $\varepsilon_{t}$ e a realização do processo estocástico $w$ é então possível obter o valor para a variável aleatória agora dada pela receita $R_{t, w}$, a qual através de um grande número simulações chega-se ao apreçamento do valor das opções por simulação. Como as garantias são apreçadas como opções, a receita é simulada como um processo neutro a risco, chegando-se a receita realizada pela expressão $\left.R_{t, w}=R_{t} \cdot e^{\left[\left(r-\delta-\frac{\sigma^{2}}{2}\right) \cdot \Delta t+\sigma \Delta z\right.}\right]$.

No modelo desenvolvido para o presente estudo, o apreçamento de garantias de demanda mínima governamentais, depende de alguns parâmetros. Neste aspecto, a própria definição de garantia de demanda mínima pelo governo merece especial atenção.

A garantia de demanda mínima é definida como um percentual da demanda prevista pelo projeto sob a qual se considera uma tarifa e chega-se a um nível de receita mínimo (floor guarantee). As compensações ocorrem de acordo com a realização da demanda e são compensadas quando a demanda realizada $\left(D_{R}\right)$ encontra-se abaixo de $90 \%$ da demanda projetada $\left(D_{P}\right)$ para o período, caracterizando uma put para o concessionário. Além disso, caso a demanda realizada supere $110 \%$ da demanda projetada, o concessionário deverá compartilhar parte da receita com o governo, tendo uma característica de uma opção do tipo call à favor do governo. $\mathrm{O}$ valor da compensação $C$ irá depender do nível de demanda observada, por faixas de demanda. Este mecanismo de compensação proposto, assim como seus respectivos percentuais por faixas de demanda realizada podem ser observados na Tabela 6 a seguir. 
Tabela 6 - Níveis de compensação da demanda

\begin{tabular}{|r|c|l|}
\hline $\begin{array}{c}\text { Demanda por faixas de } \\
\text { garantia }\end{array}$ & Compensação & \multicolumn{1}{|c|}{ Beneficiário } \\
\hline $\mathrm{Dr}<60 \% \mathrm{Dp}$ & Renegociação contratual & NA \\
\hline $60 \% \mathrm{Dp}<\mathrm{Dr}<80 \% \mathrm{Dp}$ & $\mathrm{C}=90 \%(0,8 \times \mathrm{Dp}-\mathrm{Dr})$ & Concessionário \\
\hline $80 \% \mathrm{Dp}<\mathrm{Dr}<90 \% \mathrm{Dp}$ & $\mathrm{C}=60 \%(90 \% \times \mathrm{Dp}-\mathrm{Dr})$ & Concessionário \\
\hline $90 \% \mathrm{Dp}<\mathrm{Dr}<110 \% \mathrm{Dp}$ & $\mathrm{C}=0$ & $\mathrm{NA}$ \\
\hline $110 \% \mathrm{Dp}<\mathrm{Dr}<120 \% \mathrm{Dp}$ & $\mathrm{C}=60 \%(\mathrm{Dr}-1,1 \mathrm{Dp})$ & Governo \\
\hline $120 \% \mathrm{Dp}<\mathrm{Dr}<140 \% \mathrm{Dp}$ & $\mathrm{C}=90 \%(\mathrm{Dr}-1,2 \mathrm{Dp})$ & Governo \\
\hline $\mathrm{Dr}>140 \% \mathrm{Dp}$ & Renegociação contratual & NA \\
\hline
\end{tabular}

Fonte: Elaboração a partir de Brandão et al. (2012).

Em função da relevância do impacto negativo que pode ser gerado para o orçamento do governo, e do desdobramento positivo em redução de risco para o concessionário, primeiramente é dada especial atenção neste estudo em detalhar o mecanismo de garantia (put). O custo máximo que o governo espera incorrer é definido como o limite máximo global da garantia (cap). A intenção de avaliar níveis de cap, tem como fundamento mitigar riscos e consequentemente limitar custos para o governo ao longo do tempo. No presente estudo, caso o projeto constantemente atinja níveis de realização de demanda inferiores a 90\% e ainda assim superiores a $60 \%$, seria utilizado o mecanismo de garantia. Por outro lado, caso a demanda realizada supere a prevista haverá o compartilhamento de ganhos com o governo, a partir de $110 \%$ da demanda prevista. Foram adotados estes percentuais, mas que podem variar de acordo com as premissas e definições concernentes a cada projeto.

Ainda como parâmetro para o modelo, caso a demanda realizada encontrese entre $60 \%$ e $80 \%$ do previsto, o percentual de compensação será de $90 \%$ sobre a diferença entre o previsto e o realizado. O mesmo nível de compensação é observado quando a demanda realizada encontra-se entre $120 \%$ e $140 \%$ acima do previsto. A compensação se reduz para 60\% quando a demanda realizada estiver entre $80 \%$ e $90 \%$ do previsto. O nível de compensação de $60 \%$ ao governo é considerado quando a demanda realizada encontra-se entre $110 \%$ e $120 \%$ acima do previsto. Em função do processo aleatório que impacta a demanda, a mesma pode atingir níveis abaixo de $60 \%$ ou acima de $140 \%$ do previsto. Nestes últimos casos, entende-se que a renegociação contratual ocorreria inevitavelmente, pois 
representariam desequilíbrios que inviabilizariam a relação comercial em prosseguir.

Nesse caso, as faixas de garantia de demanda mínima também podem ser entendidas como um mecanismo preliminar de restrição de gastos em cenários de exercício da put para o concessionário, ainda que não suficiente como será observado pelo presente estudo. Na outra ponta, as faixas de compartilhamento de receita (call do governo) limitam possíveis abusos do governo para com o concessionário. A Figura 8, observa-se uma adaptação a partir de Blank et al (2016), demonstrando as faixas de compensação para cada agente.

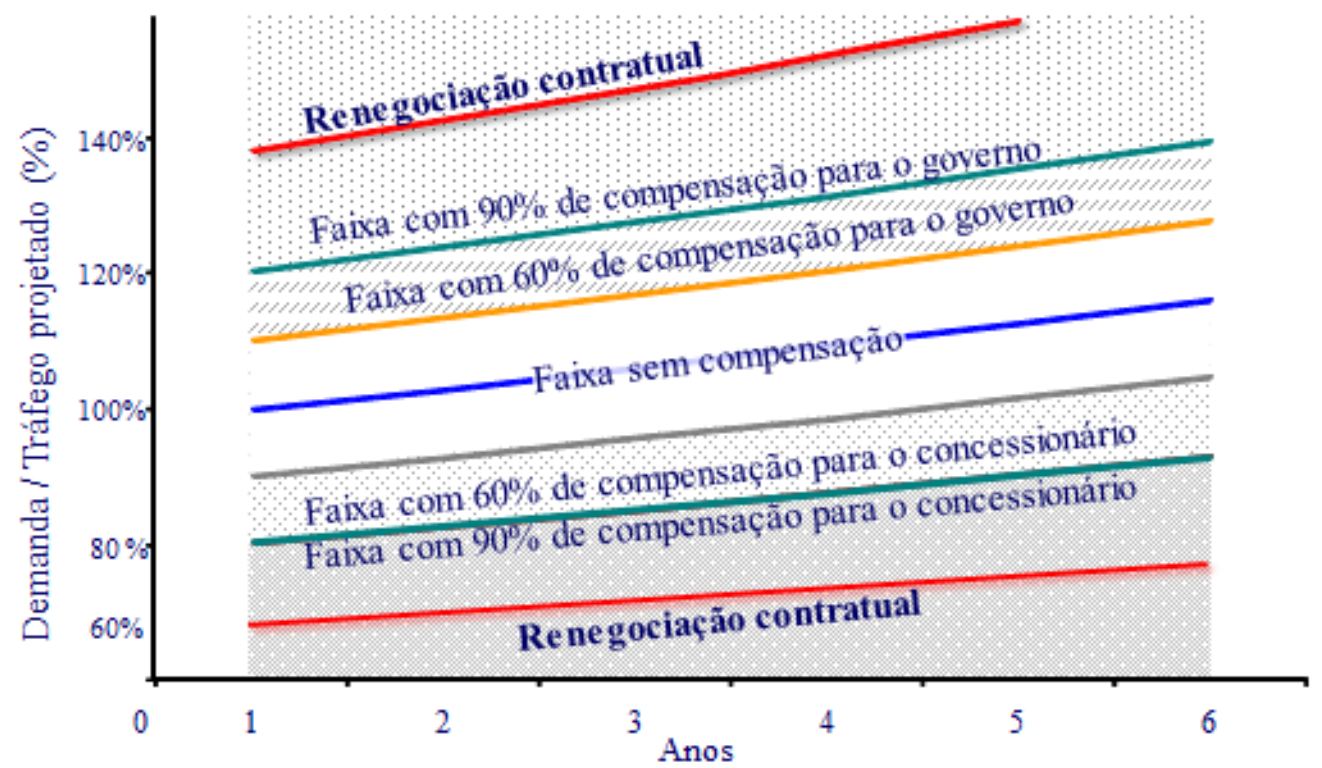

\begin{tabular}{|c|c|}
\hline $\begin{array}{l}\text { - } 120 \% \text { da Demanda Esperada } \\
\text { - } 90 \% \text { da Demanda Esperada }\end{array}$ & $\begin{array}{l}\text { - } 110 \% \text { da Demanda Esperada } \\
-80 \% \text { da Demanda Esperada }\end{array}$ \\
\hline
\end{tabular}

\section{Figura 8 - Exemplo de compartilhamento com garantia de receita mínima.}

Fonte: Elaboração própria a partir de Blank et al (2016).

O estabelecimento de faixas de garantia como parâmetros de compensação mínima (floor garantee), tem como objetivo principal mitigar riscos tanto do concessionário, quanto do governo ao longo do tempo. No entanto, este mecanismo é limitado e pode não ser suficiente para restringir, sobretudo os gastos governamentais. Com o objetivo de mitigar os custos para o governo, foram introduzidos limites orçamentários ao modelo, na forma de caps às garantias e de forma acumulativa ao longo do tempo, respeitando o horizonte 
temporal do contrato de concessão. Os limites de gastos do governo, entendidos como caps da garantia são propostos no presente estudo como percentuais entre $5 \%$ e $30 \%$ do investimento total previsto para o projeto e atuam como um mecanismo de saldo de caixa ao longo do tempo. O concessionário, portanto se limitará a ser compensado ao longo do tempo, até quando durar o benefício previsto em orçamento.

Neste modelo, o percentual de demanda realizada versus a demanda prevista abaixo de $90 \%$, por exemplo, irá acionar a compensação de receita do projeto, de acordo com cada faixa de floor guarantee $(\theta)$. O impacto para o governo em um dado instante de tempo $t$ e para uma dada realização do processo estocástico $w$, poderá ser expresso como:

$$
\max \left(\theta \cdot S_{t-\Delta t} \cdot e^{(r-\delta) \cdot \Delta t}-S_{t, w} ; 0\right)
$$

Neste caso, a receita realizada $\left(R_{t, w}\right)$, no instante de tempo $(t)$ e para uma dada realização do processo estocástico, o preço de exercício será dado pela receita mínima garantida $\left(R_{t}\right)$.

O presente estudo parte da distribuição de probabilidade da garantia e impacto desta para o concessionário ao avaliar o valor expandido do projeto com opções, mas por outro lado busca-se avaliar de forma mais contundente o risco esperado pelo governo. Dessa forma foi preciso determinar, para cada realização do processo estocástico $w$, o valor da garantia na data zero. Como a garantia deve ser calculada a partir das receitas realizadas entre $[0, T]$ e que o número de períodos é dado por $n$ discretizações de tamanho $\Delta t$, de forma que $n . \Delta t=T$, o valor estocástico da garantia $(\xi)$ sem cap, na data zero, para uma dada realização do processo estocástico, será dado por:

$$
\xi_{0, w}^{\text {sem CAP }}=\sum_{t=1}^{n}\left(\max \left(\theta \cdot R_{t-\Delta t} \cdot e^{(r-\delta) \cdot \Delta t}-R_{t, w} ; 0\right) \cdot e^{-r \cdot t}\right)
$$

onde $w \varepsilon[1, m]$ et $\varepsilon[1, n]$.

Ao observar a eq.(41), pode-se perceber que as faixas de floor guarantee irão conferir diferentes valores de garantia para cada período avaliado. Quanto maior o gap entre demanda prevista e realizada, maior será o custo esperado da garantia para o governo, mesmo considerando percentuais escalonados por faixas como observado em Brandão et al. (2012). 
Em um segundo momento, o estabelecimento de limites máximos de garantia (caps), permite tratar o valor esperado máximo que o governo está disposto a compensar o concessionário pela demanda não realizada contratualmente. O objetivo principal ao introduzir estes caps é de reduzir o risco do governo com o estabelecimento das garantias. Para tanto, são introduzidos e avaliados diferentes níveis de cap, comparando-os com o valor estocástico da garantia com e sem cap na data zero.

Neste modelo, poderá facilmente se observar que a distribuição de probabilidade da garantia com cap apresentará um valor menor do que o valor sem cap. Isto por que de forma dinâmica, nas regiões em que o valor estocástico da garantia for maior do que o cap, a opção será exercida e o valor da garantia com cap será dado pelo próprio cap. De forma alternativa, nas regiões em que valor estocástico da garantia for menor do que o cap, o valor da garantia com cap será dado pelo valor estocástico da garantia.

Supondo o valor estocástico da garantia definido como П, existe uma probabilidade associada $p_{C A P} \%$ de que as realizações da opção não sejam exercidas. Dessa forma, a contribuição para o valor esperado da garantia com cap será dado pelo valor $P_{C A P}$. e que em $p_{\Pi w} \%$ das realizações a opção não tenha sido exercida ( $\Pi \leq C A P$ ). Assim, a sua contribuição ao valor esperado da garantia com cap será dada pelo valor $\left[p_{\Gamma w} . \Pi\right]$, considerando $p_{C A P}+p_{\Pi w}=100 \%$. Em resumo, o valor esperado da garantia com cap será dado por $\xi=p_{C A P} . C A P+\sum_{w=1}^{m} p_{\Pi_{w}} \cdot \Gamma_{w}$.

Ao se observar o valor esperado da garantia sem cap, pode-se superestimar o custo da garantia para o governo e em contrapartida reduzir demasiadamente o risco do projeto para o concessionário. Para avaliar estes e outros aspectos, neste estudo utiliza-se o valor estocástico da garantia para avaliar a introdução do cap, considerando um conjunto de flexibilidades que são apreçadas pela modelagem de opções reais. Além disso, a análise do modelo complementa-se com a existência de calls para o governo e com a introdução de métricas de risco e performance, que permitirão a tomada de decisão dinâmica sob incertezas e riscos.

O cálculo da garantia (put) se justifica a partir das receitas realizadas entre $[0, T]$ e o numero de períodos é dado por $n$ discretizações de tamanho $\Delta t$, sendo 
$n . \Delta t=T$, para $n$ puts europeias entre $[0, T]$, sendo o valor estocástico da garantia sem cap expresso como:

$$
\xi_{0, w}^{\text {sem CAP }}=\sum_{t=1}^{n}\left(\max \left(\theta \cdot R_{t-\Delta t} \cdot e^{(r-\delta) \cdot \Delta t}-R_{t, w} ; 0\right) \cdot e^{-r . t}\right)
$$

para uma dada realização do processo estocástico do fator de risco do projeto.

Ao introduzir o $C A P$, o valor da garantia será dado pela eq. (43):

$$
\xi_{0, w}^{\mathrm{com} \mathrm{CAP}}=\min \left(\sum_{t=1}^{n}\left(\max \left(\theta \cdot R_{t-\Delta t} \cdot e^{(r-\delta) \cdot \Delta t}-R_{t, w} ; 0\right) \cdot e^{-r . t}\right) ; C A P\right)
$$

,cuja única diferença é a limitação do CAP. Neste caso, para cada realização do processo estocástico é avaliado se a opção de exercer o cap de fato ocorrerá.

Para um conjunto de $m$ simulações, buscar-se-á na avaliação do projeto pela ótica do concessionário, obter a distribuição de probabilidade da garantia com cap, assim como a distribuição de probabilidade das calls na data zero, descrita como $C A L L_{0, w}=-\max \left(R_{t, w}-\theta \cdot R_{t-\Delta t} \cdot e^{(r-\delta) \cdot \Delta t} ; 0\right)$. Assim, ao caracterizar as opções collar, chega-se a eq.(41):

$$
\chi_{0}^{\text {COLLAR }}=\frac{\sum_{w=1}^{m}\left(\xi_{0, w}^{\text {COm CAP }}\right)}{m}-\frac{\sum_{w=1}^{m}\left(C A L L_{0, w}\right)}{m}
$$

Uma vez que se obtêm o valor das opções, pode-se calcular o valor do VPL expandido pelo apreçamento das flexibilidades. Para isso, parte-se inicialmente do VPL estocástico sem opções, o qual na data zero, será obtido a partir da receita que é definida pela realização da simulação do processo estocástico $w$ da variável de incerteza, que neste caso se considerou sobre a demanda. Os fluxos de caixa estocásticos provenientes desse processo resultarão em:

$$
V P L_{0, w}^{\text {sem opcões }}=-I_{0}+\int_{t=0}^{T}\left(R_{t, w}-C_{t}\right) \cdot e^{-r . t} \cdot d t=-I_{0}+\int_{t=0}^{T} R_{t, w} \cdot e^{-r . t} \cdot d t-\int_{t=0}^{T} C_{t} \cdot e^{-r . t} \cdot d t
$$

onde, $w \varepsilon[1, \mathrm{~m}]$ e t $\varepsilon[1, \mathrm{~T}]$. De forma resumida, o VPL esperado sem opções é dado por $V P L_{0}^{\text {sem opscões }}=E\left(V P L_{0, w}^{\text {sem opções }}\right)$. 
Ao inserir a garantia de demanda de demanda mínima esperada sem cap, pela expressão $R_{t}^{\max }=\max \left(R_{t, w} ; R_{t}\right)$, observa-se a receita $R_{t, w}$ no instante $t$ para a realização do processo estocástico $w$ e a receita mínima garantida $R_{t}$ pelo governo no instante $t$.

O VPL estocástico do projeto com garantia de demanda mínima sem cap será calculado pelo máximo entre o valor realizado pela simulação e a receita mínima estipulada pelo governo:

$$
\begin{aligned}
& V P L_{0, w}^{\text {com garantia sem CAP }}=-I_{0}+\int_{t=0}^{T}\left(\operatorname{máx}\left(R_{t, w} ; R_{t}\right)-C_{t}\right) \cdot e^{-r \cdot t} \cdot d t= \\
& =-I_{0}+\int_{t=0}^{T}\left(R_{t, w}+\max \left(R_{t}-R_{t, w} ; 0\right)\right) \cdot e^{-r \cdot t} \cdot d t-\int_{t=0}^{T} C_{t} \cdot e^{-r \cdot t} \cdot d t \\
& V P L_{0, w}^{\text {com garantia sem CAP }}=-I_{0}+\int_{t=0}^{T} R_{t, w} \cdot e^{-r . t} \cdot d t-\int_{t=0}^{T} C_{t} \cdot e^{-r . t} \cdot d t+\int_{t=0}^{T}\left(\max \left(R_{t}-R_{t, w} ; 0\right)\right) \cdot e^{-r . t} \cdot d t
\end{aligned}
$$

Pela eq. (45) observa-se que a parcela dada por $-I_{0}+\int_{t=0}^{T} R_{t, w} \cdot e^{-r . t} \cdot d t-\int_{t=0}^{T} C_{t} \cdot e^{-r . t} \cdot d t$ representa o VPL estocástico do projeto sem garantias e $\int_{t=0}^{T}\left(\operatorname{má} x\left(R_{t}-R_{t, w} ; 0\right)\right) \cdot e^{-r . t} \cdot d t$ representa o valor estocástico da garantia sem cap $\left(\xi_{0, w}^{\text {sem CAP }}\right)$, sendo ambas na data zero e para uma realização do processo estocástico $(w)$.

Dessa forma se obtém a distribuição de probabilidade do VPL com garantia sem cap e a partir daí pode-se avaliar o nível de risco do projeto para todas as $m$ simulações.

Para o cálculo do VPL do projeto com garantia e com cap, é necessário que a receita a cada período seja composta pelo valor da demanda simulada, multiplicada pela tarifa e adicionada ao montante de garantia sem cap, limitada pelo nível de cap estabelecido. Dessa forma, o VPL é definido como:

$$
\begin{aligned}
& V P L_{0, w}^{\text {com garantia com CAP }}=-I_{0}+\left[\int_{t=0}^{T} R_{t, w} \cdot e^{-r . t} \cdot d t+\min \left(\xi_{0, w}^{\mathrm{sem} \mathrm{CAP}} ; C A P\right)\right]-\int_{t=0}^{T}\left(C_{t}\right) \cdot e^{-r . t} \cdot d t= \\
& =-I_{0}+\left[\int_{t=0}^{T} R_{t, w} \cdot e^{-r . t} \cdot d t+V G_{0, w}^{\mathrm{sem} \mathrm{CAP}}-\max \left(\xi_{0, w}^{\mathrm{sem} \mathrm{CAP}}-C A P ; 0\right)\right]-\int_{t=0}^{T}\left(C_{t}\right) \cdot e^{-r . t} \cdot d t=
\end{aligned}
$$




$$
\begin{aligned}
& =-I_{0}+\int_{t=0}^{T} R_{t, w} \cdot e^{-r . t} \cdot d t-\int_{t=0}^{T}\left(C_{t}\right) \cdot e^{-r . t} \cdot d t+\xi_{0, w}^{\text {sem CAP }}-\max \left(\xi_{0, w}^{\text {sem CAP }}-C A P ; 0\right)= \\
& V P L_{0, w}^{\text {com garantia com CAP }}=V P L_{0, w}^{\text {sem garantia }}+\xi_{0, w}^{\text {sem CAP }}+\max \left(\xi_{0, w}^{\text {sem CAP }}-C A P ; 0\right)
\end{aligned}
$$

O valor estocástico do efeito que a introdução do cap traz para a garantia sem cap, pode ser representado pelo último termo da eq. (46). Cabe observar que a esta equação ainda se considera o valor da call para o governo, como:

$$
\xi_{0, w}^{\text {com CAP }}=\min \left(\sum_{t=1}^{n}\left(\max \left(\theta \cdot R_{t-\Delta t} \cdot e^{(r-\delta) \cdot \Delta t}-R_{t, w} ; 0\right) \cdot e^{-r . t}\right) ; C A P\right)
$$

que pode representar um fluxo de caixa negativo para o concessionário a cada período, dependendo da realização do processo estocástico da demanda. Dessa forma, o VPL com collar será observado como:

$$
V P L_{0, w}^{\text {com COLLAR }}=V P L_{0, w}^{\text {sem garantia }}+\xi_{0, w}^{\text {com CAP }}-C A L L_{0, w}^{\text {GOV }}
$$

\subsection{5.}

\section{Análise de Riscos}

No presente estudo, considera-se como a terceira etapa do modelo de avaliação, realizar a análise de risco sobre a distribuição de probabilidade do valor presente do projeto com collar e cap, para analisar o impacto das flexibilidades sobre a tomada de decisão do concessionário. A partir da simulação de Monte Carlo, obtêm-se o valor esperado do projeto com flexibilidades e com a série simulada calculam-se as medidas VaR, CVaR e Ômega do modelo para observar o valor em risco para o concessionário.

Pelo VaR estima-se a perda máxima possível, num horizonte de tempo e a um certo nível de confiança. Matematicamente, ao VaR atribui-se ao nível de confiança $100 \cdot(1-\alpha)$ como o menor percentil de uma distribuição de ganhos e perdas. Para o cálculo do $C V a R$, denota-se $R$ como uma variável randômica que expressa os ganhos e as perdas do projeto, dado o $\operatorname{VaR}_{\alpha}(R)$. $\operatorname{Assim} \operatorname{CVaR}_{\alpha}(R)$ pode ser expresso como: 


$$
\operatorname{CVaR}_{\alpha}(R)=E\left[-R \mid-R \geq \operatorname{VaR}_{\alpha}(R)\right]
$$

Para o cálculo da medida Ômega, o retorno limite $(L)$ foi definido como sendo o próprio valor presente do projeto, uma vez que este representa a melhor expectativa entre o valor esperado condicional de ganhos e o valor esperado condicional de perdas. Dessa forma, o valor esperado condicional dos retornos que excedem $L$ é o ganho esperado e pode ser expresso por $E(r-L \mid r \geq L)$. Já a perda esperada será dada pelo valor esperado dos retornos que sejam menores do que $L$ e expressos como $E(L-r \mid r<L)$.

Assim, com os valores obtidos para cada ponto da distribuição, foram comparados os ganhos e as perdas potenciais para cada cenário de garantia e cap, ponderados por suas próprias probabilidades de retornos $\left(r_{i}\right)$ para encontrar o valor da medida ômega $(\Omega)$ :

$$
\Omega(L)=\frac{\sum E\left(r_{i}-L \mid r_{i=1}^{m} \geq L\right) \cdot \operatorname{Prob}\left(r_{i}\right)}{\sum E\left(L-r_{i}||_{i=1}^{m}<L\right) \cdot \operatorname{Prob}\left(r_{i}\right)}
$$

\subsection{6.}

\section{Garantias Governamentais e Análise de Riscos}

A definição de parâmetros, assim como a forma de alcançar objetivos específicos a partir do apreçamento da garantia mínima de demanda com cap pelo governo já fazendo parte da análise da etapa quatro do presente modelo, passa pela reavaliação de alguns aspectos conceituais.

A flexibilidade aumenta o valor presente do projeto, em função da garantia governamental. Além disso, o risco associado ao projeto para o concessionário se reduz com a introdução da mesma, que desloca a distribuição de probabilidade do valor presente do projeto para a direita. Este mecanismo de garantia tende a contribuir para a viabilidade de projetos que poderiam ser considerados de pouca atratividade para a iniciativa privada.

O apreçamento de tal mecanismo, no entanto, passa pela determinação das faixas de compensação de receita, bem como pelos limites orçamentários totais de recursos (caps) pelo governo. Além disso, deve-se considerar ainda que tanto o 
governo, quanto o concessionário são avessos a riscos. Neste aspecto, no modelo considera-se o menor nível de risco ao concessionário, desde que respeitando o limite máximo de dispêndios governamentais, que neste caso é considerado como um percentual do investimento a ser realizado no projeto.

Os principais objetivos com a parametrização da garantia governamental são: minimizar custos e riscos para o governo ao fornecer a garantia, definindo valor e prazo para ser ofertada; e permitir um nível de risco aceitável ao projeto, que gere atratividade à iniciativa privada ao também minimizar seu risco.

Ao analisar as garantias pela ótica da iniciativa privada (concessionário), cabe observar primeiramente a distribuição de probabilidade do VP do projeto com e sem garantias, para fins de avaliação de risco de investimento para o concessionário. Por outro lado, para o governo cabe observar a distribuição de probabilidade da garantia, analisando o impacto da put sem e com cap, uma vez que através desta distribuição de probabilidade poderá se definir o custo esperado da garantia para o governo e sua respectiva probabilidade de ocorrência. Estas distribuições de probabilidade servirão para avaliar: (i) o risco do projeto para o concessionário, a partir das métricas de risco VaR, CVaR e Ômega; e (ii) o risco gastos excessivos para o governo, ao aplicar métricas de risco VaR, CVaR e Ômega.

Para o cálculo do VaR e CVaR, adota-se a mesma dinâmica de cálculo exposta no referencial teórico. Como já exposto neste estudo, o resultado da medida Ômega é evidenciado ao dividir a integral da área da distribuição de probabilidade do valor esperado que excede um limite $L$, pela integral da área da distribuição de probabilidade abaixo deste limite. A metodologia propõe que quanto maior a medida Ômega, melhor o resultado e consequentemente, menor seria o risco associado às perdas ou valor em risco. Entretanto, no presente estudo a medida Ômega é aplicada sobre a distribuição de probabilidade da garantia sem e com cap, que na realidade representa um custo para o governo. Sendo assim, entende-se que não é de interesse do governo maximizar o valor de tal medida, mas buscar minimizá-lo. Isto posto, sugere-se no presente modelo uma adaptação da referida medida de performance, para que reflita o real interesse do governo.

Assim como proposto pela metodologia para o cálculo da medida Ômega, deve-se adotar um valor limite que divide a distribuição de probabilidade, neste caso definido como $\Lambda$, e que neste modelo proposto é compreendido como o valor 
esperado da garantia pelo governo. Como diferencial ao proposto tradicionalmente pela medida Ômega, esta agora passa a ser definida com $\omega$, e propõe-se aqui a divisão da integral da área da distribuição de probabilidade abaixo deste limite $\Lambda$, pela distribuição de probabilidade do valor esperado que excede este limite. Esta proposição equivaleria a manter a medida Ômega utilizando o mesmo cálculo original, mas com o foco em minimizar o valor da referida medida, uma vez que se busca minimizar o custo para o governo.

Assim, com os valores obtidos para cada ponto da distribuição, pode-se comparar os valores abaixo do limite $\Lambda$, com aqueles acima do limite, ponderados por suas próprias probabilidades de retornos $\left(\mathrm{r}_{\mathrm{i}}\right)$ para encontrar o valor da medida ômega $(\omega)$ :

$$
\omega(\Lambda)=\frac{\sum E\left(\Lambda-\left.r_{i}\right|_{i=1} ^{m}<\Lambda\right) \cdot \operatorname{Prob}\left(r_{i}\right)}{\sum E\left(r_{i}-\left.\Lambda\right|_{i=1} ^{m} \geq \Lambda\right) \cdot \operatorname{Prob}\left(r_{i}\right)}
$$

Com a medida ômega redefinida, pode-se determinar a combinação entre o máximo nível de garantia com cap ao concessionário, que permita a menor medida ômega $(\omega)$ e consequentemente o menor risco e custo para o governo.

Ao analisar os impactos do modelo, primeiramente continuará sendo observado o risco do projeto pelas medidas $V a R$ e $C V a R$ a partir dos níveis de caps para as garantias. Em seguida, avalia-se dentre as combinações analisadas, aquela que minimiza o custo da garantia e o risco esperado pelo governo através da nova medida Ômega.

Contudo, cabe lembrar que as etapas mencionadas visam dar condições para viabilizar o investimento a partir da introdução de garantias. Neste aspecto, para que haja coerência, o custo esperado da garantia para o governo acabará sendo diferente de zero. Considerando ainda a necessidade de parametrização da garantia de demanda mínima com cap, utiliza-se para o presente estudo o método de simulação de Monte Carlo, combinando as faixas de garantia com diferentes níveis de cap.

Neste aspecto, considera-se o máximo de discretizações possíveis dos parâmetros para que se possa validar o modelo, considerando as condições básicas existentes para as puts como sendo do tipo europeias e as características relacionadas com a garantia governamental de demanda mínima. Além disso, o 
modelo é aplicado a um projeto de infraestrutura por PPPs, respeitado as condições contratuais e sua aderência a parâmetros típicos de projetos realizados no Brasil.

\subsection{7.}

\section{Combinação Risco e Retorno}

Neste estudo, foram considerados ainda cenários de caps de garantia pelo governo, que são simulados para os níveis de compensação de garantia e compartilhamento de receitas mencionadas na Figura 9, conforme previsto na etapa quatro do desenvolvimento do modelo. A combinação para minimizar o risco para o governo e maximizar o retorno para o concessionário, com o objetivo de mensurar os valores adicionados ou subtraídos do projeto pelas opções, são definidos em função dos níveis de compensação $(\phi)$ e níveis de cap (П) pela função $f(\phi, \Pi)$, definida pela equação abaixo:

$$
\begin{aligned}
& f(\phi, \Pi)=P(\phi, \Pi)-C(\phi, \Pi) \\
& f(\phi, \Pi)=\sum_{t=2016}^{2036}(1-T) \cdot \min \left\{\sum_{t=2016}^{2036} \frac{\max \left\{S_{N R}(t) \cdot p-\bar{S}(t) \cdot \phi \cdot p ; 0\right\}}{(1+r f)^{t-2016}} ; \Pi\right\}- \\
& (1-T) \cdot \sum_{t=2016}^{2036} \frac{\max \left\{S_{N R}(t) \cdot p-\bar{S}(t) \cdot(2-\phi) \cdot p ; 0\right\}}{(1+r f)^{t-2016}}
\end{aligned}
$$

\section{3.}

\section{Opção de Expansão}

O mecanismo de opções collar aqui proposto, é sem dúvida relevante para atrair a iniciativa privada e mitigar gastos do governo, como observado em diferentes estudos acadêmicos já citados, mesmo que através de abordagens diferentes. Porém, como a demanda sofre um processo estocástico e consequentemente existe a probabilidade da demanda prevista no plano de negócios inicial estar subdimensionada para o longo prazo, entende-se que o concessionário poderá ter interesse em expandir a capacidade do projeto.

Entretanto, a existência de opções collar como mecanismo de mitigação de riscos, acaba criando um desincentivo ao concessionário expandir a capacidade do 
projeto, dado que os fluxos de caixa marginais deixariam de ser capturados exclusivamente pelo investidor privado, para serem compartilhados com o governo. Neste caso, somente fará sentido para o concessionário considerar a opção de expansão, se não houver o compartilhamento de ganhos (call) com o governo. Dessa forma, o modelo passa a ser revisto para contemplar somente a garantia de demanda mínima do concessionário (put), para que então se avalie a flexibilidade de expansão (call).

Como exemplificação, ao observar a figura 9 a seguir, percebe-se que as opções collar sobre a demanda podem representar na realidade um limitador a necessidade de expansão.

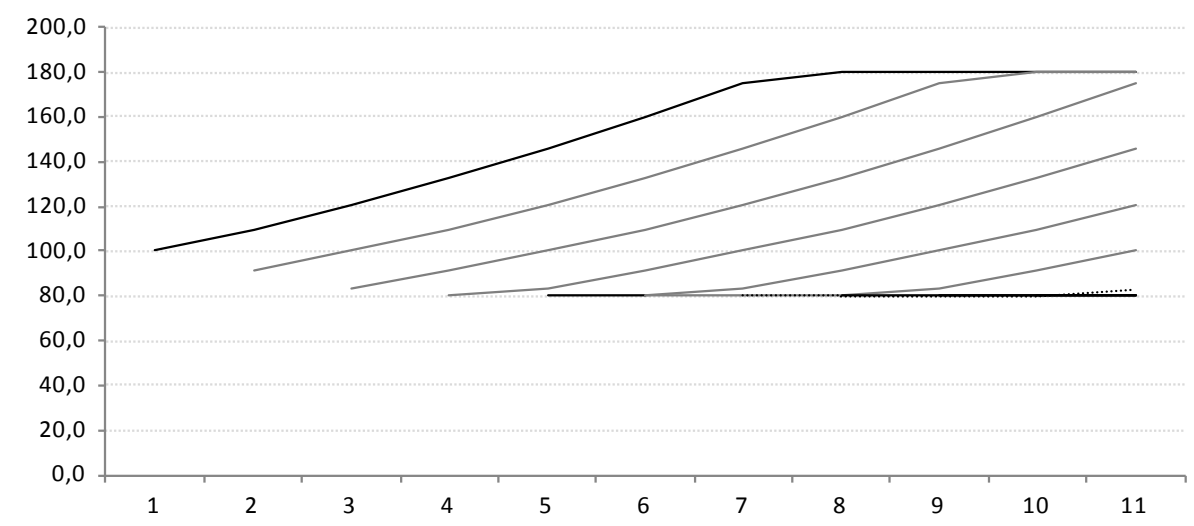

\section{Figura 9 - Exemplo simulação do efeito do collar sobre a demanda projetada}

Fonte: Elaboração própria

Para o concessionário, as opções collar podem ter na realidade um efeito negativo para os fluxos de caixa futuros, em cenários de considerável crescimento da demanda, como exemplificado na figura 10 a seguir. 


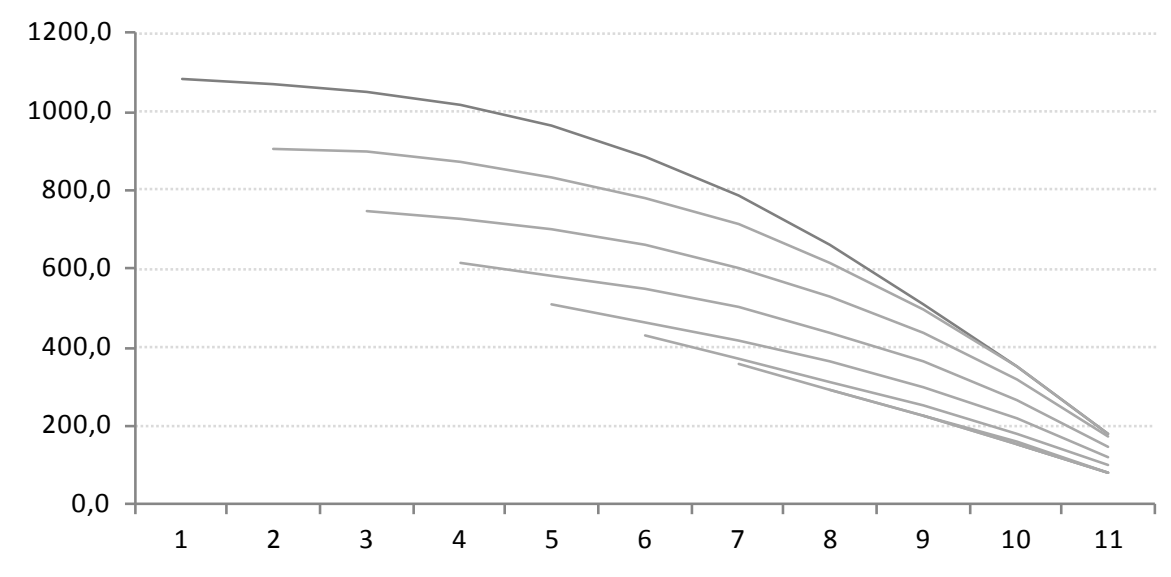

Figura 10 - Exemplo simulação do efeito do collar sobre os fluxos de caixa projetados.

Fonte: Elaboração própria

Tendo em vista que existe essa flexibilidade de expandir, nesta etapa 5 do modelo proposto busca-se o apreçamento da flexibilidade de expansão como mais um mecanismo de atratividade para o contrato, a qual também pode ser entendida como uma opção real de expansão.

Neste cenário, no modelo de avaliação proposto se mantém o mecanismo de garantia (put) do tipo europeia, mas agora sem o compartilhamento com o governo. Passa-se a contemplar a interação com a opção de expandir a capacidade do projeto pelo concessionário. Esta flexibilidade também pode ser vista como uma call de expansão americana, uma vez que o concessionário pode tomar a decisão de expandir, a qualquer momento ao longo da vida útil do contrato. O modelo, neste momento, passa a contemplar então o apreçamento de uma put do tipo europeia com uma call do tipo americana, ambas a favor do concessionário. A combinação destas flexibilidades em um mesmo modelo de avaliação por opções reais com métricas de risco busca trazer uma nova contribuição metodológica ao processo de avaliação financeira de projetos de infraestrutura.

A tomada de decisão pelo governo para conceder a garantia, continuará pelo apreçamento das garantias com cap, analisadas separadamente ao valor do projeto. Isto porque representa na realidade, o potencial custo governamental para operar o contrato no longo prazo. Sobre este valor da garantia com cap, destaca-se a aplicação da medida Ômega como métrica para permitir minimizar o risco para o governo. 
Para o cálculo da call americana e sua interação com a put europeia, o modelo até então desenvolvido em planilha eletrônica com software @Risk para rodar simulações de Monte Carlo, passa a ser conectado ao software DPL para que, seja possível o cálculo iterado das opções de forma simultânea e mais intuitiva. No DPL, foi utilizada uma abordagem por árvore binomial para o cálculo das flexibilidades do modelo.

Considera-se em qualquer nó $i$ desta, em que $i$ não seja o período final e sendo: $p$ a probabilidade de ocorrer o movimento ascendente no período seguinte a $i$ e movimentos de descida $j$, com probabilidade (1-p) de ocorrer o movimento descendente.

Assim, sendo $r$ a taxa de desconto neutra a risco do projeto, e $\sigma$ sua volatilidade, em cada nó de decisão, a variável estocástica $S{ }_{t}$ é modelada, sendo:

$$
\begin{aligned}
& S^{*+}=S^{*}+\sigma \sqrt{\Delta t} \\
& S^{*-}=S^{*}-\sigma \sqrt{\Delta t}
\end{aligned}
$$

Com probabilidades definidas como:

$$
p=\frac{e^{r}-d}{u-d}, \quad \text { e: } 1-p=\frac{u-e^{r}}{u-d}
$$

Sendo, $u=e^{\sigma}$ e: $d=e^{-\sigma}=1 / u$

O modelo binomial permite a avaliação do valor das opções pela árvore binomial, utilizando a taxa neutra a risco como taxa de desconto em todos os nós da árvore.

Na binomial, $S^{*+}$ e $S^{*-}$, são os valores aleatórios ascendentes e descendentes que são modelados dentro da árvore de fluxos de caixa (FC), sendo o fluxo de caixa determinístico tratado inicialmente pela equação (54), a partir do qual a receita, sofre o desconto dos custos operacionais (CO), abate-se depreciação (DEP) e impostos (IR), retornando com a depreciação (DEP) e descontando-se ainda a necessidade de capital de giro:

$$
F C=(S . p)-C O-D e p-I R+D e p-N C G
$$

Para fins de simplificação, o fluxo de caixa do projeto passa a ser considerado como:

$$
F C=(S \cdot p)-c_{t}
$$


,sendo $c_{t}$ a sumarização das deduções mencionadas.

O fluxo de caixa estocástico ( $\Phi$ ) é definido como:

$$
\Phi=\left[S^{*} \cdot p\right]-c_{t}
$$

Denotando o valor do projeto com opção de expansão por $F(R)$, o valor da opção real é condicionado ao exercício ótimo da opção de expansão. Note que o projeto com a opção de expansão gera um fluxo de caixa $F_{E}$ igual ao fluxo de caixa $\Phi$ neutro a risco, i.é, ${F_{E}}^{+}=F C^{+}$e ${F_{E}}^{-}=F C^{-}$. No cenário de subida o valor da opção de expansão é expresso por $\mathrm{F}_{t}^{+}=\mathrm{F}_{E}^{+}+\operatorname{Max}\left[\Phi_{t}^{+} ; E \Phi_{t}^{+}-I\right]$, sendo $E$ o fator de expansão.

No entanto, em cenários de baixa demanda, os fluxos de caixa que estejam abaixo dos níveis de previstos, serão compensados pelo mecanismo de garantia, cujo valor com cap é dado por $\xi_{0, w}^{\text {com Cap }}$ e expresso pela equação $\xi_{0, w}^{\text {com CAP }}=\min \left(\sum_{t=1}^{n}\left(\max \left(\theta \cdot R_{t-\Delta t} \cdot e^{(r-\delta) \cdot \Delta t}-R_{t, w} ; 0\right) \cdot e^{-r . t}\right) ; C A P\right)$

que permanece integrado ao fluxo de caixa estocástico do projeto.

Para o cálculo do novo valor presente do projeto com expansão, garantia e com cap, é necessário que a receita a cada período em que a demanda não seja atendida, passe a ser complementada pelo valor da demanda, multiplicada pela tarifa e adicionada ao montante de garantia limitada pelo nível de cap estabelecido.

Esquematicamente, o modelo pode ser demonstrado pela figura 11, a seguir, que ilustra o modelo da árvore binomial de decisão da opção americana de expansão com garantia e com cap. 


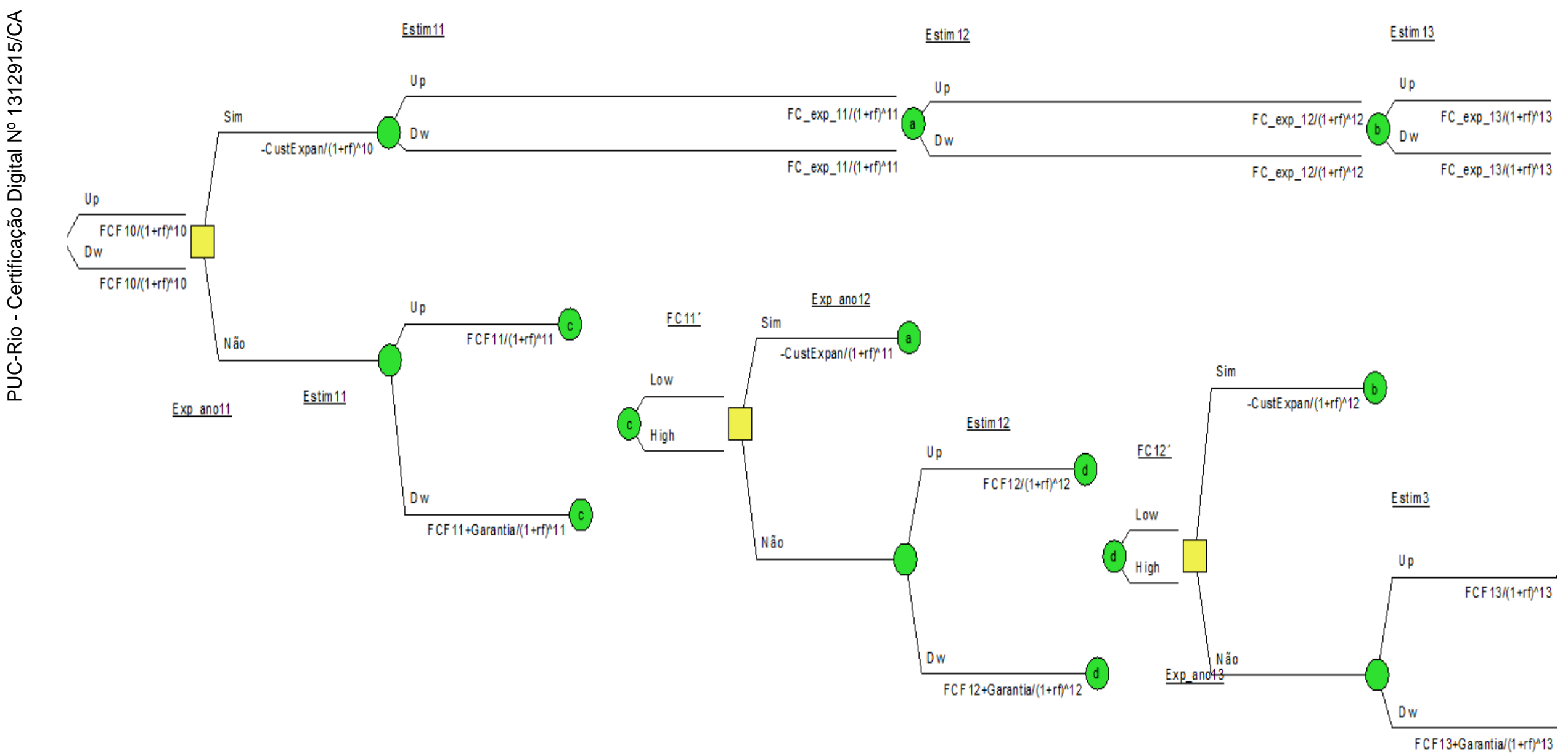

\section{Figura 11 - Visão parcial do modelo com collar e opção de expandir}

Fonte: elaboração própria com base no software DPL. 
Após o cálculo do modelo com flexibilidades, contemplando a opção americana de expansão com garantia e com cap, propõe-se na última e sexta etapa do modelo de avaliação proposto, a análise de impacto de risco para o concessionário, utilizando como parâmetro a medida Ômega, tendo em vista a vantagem do cálculo desta métrica em relação às demais no que se refere a capturar todos os momentos da distribuição de probabilidade dos valores simulados. Dessa forma, busca-se avaliar o quanto as flexibilidades gerenciais modeladas podem contribuir para redução de risco para o concessionário. 


\section{Aplicação do Modelo Proposto}

\section{1.}

\section{Modelo Base}

O modelo proposto foi desenvolvido utilizando uma série de parâmetros com base em um projeto hipotético, mas típico, de rodovia por Parceria Público Privada, fundamentado em análise de editais e de condições contratuais em projetos em curso no país. Para tanto, o modelo utiliza demanda projetada de tráfego, bem como informações sobre dispêndios de capital, receitas, custos operacionais, prazo contratual e informações de capacidade, partindo de dados de mercado divulgados pelo governo brasileiro com respeito projetos de PPPs.

O período contratual está estimado em vinte anos por simplificação e pelas características, o projeto que serve de base para o modelo, pode se encaixar em um projeto de infraestrutura rodoviária. Por ser um projeto greenfield, a fase préoperacional e de construção da infraestrutura possui duração de aproximadamente três anos e somente após este período, inicia-se a operação e a geração de receitas por parte do concessionário.

A tarifa foi definida a partir do resultado de um leilão do governo e a demanda prevista, mapeada com base em estudos encomendados previamente pelo próprio governo para esta infraestrutura.

Nestes contratos, o governo exige o início da duplicação da via (investimento de capital na ampliação) logo após o quinto ano de operação, baseando-se somente na demanda projetada inicialmente no plano de negócios, sem uma definição clara de níveis de serviço a serem cumpridos. O risco de demanda é geralmente assumido, na totalidade pelo concessionário e há ausência de garantias pelo governo.

A seguir, na Tabela 7 apresentam-se as principais premissas utilizadas e parâmetros que foram calculados e utilizados para o presente estudo. Um maior 
detalhamento para o cálculo da taxa de desconto ajustada a risco encontra-se estruturado na próxima subseção.

\section{Tabela 7 - Parâmetros do modelo}

\begin{tabular}{clc}
\hline Parâmetro & \multicolumn{1}{c}{ Descrição } & Valor \\
\hline$p$ & Tarifa (R\$) & 9,27 \\
$\tau$ & Impostos diretos (\%) & $14 \%$ \\
$\eta$ & Prazo contratual (anos) & 30 \\
$\alpha$ & Taxa de crescimento média do tráfego (\%) & $2,58 \%$ \\
$\sigma$ & Volatilidade do tráfego (\%) & $8,70 \%$ \\
I & Investimento ano 0 ao ano 5 (MM R\$) & 5.402 \\
& 70\% do investimento total com 2 anos de carência & \\
Financiamento & 3.781 \\
$d$ & para o pagamento (MM R\$) & $9,15 \%$ \\
$r$ & taxa ajustada a risco (\%) & $6,17 \%$ \\
$i$ & taxa neutra a risco (\%) & $5,50 \%$ \\
XO1 & taxa de juros do financiamento (\%) & $90 \mathrm{MM}$ \\
\hline CO2 & Custo operacional médio ano 0 ao ano 5 (MM R\$) & $186 \mathrm{MM}$ \\
$D$ & Custo operacional médio ano 6 ao ano 5 (MM R\$) & 15 \\
$I R$ & Depreciação do investimento (anos) & $34 \%$ \\
$\mu$ & Imposto de renda (\%) & $11,13 \%$ \\
\hline
\end{tabular}

Fonte: elaboração própria

\subsection{1.}

\section{Taxa de desconto ajustada a risco}

Em meio a adoção de premissas básicas para modelo pelo fluxo de caixa descontado, o cálculo da taxa de desconto ajustada a risco, ainda que simplista, merece atenção. Para o custo do equity, adotou-se primeiramente o CAPM (Capital Asse Pricing Model) e em seguida os custos de financiamento para compor o WACC (Weighted Average Cost of Capital), ao considerar que a avaliação por Opções Reais é realizada a partir da metodologia do Fluxo de Caixa da Empresa.

Pelo CAPM, a taxa de retorno (desconto) requerida pelo investidor deve incluir uma taxa livre de risco da economia, mais um prêmio que remunere o risco sistemático apresentado pelo retorno de mercado, ao qual se tem um coeficiente 
beta $(\beta)$ como multiplicador, chegando a tradicional equação $k_{e}=r_{f}+\left(r_{m}-r_{f}\right) \beta$, onde:

$k_{e}$ custo de oportunidade do capital próprio;

$\beta$ é risco sistêmico da indústria sob análise;

$r_{f}$ é a taxa de retorno de um ativo livre de risco;

$r_{m}$ é a taxa de retorno esperada de uma carteira diversificada;

$\left(r_{m}-r_{f}\right)$ é o prêmio de risco do mercado.

No cálculo do CAPM foram consideradas empresas brasileiras que atuam em concessões públicas de infraestrutura, em função da própria natureza do projeto.

Além disso, é necessário ponderar os custos de capital próprio $\left(\mathrm{k}_{\mathrm{e}}\right)$ e de terceiros $\left(\mathrm{k}_{\mathrm{i}}\right)$ pelas suas respectivas participações no investimento total no projeto e assim apurando o custo de capital total, pela tradicional equação do

$\mathrm{WACC}=\left(K_{e} \cdot \frac{E}{D+E}+K_{i} \cdot \frac{D}{D+E} \cdot(1-t)\right)$.

Ressalta-se ainda que em função dos contratos de PPPs sempre realizados com prazo determinado, o presente estudo não adota taxas em perpetuidade, como ocorre em avaliações tradicionais de projetos.

Para a taxa livre de risco, foram considerados títulos de dívidas governamentais. Assim, para o presente estudo, optou-se pela utilização da taxa de juros tendo com base os títulos governamentais indexados ao Índice de Preço ao Consumidor Amplo (IPCA), ou seja, as notas do Tesouro Nacional - série B (NTN-B), uma vez que estes títulos são os que apresentam maior liquidez entre os negociados no Brasil.

A rentabilidade média encontrada em termos reais para a NTN-B foi de 6,8\% (seis vírgula oito por cento) ao ano. Essa taxa foi obtida considerando a média do período de 2005 a 2015, por este ser um período considerado suficientemente longo onde se consegue intercalar cenários de crise e de estabilidade no mercado brasileiro. Essa análise é amplamente utilizada pelo mercado para avaliação de custo de capital por se entender que o período oferece confiabilidade sobre as nuances internas do mercado. 
Além disso, é necessário estimar o prêmio de risco de mercado, que foi calculado pela média histórica da diferença dos retornos entre um índice de ações em relação a um ativo livre de risco. No Brasil, o benchmark mais utilizado é o Índice da BM\&FBovespa, por ser o mais representativo do mercado de renda variável, portanto, frequentemente usado para avaliar o desempenho de ações e fundos de ações. Com relação à taxa livre de risco, utilizou-se a série de retornos dos títulos de dívida do governo brasileiro (NTN-B). Assim, o prêmio de risco de mercado foi calculado em 4,33\% ao ano, utilizando o período compreendido entre 2005 e 2015.

O beta foi calculado utilizando a base de dados da plataforma online Bloomberg, no qual foram extraídas séries históricas de todas as empresas do setor de infraestrutura no Brasil para período de 2005 e 2015. Inicialmente, foi extraída uma amostra de três empresas que tiveram movimentação (compra e venda) no período considerado.

Para o cálculo do beta da empresa foi utilizado o método de regressão linear simples, onde os retornos das ações foram regredidos contra retornos do índice Bovespa. Em seguida, os betas foram desalavancados e posteriormente realavancados pela estrutura de capital alvo, descontada a alíquota de 34\% (trinta e quatro por cento) de imposto incidente sobre o seu lucro (IR e CSLL).

A estrutura de capital para o projeto foi definida com base na composição de $70 \%$ (setenta por cento) de capital de terceiros e 30\% (trinta por cento) de capital próprio. Este nível de alavancagem financeira foi identificado como um patamar adequado aos parâmetros do projeto em questão e em linha com os projetos de infraestrutura financiados pelo Banco Nacional de Desenvolvimento Econômico e Social (BNDES), possivelmente, uma das fontes de financiamento do projeto. Esta estrutura de alavancagem foi considerada ao longo do período de avaliação do projeto, tendo em vista um nível ótimo de endividamento a ser mantido. Estes percentuais poderão ser futuramente alterados em função do detalhamento da estrutura ótima de capital requerida por seus investidores.

O beta do setor foi calculado pela média dos betas individuais pela participação nos ativos totais da amostra. O beta alavancado do setor, calculado no período de 2005 a 2015, foi de 0,83 , tendo por base o Ibovespa. Pela equação do CAPM, substituídos os valores encontrados, chega-se a um custo de capital próprio de 10,39\% ao ano. 
Em função deste estudo estar relacionado a um projeto de elevado investimento em infraestrutura, entende-se que haveria a possibilidade de obter linhas de financiamento junto ao Banco Nacional de Desenvolvimento Econômico e Social (BNDES).

No caso do BNDES, a taxa de juros para apoio direto (soma do custo financeiro + Remuneração básica do BNDES + Taxa de risco de crédito), a projetos de infraestrutura totaliza 9,48\% (nove vírgula quarenta e oito por cento) ao ano em termos nominais (TJLP $+4,48 \%$ ao ano), sendo a TJLP de 5\% (cinco por cento) ao ano, conforme obtido no website do BNDES (2016) pelo link: http://www.bndes.gov.br/SiteBNDES/bndes/bndes_pt/Ferramentas_e_Normas/Cu stos_Financeiros/Taxa_de_Juros_de_Longo_Prazo_TJLP/. Dado que todos os valores do modelo financeiro estão sendo considerados livres de inflação, cabe ainda descontar a taxa obtida pela inflação esperada, chegando a 3,28\% (três vírgula vinte e oito por cento) ao ano.

Ao considerar o custo de capital próprio atrelado ao custo de oportunidade do acionista e o custo da dívida atrelado ao percentual de endividamento com benefício fiscal, chega-se a um custo de capital ponderado de 9,15\% ao ano.

As condições de financiamento e, consequentemente, de amortização tomaram como base informações obtidas junto ao BNDES. Sendo assim, estimase que as parcelas de financiamento sejam liberadas conforme a conclusão das Etapas de implantação, a partir do ano subsequente ao aporte de garantias do governo. Considerando ainda uma carência mínima de 2 (dois) anos de amortização para cada parcela a ser liberada, sendo observado somente o pagamento de juros durante este período. Dessa forma, o fluxo de amortização foi adequado ao fluxo operacional do projeto. A amortização de cada parcela de investimento a ser liberada pelo banco passará a ser contada após o término do período de carência e a concessionária terá prazo máximo de 10 (dez) anos para sua quitação. 


\subsection{2.}

\section{Resultados do Modelo Base}

Para a análise do modelo base, assume-se que os dados utilizados para a análise de viabilidade, são parte integrante de estudos preliminares do projeto em análise. A Tabela 8 apresenta a análise preliminar sobre viabilidade financeira do projeto.

\section{Tabela 8 - Análise Preliminar Viabilidade do Projeto}

\begin{tabular}{lc}
\hline \multicolumn{1}{c}{ Indicadores } & $\begin{array}{c}\text { Valores } \\
\text { (milhões R\$) }\end{array}$ \\
\hline Valor esperado do projeto na data zero $\left(V P_{0}\right)$ & 2.652 \\
Investimento $(I)$ & 2.658 \\
Valor presente líquido $(V P L)$ & $(5,4)$ \\
Custo de Capital (WACC) & $9,15 \%$ \\
\hline
\end{tabular}

Fonte: elaboração própria

Ao analisar os resultados na Tabela 8, é possível observar que ao adotar as premissas observadas, o projeto não seria viável financeiramente, pela simples análise do VPL. Apenas esse resultado já cria a percepção de que o projeto apresenta riscos que vão além do que se poderia entender por suportável pelos investidores privados, para a realização do investimento.

Para viabilizar o projeto, uma alternativa seria via aumento de pedágios. Essa solução seria provavelmente inviabilizada pelo governo, em função de análises comparativas de custo de pedágio por km. Haveria também um efeito de elasticidade da demanda, fazendo com que um aumento do pedágio não necessariamente aumentasse a receita total.

Uma alternativa para mitigar riscos para o privado e minimizar efeitos indesejados de custos e nível de serviço à população, seria o governo garantir uma demanda mínima e consequentemente uma receita mínima esperada do projeto ao concessionário, como indicado por diferentes autores em trabalhos reunidos e mencionados no referencial teórico do presente estudo.

O que não se mostra tão trivial é endereçar a questão, sem novamente recair em custos elevados ao governo e à população, ou até mesmo soluções que 
determinem níveis de garantia do governo demasiadamente elevados e fora da realidade de estruturação de projetos por PPPs em países subdesenvolvidos como o Brasil. Dessa forma, para definir o mínimo de receita a ser garantida é necessário estruturar algumas condições de contorno, atendo-se ainda aos níveis de garantia atualmente ofertados pelo governo em edital e licitações.

Pela lógica de cobertura da garantia, a receita realizada abaixo de um nível mínimo estipulado, deverá ser parcialmente complementada pelo governo para que seja atingido um nível mínimo de receita ao concessionário. No entanto, esse nível mínimo deve ser suficiente para que o concessionário tenha interesse em manter os níveis de investimento e níveis de serviço, mitigando seus riscos, mas também que seja o mínimo custo esperado para o governo.

\section{2.}

\section{O Modelo com Flexibilidades}

O modelo estocástico partiu da análise da principal variável de incerteza do projeto que foi definida, no presente estudo, como a demanda de tráfego. Primeiramente, coube a análise do tráfego projetado de forma determinística (linha crescente em destaque na figura 10). Ao se observar esta série projetada da demanda, extraiu-se o retorno médio $(\alpha)$ de $2,58 \%$ para o projeto e taxas de crescimento período a período $(\mu)$.

Considerando que esse crescimento ao longo do tempo poderá ser impactado por significativa volatilidade do PIB da região em que encontra-se a rodovia, considerou-se inicialmente como premissa de volatilidade o próprio PIB regional $(\sigma)$, que nos últimos dez anos esteve em 8,7\%, ao extrair a volatilidade pelo log retorno do PIB regional. A partir desses parâmetros iniciais, projetou-se uma série de dados com o tráfego $S_{t+1}=S_{t} e^{\left(\mu-\frac{\sigma^{2}}{2}\right) \Delta t+\sigma \varepsilon \sqrt{\Delta t}}$, variando estocasticamente por um processo geométrico browniano.

Assumiu-se que no primeiro ano de projeção de demanda poderá haver grande variabilidade, a qual intuitivamente assemelha-se a uma distribuição triangular dos retornos, assumida como simétrica, podendo variar em até $20 \%$ do projetado, como observado em Brandão et al. (2012). 
Importante lembrar que mesmo adotando esta premissa de volatilidade para a projeção do tráfego, para fins do cálculo das flexibilidades do projeto, utilizouse o método BDH para o cálculo da volatilidade do projeto.

O passo seguinte foi obter o prêmio de risco do projeto, cujo cálculo foi detalhado na seção metodológica do presente estudo. A série de tráfego estocástica que foi gerada a partir da taxa de crescimento e volatilidade é utilizada para ser multiplicada pela tarifa já pré-definida e gerar ao final, um fluxo de caixa estocástico do projeto. Ao se analisar o componente randômico da variável de incerteza, observa-se que a série de tráfego apresenta um comportamento diferente da série determinística projetada, em decorrência do prêmio de risco a ela incorporado. Para que se possa calcular o valor do projeto com flexibilidades, é necessário extrair o prêmio de risco do fluxo de caixa estocástico do projeto, chegando-se a uma série simulada neutra a risco. A taxa encontrada é, portanto uma taxa penalizada pelo prêmio de risco, que será utilizada para o cálculo do valor do projeto com flexibilidades. A projeção neutra a risco, assim como a estocástica ajustada a risco pode ser observada pela Figura 12 a seguir.

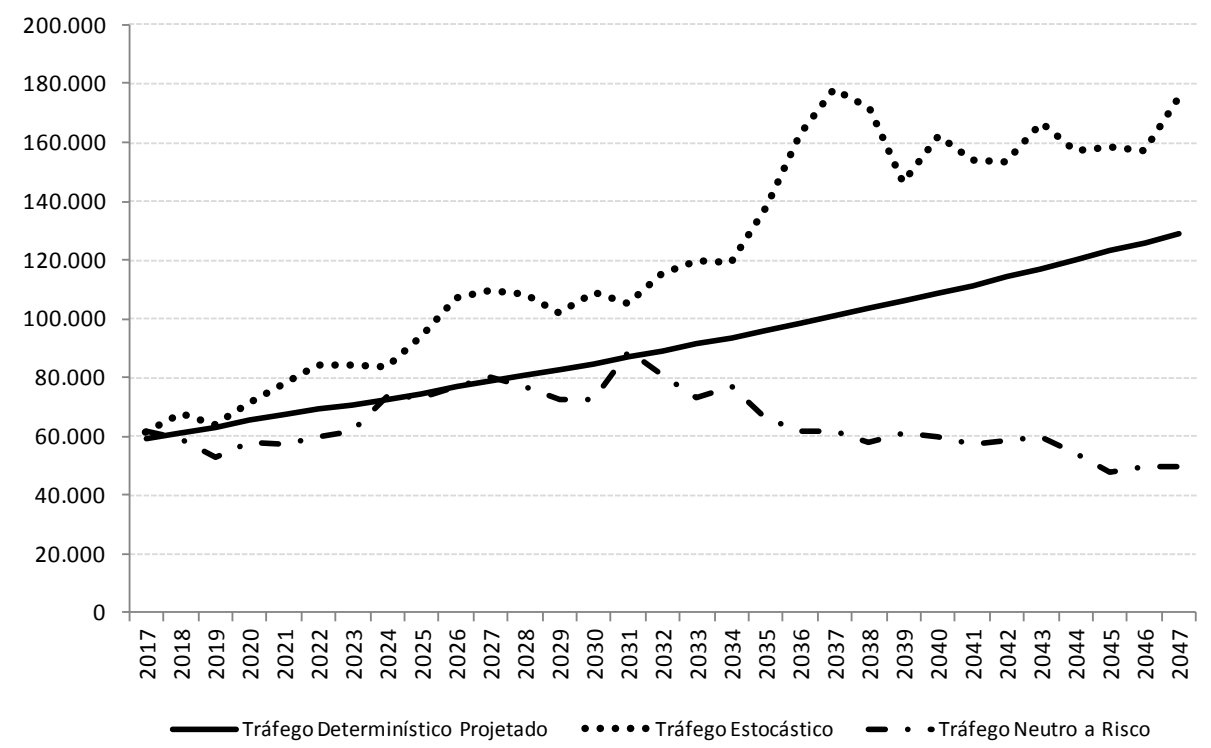

\section{Figura 12 - Análise da demanda}

Fonte: elaboração própria

Uma vez analisada a principal variável de incerteza do modelo e obtidos os parâmetros que permitiram realizar as projeções, volta-se a atenção em estruturar 
as premissas básicas do modelo pelo fluxo de caixa descontado, para somente em seguida avaliar o projeto com flexibilidades.

\subsection{1.}

\section{Análise do Modelo Estocástico}

A partir das premissas já expostas e dos resultados do modelo determinístico, a metodologia aqui proposta para as etapas 2 a 6 do modelo para mitigar riscos para o governo e manter a atratividade ao empreendedor são a seguir apresentados. Na Tabela 7 foram apresentados alguns parâmetros e premissas que foram estimados para o presente estudo.

Tais parâmetros serviram para a estruturação dos fluxos de caixa do projeto utilizados como base para as simulações realizadas. Após rodar uma simulação com 50.000 iterações para o modelo sem flexibilidades, foi possível obter o resultado da figura 13. Pode-se observar que há uma probabilidade de 55,8\% de que o VPL do projeto seja negativo. A diferença entre o melhor e o pior resultado é de R \$ 6,41 bilhões, sendo o valor médio do VPL simulado de R \$ -5,9 milhões e, portanto muito próximo do valor determinístico de $\mathrm{R}$ \$ -5,4 milhões, calculado anteriormente.

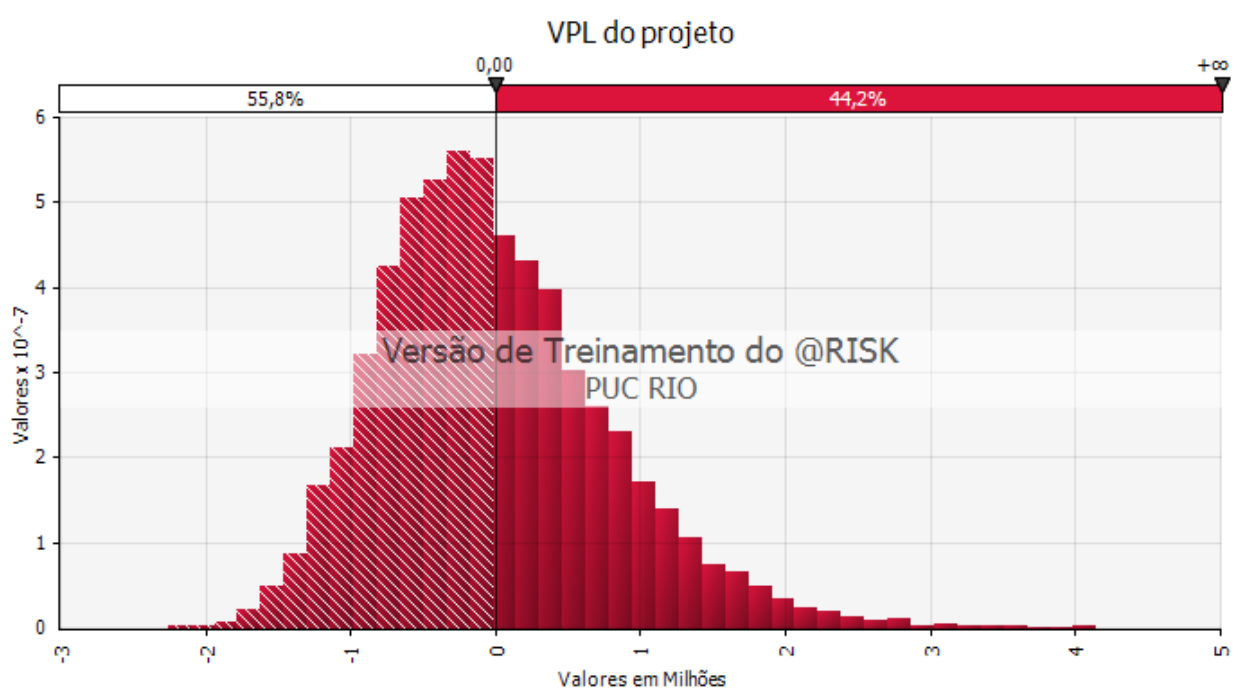

\section{Figura 13 - VPL do projeto sem opções}

Fonte: elaboração própria a partir do software @Risk.

Para o cálculo do valor presente (VP) do projeto com flexibilidade, partiu-se do modelo neutro a risco. As flexibilidades primeiramente avaliadas, conforme 
etapa 2 do modelo proposto, estão relacionadas ao exercício da garantia (put) pelo concessionário e ao compartilhamento de receita pelo governo (call), que resultam no mecanismo de opções collar.

Para tanto, considera-se que a demanda segue um processo estocástico do tipo geométrico browniano (MGB) e que as flexibilidades são apreçadas por simulação de Monte Carlo. A cada rodada, são realizadas 50.000 simulações que geram distribuições de probabilidade do valor presente do projeto com flexibilidades, a cada diferente cenário de máximo de orçamento disponível (cap).

A partir da análise de diferentes níveis de caps para as garantias, foram avaliados também, os níveis de risco do projeto. A Tabela 9 demonstra o nível de risco do projeto simulado utilizando a garantia juntamente com o compartilhamento de receita com o governo (opção collar), mas nesse momento ainda sem um limite de orçamento (cap).

Ressalta-se que a determinação da combinação entre o nível garantia e o limite máximo de orçamento previsto pelo governo para disponibilizar a garantia são observados em conjunto com as métricas de risco VaR, CVaR e Ômega, primeiramente considerando o valor em risco pela ótica do fluxo de caixa do concessionário.

Ao incluir as opções (collar), observa-se um significativo aumento do valor presente (VP) do projeto, na hipótese de viabilizar o collar sem nenhum tipo de limite (cap) a ser imposto pelo governo. O anterior VP que foi calculado em R\$ 2,652 bilhões, passa a ser de R 2,885 bilhões para o projeto com collar sem cap. 


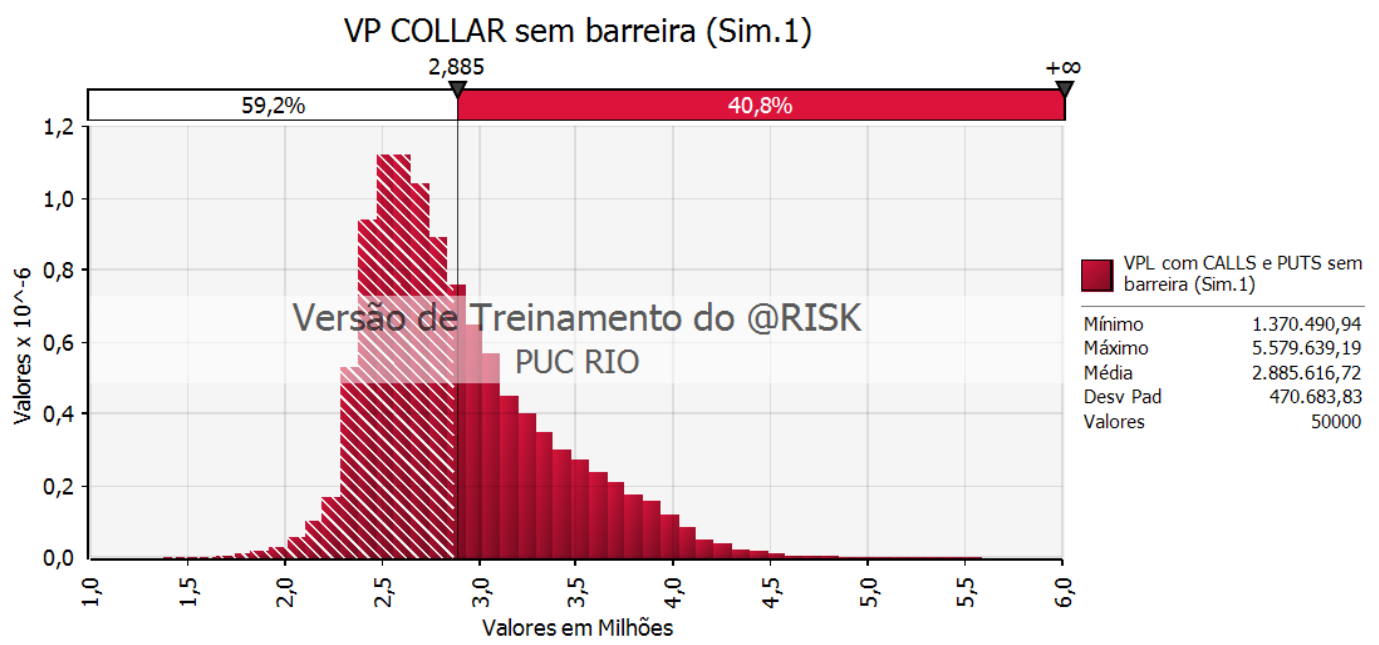

Figura 14 - VP com collar sem cap

Fonte: Elaboração a partir do software @Risk

Do anterior VPL de R\$ -5,4 milhões, observado na tabela 5, o projeto passaria a ter um VPL positivo de R 233 milhões, conforme figura 16 a seguir. A probabilidade do projeto ter um valor presente negativo, cairia de 55,8 para 38,6\% com o projeto simulado com opções collar. Esse resultado, também pode ser interpretado como o governo assumindo o diferencial de risco do concessionário.

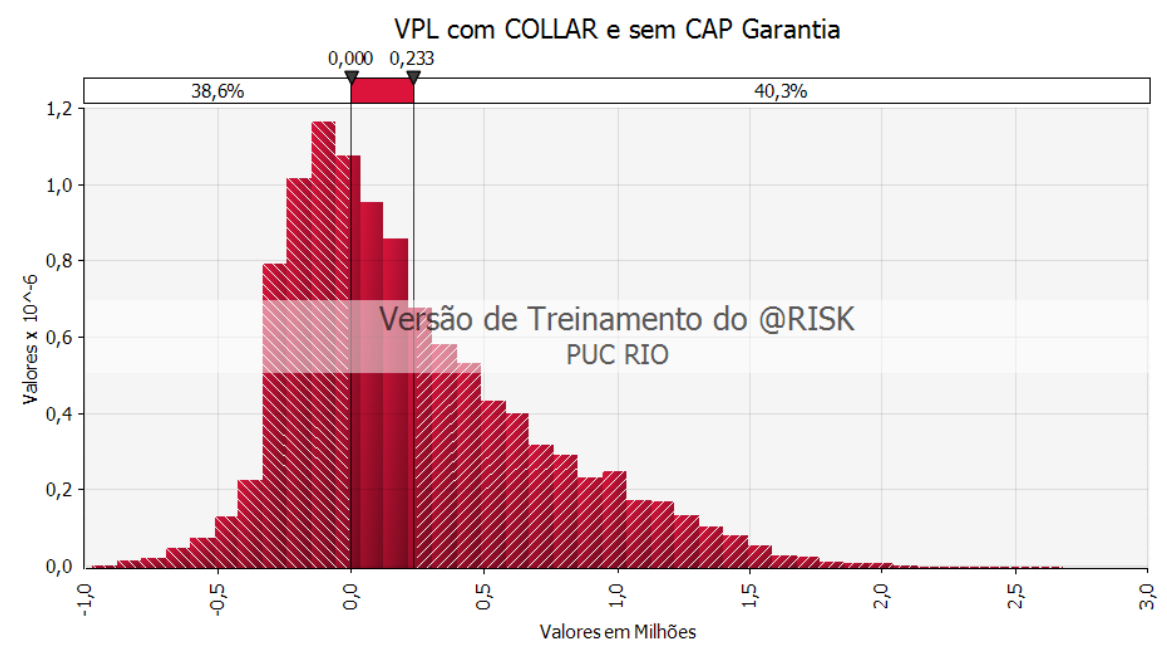

\section{Figura 15 - VPL com collar sem cap}

Fonte: Elaboração a partir do software @Risk

Sobre a distribuição de probabilidade do valor presente $(V P)$ do projeto, calcula-se o nível de risco apontado pelas medidas VaR, CVaR e Ômega, conforme observado na tabela 9 a seguir. 
Tabela 9 - Risco do projeto com garantia e sem cap (R\$ milhões)

\begin{tabular}{|c|c|c|c|}
\hline \multicolumn{4}{|c|}{ VP Projeto sem e com Opções } \\
\hline & \multirow{2}{*}{ VP Estático } & $\begin{array}{c}\text { VP Simulação } \\
\text { Neutra a Risco }\end{array}$ & $\begin{array}{c}\text { VP com } \\
\text { COLLAR sem } \\
\text { CAP }\end{array}$ \\
\hline VP Médio & $2.652,45$ & $2.645,30$ & $\mathbf{2 . 8 8 5 , 6}$ \\
Desv Pad & & 480,9 & $\mathbf{4 7 0 , 6}$ \\
Prob VPL $<0$ & & $58,60 \%$ & $\mathbf{3 8 , 6 \%}$ \\
VAR (R\$ MM) & & & $\mathbf{1 . 1 6 9 , 7}$ \\
CVAR (R\$MM) & & & $\mathbf{1 . 4 0 1 , 5}$ \\
Ômega & & & $\mathbf{1 , 1 5}$ \\
\hline
\end{tabular}

Tendo em vista a realidade fiscal e orçamentária de países em desenvolvimento como o Brasil, é razoável supor que tal proposição de garantia governamental apresente-se como inviável ainda que reduza significativamente o risco do valor presente líquido do projeto ser negativo.

Na aplicação da metodologia proposta, a inclusão de caps para as garantias foi realizada, a partir do que atualmente se adota em projetos típicos no Brasil, como padrão de garantias contratuais, as quais determinam um limite governamental de $10 \%$ do valor dos dispêndios de capital (Capex) do projeto. Tendo em vista que a adoção deste percentual não apresenta fundamentação entre os editais e contratos analisados, buscou-se no presente estudo avaliar cenários para aplicação dos percentuais (Tabela 10), considerando a mesma premissa de avaliar o cap a partir do volume de dispêndios de capital do projeto para cálculo dos possíveis níveis de caps.

Tabela 10 - Cenários para liberação de garantias

\begin{tabular}{|l|c|c|c|c|c|}
\hline Cenários de Garantia & $\mathbf{1}$ & $\mathbf{2}$ & $\mathbf{3}$ & $\mathbf{4}$ & $\mathbf{5}$ \\
\hline $\begin{array}{l}\text { \% CAP aplicado sobre } \\
\text { o CAPEX }\end{array}$ & & $5 \%$ & $10 \%$ & $15 \%$ & $20 \%$ \\
\hline $\begin{array}{l}\text { Limite da Garantia - } \\
\text { CAP (R\$ milhões) }\end{array}$ & $2.657,8$ & 132,9 & 265,8 & 398,7 & 531,6 \\
\hline
\end{tabular}

Dado que o mínimo de cobertura de garantias já é estipulado pelas faixas de garantia, o governo fica responsável por cobrir entre 60\% e 90\% da demanda não realizada. A metodologia aqui proposta busca inicialmente observar o nível de compensação que fornecerá o menor nível de risco para o concessionário, medido 
pelas métricas VaR, CVaR e Ômega, que poderiam trazer informações relevantes para a tomada de decisão pelo governo, em termos de nível de garantia a ser ofertado.

Para estas configurações e considerando os parâmetros definidos, pela Tabela 11 pode-se perceber que o risco do projeto determinado pelas métricas de risco e pela probabilidade de trazer resultados negativos pode ser considerado demasiadamente alto, tendo ainda em vista que o concessionário compartilha upsides de receita com o governo (call). Apenas no primeiro cenário, no qual entende-se que não seria factível a entrada do governo é que a probabilidade de resultados negativos seria em aproximadamente 38,6\%. Para os demais cenários, a probabilidade de perdas pode se reduzir de $52 \%$ para $46 \%$, associada a pouca variação do valor em risco do projeto, por mais que o VP tenha se elevado consideravelmente com as opções. Observando os cenários de garantia com cap e os resultados obtidos, para as medidas $\mathrm{VaR}$ e $\mathrm{CVaR}$ fica claro que o melhor resultado para o concessionário seria o governo ofertar garantias ao limite máximo estipulado, que neste caso seria $20 \%$ do Capex como cap. O mesmo se observa para a medida Ômega, sem considerar é claro, que o melhor resultado para o privado seria não haver cap algum de garantia pelo governo.

\section{Tabela 11 - Análise de resultados do projeto}

\begin{tabular}{|l|c|c|c|c|c|}
\hline Cenários para o Acionista & $\mathbf{1}$ & $\mathbf{2}$ & $\mathbf{3}$ & $\mathbf{4}$ & $\mathbf{5}$ \\
\hline \% CAP aplicado sobre o CAPEX & & $5 \%$ & $10 \%$ & $15 \%$ & $\mathbf{2 0 \%}$ \\
\hline VP do Projeto (R\$ milhões) & $2.885,6$ & $2.664,8$ & $2.678,8$ & $2.708,3$ & $\mathbf{2 . 7 3 3 , 6}$ \\
\hline VPL com garantia (R\$ milhões) & 227,8 & 7,0 & 20,9 & 50,5 & $\mathbf{7 5 , 8}$ \\
\hline Prob (VPL < 0) & $39 \%$ & $52 \%$ & $52 \%$ & $52 \%$ & $\mathbf{5 1 \%}$ \\
\hline VaR (R\$ milhões) & $1.169,7$ & $1.179,2$ & $1.175,4$ & $1.170,1$ & $\mathbf{1 . 1 6 9 , 6}$ \\
\hline CVaR (R\$ milhões) & $1.401,5$ & $1.411,0$ & $1.419,2$ & $1.409,1$ & $\mathbf{1 . 4 0 8 , 2}$ \\
\hline Ômega & 1,150 & 0,997 & 0,998 & 1,003 & $\mathbf{1 , 0 0 6}$ \\
\hline
\end{tabular}

As distribuições de probabilidade referentes as simulações realizadas, que foram utilizadas para a análise das medidas de risco, podem ser observadas na figura 16. 

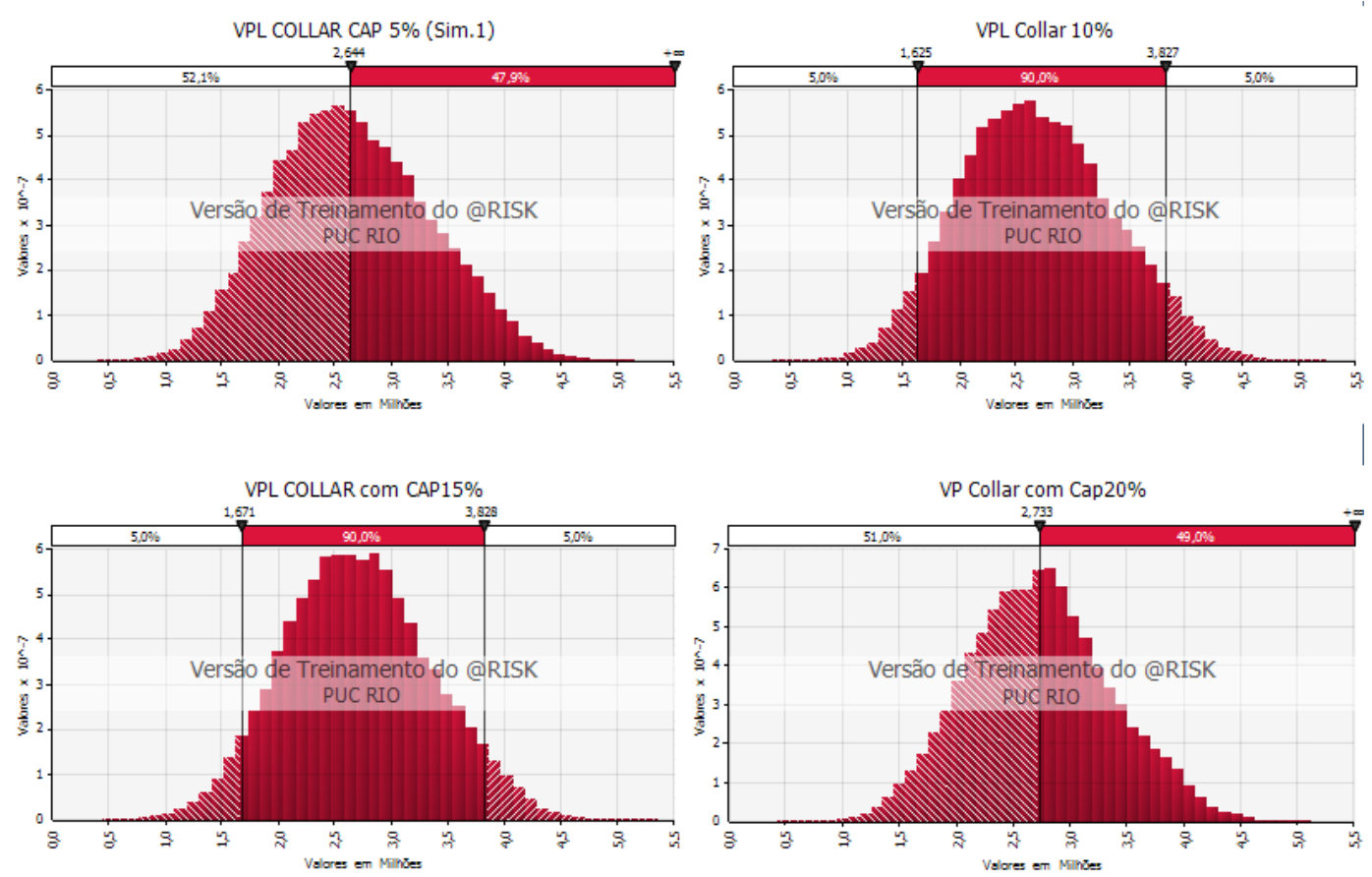

Figura 16 - Distribuições de probabilidade do VPL com diferentes níveis de collar

Fonte: Elaboração a partir do software @Risk

\subsection{2.}

\section{Níveis de Garantia pela Ótica do Governo}

Pelo modelo proposto, o governo fica vendido nas puts e, caso o tráfego seja inferior ao do cenário projetado, as opções serão acionadas e o governo terá desembolsos anuais. O valor presente desses desembolsos corresponde a função $f(\phi, \Pi)$, razão pela qual as medidas de risco para o governo podem ser medidas pelo VaR, CVaR e Ômega das simulações de Monte Carlo, sendo aqui realizadas 50.000 iterações, para gerar essa função. O VaR(95\%) é dado pelo valor do percentil 95 dessa distribuição. O CVaR será a média dos 20.000 •0,05 =1.000 valores acima do percentil 95.

A partir da distribuição de probabilidade acumulada para os diferentes cenários de garantia estipulados, foram calculadas as medidas VaR, CVaR e Ômega. Pelos resultados da simulação, estima-se que em média há uma probabilidade $62 \%$ do valor esperado da garantia ofertada superar o valor médio da simulação. Sendo assim, pela ótica do governo, cabe certo conservadorismo ao 
ofertar tanto por prazo, quanto o valor da garantia, uma vez que este valor possui significativa probabilidade de exceder o esperado.
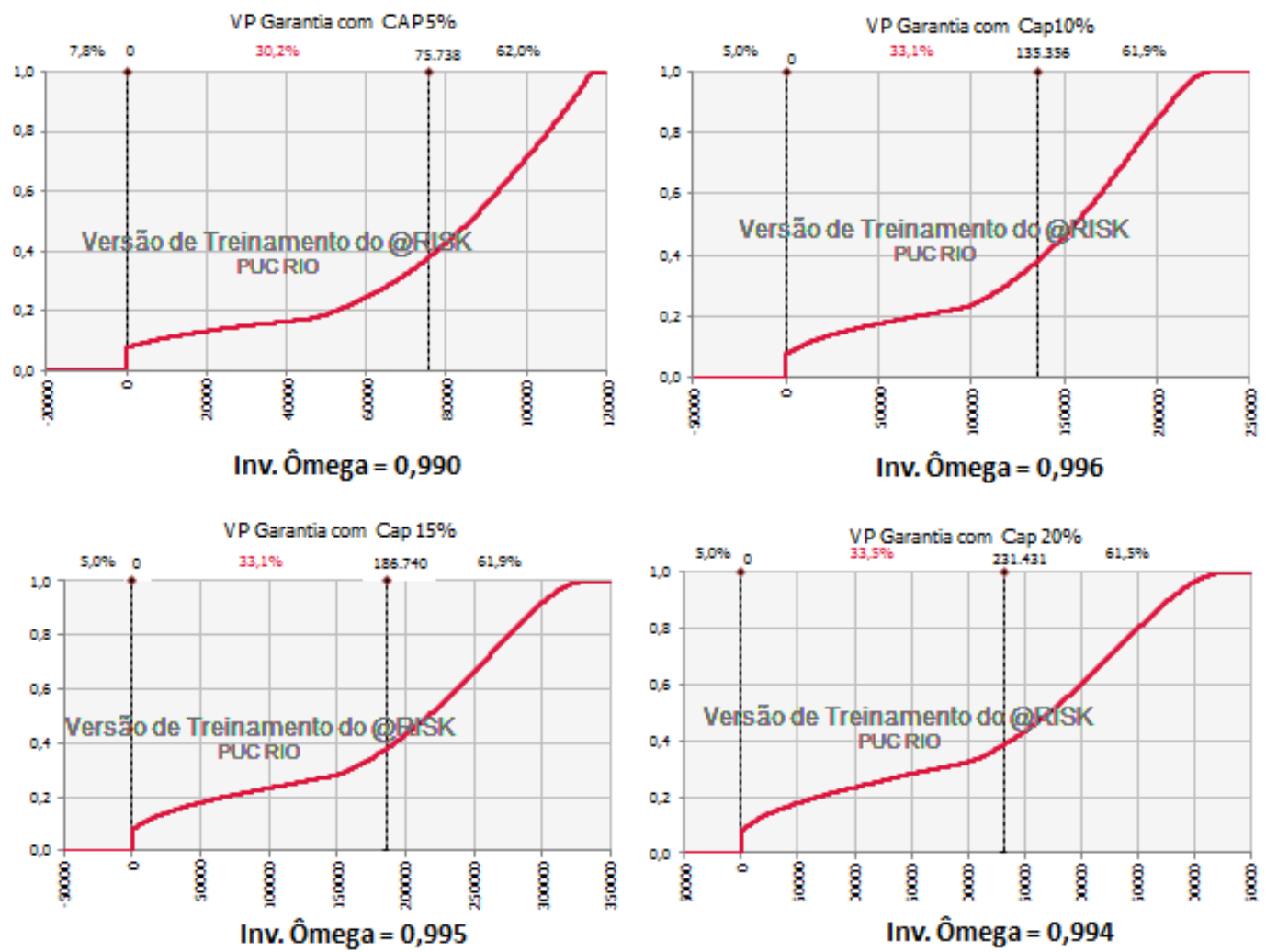

Figura 17 - Distribuição de probabilidade acumulada para cada cenário de garantia com CAP

Fonte: Elaboração a partir do software @Risk

Ao analisar os resultados dos cenários simulados, apresentados na Figura 17 e avaliando ainda os resultados da tabela 12, entende-se que a garantia poderia ser concedida para um cap de $10 \%$, sobretudo tendo como foco o cenário de maior valor para a medida Ômega, que permite com maior acuracidade limitar os riscos do governo, quando comparada as medidas VaR e CVaR. 
Tabela 12 - Condições simuladas para a garantia por nível de cap

\begin{tabular}{|l|c|c|c|c|c|}
\hline $\begin{array}{l}\text { Cenários da Garantia para o } \\
\text { Governo }\end{array}$ & $\mathbf{1}$ & $\mathbf{2}$ & $\mathbf{3}$ & $\mathbf{4}$ & $\mathbf{5}$ \\
\hline \% CAP aplicado sobre o CAPEX & & $5 \%$ & $\mathbf{1 0 \%}$ & $15 \%$ & $20 \%$ \\
\hline Limite da Garantia - CAP (R\$ milhões) & $2.657,8$ & 132,9 & $\mathbf{2 6 5 , 8}$ & 398,7 & 531,6 \\
\hline Valor Esperado para PUT (R\$ milhões) & & 75,7 & $\mathbf{1 3 5 , 4}$ & 186,7 & 231,4 \\
\hline VaR (R\$ milhões) & $1.345,1$ & $1.273,5$ & $1.281,2$ & $1.287,1$ & $1.345,1$ \\
\hline CVaR (R\$ milhões) & $1.611,7$ & $1.523,9$ & $1.546,9$ & $1.550,0$ & $1.619,4$ \\
\hline Prazo estimado de vigência (em anos) & 15,8 & 6,5 & $\mathbf{9 , 2}$ & 11,1 & 12,6 \\
\hline Ômega para o Governo & & 0,990 & $\mathbf{0 , 9 9 6}$ & 0,995 & 0,994 \\
\hline
\end{tabular}

Ao avaliar o projeto somente pela ótica do governo, deve-se analisar o quanto de risco e custos poderão ser suportados na forma de cumprimento da garantia (put) ao longo do tempo. Seguindo a mesma lógica do VP com opções para o concessionário, para cada nível de cap e a cada simulação permitiu-se obter prazos de concessão da garantia compatíveis com a restrição de orçamento do governo para o exercício da put ao longo do tempo. As restrições orçamentárias são tratadas por valor total e por prazo em uma proposição na qual se assemelha muito a um orçamento de capital.

Ao considerar os possíveis níveis de garantia a serem ofertados pelo governo, cabem observar os resultados obtidos principalmente para a medida Ômega, com o objetivo de simular o menor risco do governo para cada nível de garantia e cap proposto. A aplicação da medida Ômega às distribuições de probabilidade acumulada, conforme proposto na metodologia do presente estudo, permite avaliar pela ótica do governo o nível máximo de garantia a ser ofertada, ao se observar todos os momentos da distribuição de probabilidade e considerando a razão entre a distribuição de valores abaixo dos limites estipulados e os valores que encontram-se acima destes limites. Tendo em vista que a decisão para liberação da garantia caberá ao governo, o resultado de 0,996 obtido para a medida Ômega com a garantia de 10\% do Capex como cap, ainda que demonstre ser de difícil comparação em função de variar pouco em relação aos demais cenários, contribui para explicar os atuais limites observados em contratos de PPPs, também estipulados muitas vezes para este patamar. 
É importante observar, no entanto, que a pouca diferença relativa apresentada pelos resultados da medida Ômega, poderia dificultar a tomada de decisão pelo governo. Além disso, esta configuração não se ajusta exatamente com os melhores resultados obtidos pelo VaR e CVaR.

Sendo assim, entende-se que é necessário buscar alternativas que permitam contornar situações como aqui apresentadas, na qual não se obtém conclusões tão assertivas para a mitigação de gastos governamentais, alinhadas às expectativas de retornos máximos requeridos pela iniciativa privada. Tal problemática se assemelha às limitações observadas pelos resultados encontrados em Moreira (2010) e Monteiro (2014).

Para tomada de decisão em situações como a aqui observada, propõe-se que sejam reavaliadas as flexibilidades contratuais embutidas no projeto. Para tanto, propõe-se avaliar a flexibilidade de expansão da capacidade da infraestrutura, de forma simultânea a proposta do governo em ofertar a garantia com cap de 10\% do CAPEX.

\subsection{3.}

\section{O Modelo com Opção de Expansão}

A demanda projetada em estudos prévios de projetos típicos de infraestrutura rodoviária é comumente entendida como linear e crescente para todo o prazo de concessão. O mesmo se verifica para a projeção simulada para o presente estudo, no qual se observa que para atender tal demanda, a capacidade da rodovia precisaria se elevar para atender a um incremento de $50 \%$ no ano 10 do contrato.

Tal perspectiva leva a consideração de que é indispensável realizar investimentos em aumento de capacidade (opção de expansão) ao longo do tempo, na medida em que cenários se revelem de fato favoráveis. O apreçamento de tal flexibilidade torna-se não só relevante para ampliar o valor do projeto, como também reduzir o risco do mesmo. Essa alternativa foi justamente a lacuna na literatura apontada por Blank et al. (2016) como relevante para novos estudos, no qual apreçaram a opção de abandono em concessões de infraestrutura.

Neste caso, propõe-se o apreçamento do valor da flexibilidade de expandir a capacidade a qualquer instante (call americana), tendo como prêmio o resultado 
os fluxos de caixa incrementais futuros, mas agora sem a proposição das opções collar para fins contratuais. Cabe, por outro lado manter o mecanismo de garantia contratual (put europeia) de cumprimento de demanda ao concessionário, como mecanismo de redução de riscos relevante para o projeto, mas sendo agora avaliado para um nível de cap de 10\% do CAPEX.

Tendo como objetivo otimizar o processo de tomada de decisão gerencial, foi utilizada a modelagem discreta através de árvore binomial com abordagem neutra a risco, que de maneira mais intuitiva contribui para o apreçamento da call americana de expansão e sua interação com a put europeia da garantia, checandose em cada nó a decisão gerencial ótima.

O cálculo é realizado inicialmente ao simular o que aconteceria se o risco fosse eliminado em todos os nós de decisão e faz com que o valor presente (VP) seja sempre o mesmo daquele obtido pela árvore binomial com risco. Assume-se o resultado neutro de risco e a solução do problema através de probabilidades neutras ao risco, como propostas por Cox, Ross e Rubinstein (1979).

Neste caso, a dinâmica da demanda continua a seguir um Movimento Geométrico Browniano (MGB) e o mesmo se verifica para os fluxos de caixa do projeto. Dessa forma pode-se assumir que o $V P_{t}$ obedecerá a expressão diferencial: $d V P_{t}=\mu V P_{t} d t+\sigma V P_{t} d z$, na qual $d z$ é o incremento padrão de Wiener.

Parte-se no instante inicial do valor do caso base do projeto: $V P_{0}=-5,4 R \$$ milhões, com a volatilidade do projeto $(\sigma)$ como sendo de $9,35 \%$, já calculada anteriormente pelo método $\mathrm{BDH}$, aplicando-se os multiplicadores de subida $u=e^{(\sigma \sqrt{\Delta t})}=1,098$, e descida $d=\frac{1}{u}=0,9107$. Assumindo uma taxa de juros neutra de risco (r) de 5,93\%\% em termos reais, calcula-se a probabilidade neutra ao risco da ocorrência de um movimento de subida na árvore, como sendo $p=\frac{1+r-d}{u-d}=0,7927$.

Considera-se que não existe custo de carregar a opção, ou seja, o não exercício do investimento numa data $t$ não implica em nenhum fluxo de caixa negativo. Porém, para viabilizar a obtenção de fluxos de caixa incrementais, os acionistas deverão investir R \$ 851,2 milhões.

A árvore foi estruturada em 20 períodos, sendo todos ajustados à mesma

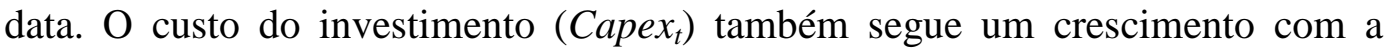


mesma tendência esperada que o $V P_{t}$, porém determinístico. Sendo a concessionária indiferente quanto a data de exercício da opção, pode-se calcular o valor das opções acima, descontando a árvore de $V P_{t}$ desde a data $t=20$ até $\mathrm{t}=0$, exercendo as opções americanas e europeias que maximizam o valor da árvore em cada nó, entre o valor de exercício, o valor da continuidade (ponderação dos nós subsequentes pelas probabilidades neutras ao risco e descontadas pela taxa neutra a risco).

O cálculo da opção americana de investir na expansão para fins de incremento na capacidade foi modelado no DPL, mantendo o processo de simulação de Monte Carlo para fins de apreçamento da garantia conectado e sendo operacionalizado pelo software @Risk em planilha eletrônica. O concessionário tem a oportunidade recorrente de investir entre o $10^{\circ}$ e o $20^{\circ}$ período, e exercendo a garantia de demanda em cenários nos quais a mesma se verifique abaixo do previsto.

O valor presente (VP) do projeto considerando a opção de expandir a capacidade entre o $10^{\circ}$ e o $20^{\circ}$ período, foi calculado em $\mathrm{R} \$ 2,73$ bilhões, que comparado ao valor determinístico de $\mathrm{R}$ \$ 2.65 bilhões sem flexibilidade, representa um aumento de $\mathrm{R} \$ 73$ milhões ao valor do projeto no caso base. $\mathrm{O}$ valor das opções, em relação ao valor do projeto determinístico, pode ser observado pela figura 18 a seguir.

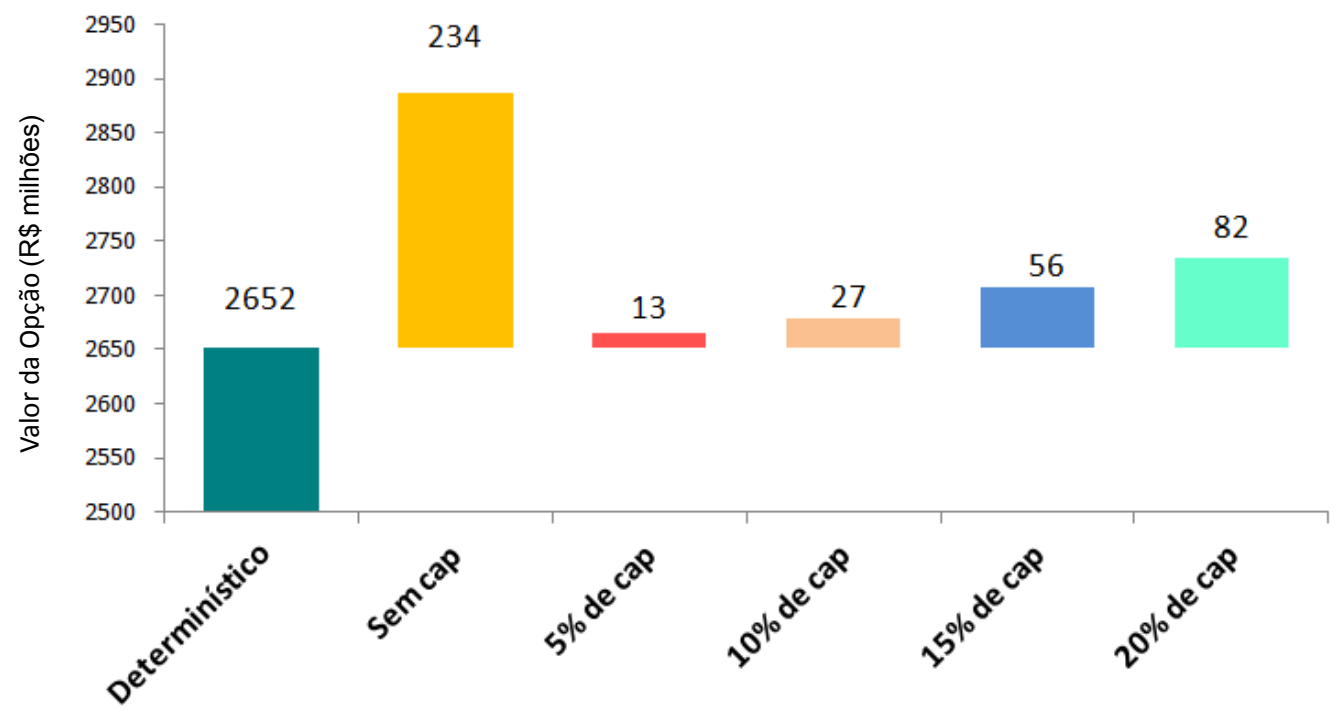

Figura 18 - Valor das opções para cada nível de cap de garantia. 
De forma complementar a análise do modelo com expansão de capacidade, a etapa 6 da metodologia proposta envolve realizar uma nova simulação com o modelo expandido para então reavaliar o risco do projeto, a partir da distribuição de probabilidade acumulada, com o modelo integrado: na presença da garantia de demanda (put europeia) e com a flexibilidade de expansão (call americana), como pode ser visto pela figura 19 .

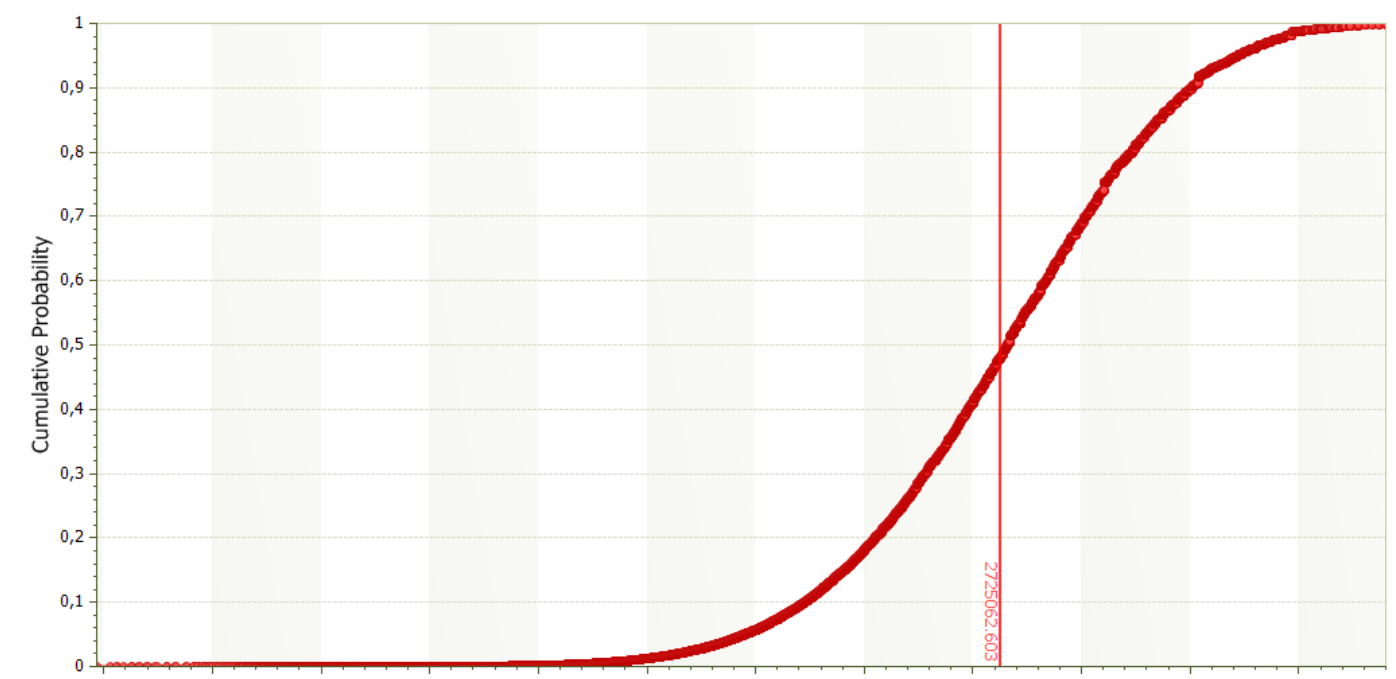

Figura 19 - Análise de risco do modelo integrado

Ao analisar a nova distribuição de probabilidade acumulada sobre o valor presente do projeto com a flexibilidade de expansão (call americana) e a garantia de demanda (put europeia) de 10\% do Capex, é possível perceber que o novo valor presente de R 2,73 bilhões, é superior ao valor determinístico de R 2,65 bilhões sem flexibilidade, como também supera o valor presente de R\$ 2,70 que seria obtido, caso o governo ofertasse uma garantia de 15\% do Capex, cuja medida Ômega foi calculada em 1,003.

Com o apreçamento dessas flexibilidades foi possível obter o valor de 3,33 para a medida Ômega, versus o valor anterior de 0,996, deixando claro o quanto a distribuição de probabilidade de ganhos, supera a distribuição de probabilidade de perdas do projeto com a flexibilidade de expansão integrada ao modelo com garantia. Ainda que o cap de garantia de $15 \%$ ou $10 \%$ não altere significativamente o valor da opção, a maior contribuição coube a redução de risco do projeto para o governo. 
Entende-se, portanto, diante dos resultados do presente estudo, que o governo pode continuar ofertando um nível reduzido de garantias (até 10\% do Capex), buscando mitigar riscos, mas desde que as flexibilidades contratuais sejam adequadamente mapeadas e apreçadas. Além disso, a medida Ômega para este tipo de avaliação de projetos, pode ser mostrar um instrumento bastante relevante para complementar o processo de tomada de decisão sob incerteza, de forma integrada à metodologia de opções reais. 


\section{Considerações Finais}

O modelo desenvolvido no presente estudo teve como principal contribuição, em relação aos modelos até então propostos, o estabelecimento do nível ótimo de garantia governamental a ser ofertada à iniciativa privada em uma concessão de rodovia por PPP, utilizando a teoria de opções reais de forma integrada à métrica de performance Ômega, a qual obteve melhor resposta entre demais métricas propostas. Além disso, outra contribuição do modelo se deu quanto ao apreçamento das opções do tipo collar europeia (calls e puts) com caps, integrado ao apreçamento da opção americana de expansão (call) do projeto.

O valor presente (VP) do projeto, considerando a opção de expandir a capacidade, foi calculado em $\mathrm{R}$ \$ 2,73 bilhões, que comparado ao valor determinístico de R\$2,65 bilhões sem flexibilidade, representa um aumento de R\$ 73 milhões ao valor do projeto no caso base. Ao analisar a nova distribuição de probabilidade acumulada sobre o valor presente do projeto com a flexibilidade de expansão (call americana) e com garantia de receita mínima (put europeia) com cap 10\% do Capex, é possível perceber que pode-se obter o valor de 3,33 para a medida Ômega, que é muito superior ao valor anterior de 0,996 com collar e superior a medida Ômega de 1,003 com cap de 15\% do Capex.

O processo de tomada de decisão pelo governo quanto ao nível ótimo de garantia a ser ofertada, entretanto, não se mostrou adequado ao utilizar as métricas de risco VaR e CVaR. Tendo em vista que a decisão para liberação da garantia cabe ao governo, conclui-se que as garantias poderiam ser ofertadas ao limite máximo 10\% do Capex como cap, que foi o maior resultado obtido para a medida Ômega, mas desde que sejam avaliadas outras flexibilidades contratuais que vão além do mecanismo de garantia de receita mínima, para que assim possam agregar valor ao projeto e mitigar riscos ao concessionário.

Outro aspecto relevante do modelo desenvolvido, está relacionado a integração da medida Ômega ao processo de tomada de decisão pela metodologia 
de opções reais, a partir do qual permite não só apreçar o valor das flexibilidades, como também servir como instrumento para avaliar valor em risco em projetos de investimento sob condições de incerteza, como observado em PPPs de infraestrutura.

O modelo desenvolvido tratou especificamente da modelagem de flexibilidades e análise de riscos em rodovias pedagiadas em PPPs do tipo patrocinadas. Assim, o modelo poderia não se adequar a outras modalidades de PPPs ou seguimentos cujos aportes governamentais de recursos estejam presentes. Importante ressaltar também que por simplificação, o modelo não contemplou custos de outorga crescentes para fins de projeção e nem mesmo possíveis variações ao longo do tempo.

Apesar dos esforços empenhados no presente estudo, entende-se como relevante para futuros estudos avaliar outras flexibilidades ainda não observadas em projetos de infraestrutura por PPPs, bem como modelar mais de uma variável de incerteza. Estudos futuros podem ainda avaliar a flexibilidade de extensão do prazo contratual integrada ao modelo proposto.

Ainda em linha com o modelo proposto, cabem discussões para estudos futuros sobre a modelagem de incertezas quanto ao prazo e custo associado aos dispêndios de capital, para fins de projetos de infraestrutura por PPPs. Tais incertezas geram atrasos consideráveis em projetos, os quais impactam significativamente a geração dos fluxos de caixa futuros e, por conseguinte comprometem o retorno esperado pelos investidores.

Outro aspecto que merece destaque em modelagem de PPPs e que pode ser desenvolvido futuramente está relacionado à integração de metodologias de análise de viabilidade financeira de projetos, com metodologias de análise de impactos socioeconômicos em PPPs. Isto porque entre as metodologias utilizadas para observar o Value for Money em projetos de PPPs, restringem-se ainda a análise por custo-benefício, análise por benchmark e fluxo de caixa descontado, sem adoção de métodos mais robustos que considerem as flexibilidades existentes nessa classe de projetos. 


\section{Referências bibliográficas}

AGUIAR, A. S. Equivalente Certo e Medidas de Risco em Decisões de Comercialização de Energia Elétrica. (Tese de D outorado) Departamento de Engenharia Elétrica, PUC-Rio, Rio de Janeiro, 2008.

ALONSO-CONDE, A. B.; BROWN, C.; ROJO-SUAREZ, J. Public private partnerships: Incentives, risk transfer and real options. Review of Financial Economics [S.I.], v. 16, n. 4, p. 335-349, 2007.

ARAKI, I.; YOSHIZU, Y. Nam Ngiep 1: The first hydro PPP to be promoted by Japan. International Journal on Hydropower and Dams [S.I.], v. 14, n. 1, p. 55-60, 2007.

AZEVEDO NETO, F. Reajuste e Revisão nas Parcerias PúblicoPrivadas Revisitando o Risco nos Contratos de DelegaçãoParceria Público-Privada: Aspectos Jurídicos Relevantes. São Paulo Quartier Latin, 2008. p. 53-78.

BACEN. Risco-País. Diretoria de Política Econômica do Banco Central do Brasil. Disponível em: http://www.bcb.gov.br/busca.asp?consulta=pec + gci+embi\&pesquisar. $x=5$ \&pesquisar.y=6\&pesquisar=submit. Acesso em 10/01/2012. 2010.

BANCOMUNDIAL. Private Participation in Infrastructure Database. Disponível em: https://ppi.worldbank.org/. Acesso em: 15/07/2016, 2013.

BASTIAN-PINTO, C.; BRANDAO, L.; GOMES, L. L. Government Supports in PPP Contracts: The Case of São Paulo Subway. 15th Annual International Conference on Real Options [S.I.], 2011.

BING, L.et al. The allocation of risk in PPP/PFI construction projects in the UK. International Journal of Project Management [S.I.], v. 23, n. 1, p. 25-35, 2005.

BLACK, F.; SCHOLES, M. The Pricing of Options and Corporate Liabilities. Journal of Political Economy [S.I.], v. n. 81, May-Jun, 1973.

BLANK, F. F.et al. Economic valuation of a toll road concession with traffic guarantees and the abandonment option. Production [S.I.], v. 26, n. 1, p. 39-53, 2016.

BNDES. Banco Nacional de Desenvolvimento Econômico e Social. v. 2014, n. 15/06/2014, 2016. 
BORGES, L. X. F. Aplicabilidade das técnicas de project finance para financiamento da infra-estrutura no Brasil: caso da implantação da telefonia celular banda B de 1997 a 2001. (Tese de D outorado) COPPE, Universidade Federal do Rio de Janeiro - UFRJ, Rio de Janeiro, 2005.

BOWE, M.; LEE, D. L. Project evaluation in the presence of multiple embedded real options: evidence from the Taiwan High-Speed Rail Project. Journal of Asian Economics [S.I.], v. 15, n. 1, p. 71-98, 2004.

BRANDAO, L.; DYER, J. S. Decision analysis and real options: A discrete time approach to real option valuation. Annals of Operations Research [S.I.], v. 135, n. 1, p. 21-39, 2005.

BRANDÃO, L.; DYER, J. S.; HAHN, W. J. Volatility estimation for stochastic project value models. European Journal of Operational Research [S.I.], v. 220, n. 3, p. 642-648, 2012.

BRANDÃO, L. E.et al. Government supports in public-private partnership contracts: Metro line 4 of the São Paulo subway system. Journal of Infrastructure Systems [S.I.], v. 18, n. 3, p. 218-225, 2012.

BRANDÃO, L. E. T. Uma Aplicação da Teoria das Opções Reais em Tempo Discreto para Avaliação de um Projeto de Concessão Rodoviária. (Tese de Doutorado), PUC-Rio, Rio de Janeiro, 2002.

BRANDAO, L. E. T.et al. Incentivos governamentais em PPP: uma análise por opções reais. Rev. adm. empres. [online] [S.I.], v. 52. n.1, p. 10-23, 2012.

BRANDÃO, L. E. T.; CURY, M. V. Q. Modelagem Híbrida para Concessões Rodoviárias com o uso da Teoria das Opções Reais: 0 caso da Rodovia BR-163. Gestão.Org [S.I.], v. v.4, n. 2, p. 121-140, 2006.

BRANDÃO, L. E. T.; SARAIVA, E. C. G. The option value of government guarantees in infrastructure projects. Construction Management and Economics [S.I.], v. 26, n. 11, p. 1171 - 1180, 2008.

BRASIL. Lei $n^{\circ}$. 9.795, de $27 \mathrm{~d}$ e abril de 1999. Política Nacional de Educação Ambiental (PNEA), 1999.

BRENNAN, M. J.; SCHWARTZ, E. S. Evaluating Natural Resource Investments. The Journal of Business [S.I.], v. 58, n. 2, p. 135-157, 1985.

BRIGHAM, E.; HOUSTON, J. F. Fundamentals of Financial Management. South Western Cengage Learning. Concise 7th Edition. 2012.

CABRAL, S.; SILVA JR, A. F. An approach for evaluating the risk management role of governments in public-private partnerships for 
mega-event stadiums. European Sport Management Quarterly [S.I.], v. 13, n. 4, p. 472-490, 2013.

CARBONARA, N.; COSTANTINO, N.; PELLEGRINO, R. Revenue guarantee in public-private partnerships: a fair risk allocation model. Construction Management and Economics [S.I.], v. 32, n. 4, p. 403-415, 2014.

CARVALHO, M. A. D. S. Privatização: Aspectos Fiscais e Dívida Pública. (Mestrado) - Economia - EPGE, Fundação Getúlio Vargas, 2001.

CASTRO. Otimização da Performance de um Portfólio de Ativos e Opções Reais utilizando a Medida Omega. Doctoral Thesis (Ph.D.) Departamento de Engenharia Industrial, Pontifícia Universidade Católica do Rio de Janeiro, Rio de Janeiro, Brazil, 2008.

CCPPP. Canadian Council for Public-Private Partnerships. v. 2016, n. 06.06, 1993.

CHAGAS, E. B. Project finance no setor elétrico brasileiro: um estudo de caso da Usina Hidrelétrica de Barra Grande. (Dissertação de Mestrado) - Departamento de Administração, Pontifícia Universidade Católica do Rio de Janeiro, Rio de Janeiro, 2006.

CHANG, C. Y. A critical analysis of recent advances in the techniques for the evaluation of renewable energy projects. International Journal of Project Management [S.I.], v. 31, n. 7, p. 1057-1067, 2013.

CHAROENPORNPATTANA, S.; MINATO, T.; NAKAHAMA, S. Government supports as bundle of real options in built-operatetransfer highways projects. In: 7th Annual International Conference on Real Options. 2002.

CHEAH, C. Y. J.; LIU, J. Valuing governmental support in infrastructure projects as real options using Monte Carlo simulation. Construction Management and Economics [S.I.], v. 24, n. 5, p. 545 - 554, 2006.

CHIARA; GARVIN; VECER. Valuing Simple Multiple-Exercise Real Options in Infrastructure Projects. Journal of Infrastructure Systems. [S.I.], v. 13, n. 2, 2007.

CNI. Mapa estratégico da indústria 2013-2022. Confedereção Nacional da Indústria. Brasília p.137, 2013

. Infraestrutura: o custo do atraso e as reformas necessárias. Confederação Nacional da Indústria. Brasília, p.177, 2014

Financiamento do investimento em infraestrutura no Brasil: uma agenda para sua expansão sustentada. Confederação Nacional da Indústria. CNI. Brasília, 2016 
COPELAND, T.; ANTIKAROV, V. Opções Reais. São Paulo: Editora Campus. 2002.

COULSON, A. Value for money in pfi proposals: A commentary on the UK treasury guidelines for public sector comparators. Public Administration [S.I.], v. 86, n. 2, p. 483-498, 2008.

COX, J. C.; ROSS, S. A.; RUBINSTEIN, M. Option pricing: A simplified approach. Journal of Financial Economics [S.I.], v. 7, n. 3, p. 229-263, 1979.

DALTON, G.et al. Economic and socio-economic assessment methods for ocean renewable energy: Public and private perspectives. Renewable and Sustainable Energy Reviews [S.I.], v. 45, n. 0, p. 850-878, 2015.

DIAS, M. A. G.; ROCHA, K. Petroleum Concessions With Extendible Options using Mean Reversion with Jumps to model Oil Prices. 3rd Real Option Conference [S.I.], 1999.

DICHTL, H.; DROBETZ, W.; WAMBACH, M. Where is the value added of rebalancing? A systematic comparison of alternative rebalancing strategies. Financial Markets and Portfolio Management [S.I.], v. 28, n. 3, p. 209-231, 2014.

DIXIT, A. K.; PINDYCK, R. S. Investment under uncertainty. Princeton University Press Princeton, NJ. 1994.

DU, X.; LI, A. N. Monte Carlo simulation and a value-at-risk of concessionary project: The case study of the Guangshen Freeway in China. Management Research News [S.I.], v. 31, n. 12, p. 912-921, 2008.

ESTACHE, A.; GONZÁLEZ, M.; TRUJILLO, L. What Does "Privatization" Do for Efficiency? Evidence from Argentina's and Brazil's Railways. World Development [S.I.], v. 30, n. 11, p. 1885-1897, 2002.

ESTACHE, A.; GUASCH, J. L.; TRUJILLO-CASTELLANO, L. Price Caps, Efficiency Payoffs and Infrastructure Contract Renegotiation in Latin America. SSRN eLibrary [S.I.], 2003.

FAN, J. P. H. Price uncertainty and vertical integration: an examination of petrochemical firms. Journal of Corporate Finance [S.I.], v. 6, n. 4 , p. 345-376, 2000.

FANTOZZI, F.et al. Public-private partnerships value in bioenergy projects: Economic feasibility analysis based on two case studies. Biomass and Bioenergy [S.I.], v. 66, p. 387-397, 2014.

FERNANDEZ, N. R.; CARRARO, A. A. A teoria econômica das parcerias público-privadas: Uma análise microeconômica. Rio Grande 
do Sul: Universidade Federal do Rio Grande do Sul (UFRGS). Unpublished Work, 2006.

FILHO, N. F. S.et al. O Papel do BNDES na Expansão do Setor Elétrico Nacional e o Mecanismo de Project Finance. Departamento de Energia Elétrica da Área de Infraestrutura do BNDES.Disponível em:<http://www.bndes.gov.br/SiteBNDES/bndes/bndes_pt/Institucional/Pu blicacoes/Consulta_Expressa/Setor/Energia_Eletrica/200903_01.html>. 2009.

FLYVBJERG, B. Survival of the unfittest: why the worst infrastructure gets built-and what we can do about it. Oxford review of economic policy [S.I.], v. 25, n. 3, p. 344-367, 2009.

FRISCHTAK, C. R. O investimento em infraestrutura no Brasil: histórico recente e perspectivas. Pesquisa e Planejamento Econômico [S.I.], v. 38, 2008.

PPPs: a experiência internacional em infraestrutura. In: LTC, G. (Ed.). Parcerias Público-Privadas: Experiências, Desafios e Propostas. Rio de Janeiro, 2013.

GARVIN, M. J.; CHEAH, C. Y. J. Valuation techniques for infrastructure investment decisions. Construction Management and Economics [S.I.], v. 22, n. 4, p. 373 - 383, 2004.

GEMAN, H. Commodities and Commodity Derivatives: Modeling and Pricing for Agriculturals, Metals and Energy. New York: Wiley Finance. 2005.

GRILO, L. M. Modelo de Análise da Qualidade do Investimento para Projetos de Praceria Público-Privada (PPP). (Doutorado) - Engenharia Civil, Universidade de São Paulo, São Paulo, 2008.

GRIMSEY, D.; LEWIS, M. K. Evaluating the risks of public private partnerships for infrastructure projects. International Journal of Project Management [S.I.], v. 20, n. 2, p. 107-118, 2002.

Are Public Private Partnerships value for money?: Evaluating alternative approaches and comparing academic and practitioner views. Accounting Forum [S.I.], v. 29, n. 4, p. 345-378, 2005.

HMTREASURY. Private opportunity, public benefit-progressing the private finance initiative. Private Finance Panel. HM Treasury. London, 1995

HUANG, Y. L.; CHOU, S. P. Valuation of the minimum revenue guarantee and the Option to abandon in BOT infrastructure projects. Construction Management and Economics [S.I.], v. 24, n. 5, p. 379-389, 2006. 
JENSEN, M. C. The Performance of Mutual Funds in the Period 19451964. The Journal of Finance [S.I.], v. 23, n. 2, p. 389-416, 1968.

JORION, P. Value at Risk: The New Benchmark for Managing Financial Risk. New York, NY: McGraw-Hill. 2000.

KANE, S. J.et al. Optimizing Omega. Journal of Global Optimization [S.I.], v. 45, n. 1, p. 153-167, 2009.

KAPSOS, M.; CHRISTOFIDES, N.; RUSTEM, B. Worst-case robust Omega ratio. European Journal of Operational Research [S.I.], v. 234, n. 2, p. 499-507, 2014.

KE, Y.; LIU, X.; WANG, S. Equitable Financial Evaluation Method for Public-Private Partnership Projects. Tsinghua Science and Technology [S.I.], v. 13, n. 5, p. 702-707, 2008.

KEATING, C.; SHADWICK, W. F. A Universal Performance Measure. The Journal of Performance Measurement [S.I.], v. 6, n. 3, 2002.

KENMA, A. G. Z. Case Studies on Real Options. Financial Management [S.I.], 1993.

KRÜGER. To kill a real option - Incomplete contracts, real options and PPP. Transportation Research Part A: Policy and Practice [S.I.], v. 46, n. 8, p. 1359-1371, 2012.

LAFFONT, J.-J.; TIROLE, J. A theory of incentives in procurement and regulation. MIT press. 1993.

LEVY, S. M. Build, operate, transfer: paving the way for tomorrow's infrastructure. John Wiley \& Sons. 1996.

MARKOWITZ, H. Portfolio Selection. Journal of Finance [S.I.], v. 7, n. 1, p. 77-91, 1952.

MARTINS; MARQUES; CRUZ. Maximizing the value for money of PPP arrangements through flexibility: An application to airports. Journal of Air Transport Management [S.I.], v. 39, n. 0, p. 72-80, 2014.

MARZANO, L. G. Otimização de Portfólio de Contratos de Energia em Sistemas Hidrotérmicos com Despacho Centralizado. (Tese de doutorado) - Departamento de Engenharia Elétrica, PUC-Rio, Rio de Janeiro, 2004.

MERTON, R. C. Option Pricing when Underlying Stock Returns are Discontinuous. Journal of Financial Economics 3 [S.I.], p. 125-144, 1976.

METCALF, G. E.; HASSET, K. A. Investment under Alternative Return Assumptions Comparing Random Walks and Mean Reversion. Journal of Economic Dynamics and Control [S.I.], v. 19, n. 8, p. 14711488, 1995. 
MONTEIRO, L. D. Precificação de garantias governamentais em PPP através de opções reais. Estudo de caso do TAV Brasil. Administração, Pontifícia Universidade Católica, Rio de Janeiro, 2014.

MOREIRA, A. P. Parametrização Ótima de Garantia Governamental em Projetos de Infraestrutura. PUC-Rio, 2010.

NCPPP. National Council for Public-Private Partnership. v. 2016, n. 06.06, 1985.

NG, S. T.et al. A simulation model for optimizing the concession period of public-private partnerships schemes. International Journal of Project Management [S.I.], v. 25, n. 8, p. 791-798, 2007.

NGUYEN, T. Selection of the right risk measures for portfolio allocation. International Journal of Monetary Economics and Finance [S.I.], v. 7, n. 2, p. 135-156, 2014.

NISAR, T. M. Value for money drivers in public private partnership schemes. International Journal of Public Sector Management [S.I.], v. 20, n. 2, p. 147-156, 2007.

OLIVEIRA, G.; MARCATO, F. S.; SCAZUFCA, P. Como destravar as parcerias público-privadas.Parcerias Público-Privadas: Experiências, Desafios e Propostas. Rio de Janeiro: gen LTC, 2013.

PINDYCK, R. S. The long-run evolution of energy prices. Energy Journal [S.I.], v. 20, n. 2, p. 1-27, 1999.

PINHEIRO, A. C.et al. Estruturação de projetos de PPP e concessão no Brasil: diagnóstico do modelo brasileiro e propostas de aperfeiçoamento. International Finance Corporation (IFC). World Bank Group. São Paulo, 2015

RADARPPP. Guia Prático para Estruturação de Programas e Projetos De PPPs. São Paulo: 2014.

. Radar de Projetos. n. 01.11.2016, 2016.

RAKIC, B.; RAĐENOVIĆ, T. Real Options Methodology in PublicPrivate Partnership Projects Valuation. Economic Annals, Volume LIX, No. 200. UDC: 3.33 ISSN: 0013-3264 [S.I.], 2014.

RANASINGHE, M. Private sector participation in infrastructure projects: a methodology to analyse viability of BOT. Construction Management and Economics [S.I.], v. 17, n. 5, p. 613-623, 1999.

ROCHA ARMADA, M. J.; PEREIRA, P. J.; RODRIGUES, A. Optimal subsidies and guarantees in public-private partnerships. European Journal of Finance [S.I.], v. 18, n. 5, p. 469-495, 2012. 
ROCKAFELLAR , R.; URYASEV, S. Optimization of Conditional Valueat-Risk. Journal of Risk 2 [S.I.], p. 21-41, 2000.

RODRIGUES JÚNIOR, W. A participação privada no investimento em infra-estrutura e o papel do Project Finance. Texto para discussão, $n^{\circ}$. 495. Brasília: IPEA [S.I.], 1997.

ROSE, S. Valuation of interacting real options in a tollroad infrastructure project. The Quarterly Review of Economics and Finance [S.I.], v. 38, n. 3, Part 2, p. 711-723, 1998.

ROSS, S. A. The arbitrage theory of capital asset pricing. Journal of Economic Theory [S.I.], v. 13, n. 3, p. 341-360, 1976.

RUS, G. D .; NOMBELA, G. Variable-term concessions for road construction and operation. Munich: University Library of Munich, Germany. Unpublished Work, 2003.

SALMAN, A.; SKIBNIEWSKI, M.; BASHA, I. BOT Viability Model for Large-Scale Infrastructure Projects. Journal of construction engineering and management [S.I.], v. 133, n. 1, p. 50-63, 2007.

SAVI, E. M. D. S.; Albuquerque, A. A.; Rebelatto, A. D. N. D. Parcerias Público-Privadas (PPPs) Uma Alternativa para o Desenvolvimento em Infra-estrutura no Cenário Brasileiro. RDERevista de Desenvolvimento Econômico [S.I.], v. 11, n. 20, 2010.

SCHUHMACHER, F.; ELING, M. A decision-theoretic foundation for reward-to-risk performance measures. Journal of Banking \& Finance [S.I.], v. 36, n. 7, p. 2077-2082, 2012.

SCHWARTZ, E. S. Stochastic Behavior of Commodity Prices: Implications for Valuation and Hedging. Journal of Finance 52(3) [S.I.], v. 923-973, 1997.

SHAOUL, J. A critical financial analysis of the Private Finance Initiative: selecting a financing method or allocating economic wealth? Critical Perspectives on Accounting [S.I.], v. 16, n. 4, p. 441-471, 2005.

SHARPE, W. F. Capital Asset Prices: A Theory of Market Equilibrium under Conditions of Risk. The Journal of Finance [S.I.], v. 19, n. 3, p. 425-442, 1964.

SHARPE, W. F. Mutual Fund Performance. Journal of Business [S.I.], v. 39, n. 1, p. 119, 1966.

SHARPE, W. F. Portfolio Theory and Capital Market. New York, NY: McGraw-Hill. 1970.

SHEN, L.-Y.; PLATTEN, A.; DENG, X. P. Role of public private partnerships to manage risks in public sector projects in Hong Kong. 
International Journal of Project Management [S.I.], v. 24, n. 7, p. 587-594, 2006.

SHEN, L.; LI, H.; LI, Q. Alternative Concession Model for Build Operate Transfer Contract Projects. Journal of construction engineering and management [S.I.], v. 128, n. 4, p. 326-330, 2002.

SHEN, L.; WU, Y. Risk Concession Model for Build/Operate/Transfer Contract Projects. Journal of construction engineering and management [S.I.], v. 131, n. 2, p. 211-220, 2005.

SIMÕES, M. D. P.; GOMES, L. L. Decisão de sazonalização de contratos de fornecimento de energia elétrica no Brasil através da otimização da medida ômega $(\Omega)$. Revista Eletrônica de Administração [S.I.], v. 17, n. 1, 2011.

SORTINO, F. A.; PRICE, L. N. Performance Measurement in a Downside Risk Framework. The Journal of Investing [S.I.], v. 3, n. 3, p. 55-64, Fall 1994.

SOUZA, M. C. D. As Parceiras Público-Privadas à luz do artigo 175 da Constituição Federal. In: SOUZA, Mariana Campos de (Org.) Parceria Público-Privada: Aspectos Jurídicos Relevantes. São Paulo: Quartier Latin, 2008.

SPACKMAN, M. Public-private partnerships: lessons from the British approach. Economic Systems [S.I.], v. 26, n. 3, p. 283-301, 2002.

TANG, L.; SHEN, Q.; CHENG, E. W. L. A review of studies on PublicPrivate Partnership projects in the construction industry. International Journal of Project Management [S.I.], v. 28, n. 7, p. 683-694, 2010.

TINSLEY, R. Advanced project financing. Londres: Euromoney Books. 2000.

TORRES, R. C. Avaliação de Portfolios de Contratos de compra e Venda de Energia Elétrica: Uma abordagem pela Teoria de Opções.117 f. (Dissertação de Mestrado) - Departamento de Engenharia Industrial, PUC-Rio, Rio de Janeiro, 2006.

TREYNOR, J. L. How to Rate Management of Investment Funds. Harvard Business Review [S.I.], v. 43, n. 1, p. 63-75, 1965.

TRIGEORGIS, L. The Nature of Option Interactions and the Valuation of Investments with Multiple Real Options. The Journal of Financial and Quantitative Analysis [S.I.], v. 28, n. 1, p. 1-20, 1993.

UNPD. United Nations Development Programme. What are PublicPrivate Partnerships. v. 2016, n. 06.06, 2005.

WALKER, C. T.; SMITH, A. J. Privatized infrastructure: The build operate transfer approach. Thomas Telford. 1995. 
XIONG, W.; ZHANG, X. Concession Renegotiation Models for Projects Developed through Public-Private Partnerships. Journal of construction engineering and management [S.I.], v. 140, n. 5, p. 04014008, 2014.

$\mathrm{XU}$, Y.et al. System Dynamics (SD) -based concession pricing model for PPP highway projects. International Journal of Project Management [S.I.], v. 30, n. 2, p. 240-251, 2012.

$\mathrm{XU}$, Y.et al. Developing a risk assessment model for PPP projects in China - A fuzzy synthetic evaluation approach. Automation in Construction [S.I.], v. 19, n. 7, p. 929-943, 2010.

YE, S.; TIONG, R. NPV-at-Risk Method in Infrastructure Project Investment Evaluation. Journal of construction engineering and management [S.I.], v. 126, n. 3, p. 227-233, 2000.

YE, S.; TIONG, R. L. K. The effect of concession period design on completion risk management of BOT projects. Construction Management and Economics [S.I.], v. 21, n. 5, p. 471-482, 2003.

ZAYED, T.; CHANG, L. Prototype Model for Build-Operate-Transfer Risk Assessment. Journal of Management in Engineering [S.I.], v. 18, n. 1, p. 7-16, 2002.

ZHANG; KUMARASWAMY. Hong Kong Experience in Managing BOT Projects. Journal of construction engineering and management [S.I.], v. 127, n. 2, p. 154-162, 2001.

ZHANG, G.; Z OU, P. Fuzzy Analytical Hierarchy Process Risk Assessment Approach for Joint Venture Construction Projects in China. Journal of construction engineering and management [S.I.], v. 133, n. 10, p. 771-779, 2007.

ZHANG, X. Financial Viability Analysis and Capital Structure Optimization in Privatized Public Infrastructure Projects. Journal of construction engineering and management [S.I.], v. 131, n. 6, p. 656-668, 2005.

ZHANG, X.et al. Concessionaire Selection for Build-Operate-Transfer Tunnel Projects in Hong Kong. Journal of construction engineering and management [S.I.], v. 128, n. 2, p. 155-163, 2002.

ZITRON, J. Public-private partnership projects: Towards a model of contractor bidding decision-making. Journal of Purchasing and Supply Management [S.I.], v. 12, n. 2, p. 53-62, 2006. 